This is the submitted version of the article.

The article, after peer-review and revision, is published in Renewable and Sustainable Energy Reviews. https://doi.org/10.1016/j.rser.2020.110625

\title{
Photovoltaic/thermal systems based on concentrating and non- concentrating technologies: Working fluids at low, medium and high temperatures
}

\author{
Chr. Lamnatou ${ }^{1}$, R.Vaillon ${ }^{2}$, S. Parola ${ }^{2}$, D. Chemisana ${ }^{1 *}$ \\ ${ }^{1}$ Applied Physics Section of the Environmental Science Department, University of Lleida, Jaume II \\ 69, 25001 Lleida, Spain \\ ${ }^{2}$ IES, Univ Montpellier, CNRS, Montpellier, France \\ *Corresponding author: daniel.chemisana@udl.cat
}

\section{ABSTRACT}

The present article provides an overview about photovoltaic/thermal systems categorised by the temperature of the working fluid: Low-temperature (lower than $60^{\circ} \mathrm{C}$ ), medium-temperature (between 60 and $90{ }^{\circ} \mathrm{C}$ ) and high-temperature (higher than $90{ }^{\circ} \mathrm{C}$ ). Concerning photovoltaic/thermal-air systems for low-temperature use, the majority of studies involve building-integrated non-concentrating systems with phase change materials and working-fluid temperatures at around $30-55{ }^{\circ} \mathrm{C}$. Concerning lowtemperature photovoltaic/thermal-water systems, a large number of studies are about nonconcentrating configurations appropriate for building-integrated and, in general, domestic applications with working fluids at approximately $50-60^{\circ} \mathrm{C}$. Regarding non-concentrating photovoltaic/thermal systems for medium-temperature use, a large number of references are appropriate for industrial and domestic applications (working fluids: air; water) with around $60-70{ }^{\circ} \mathrm{C}$ working-fluid temperatures. The literature review about mediumtemperature concentrating photovoltaic/thermal systems shows that the majority of investigations concern photovoltaic/thermal-water systems with concentration ratios up to $190 \mathrm{X}$ and working fluids at approximately $62-90{ }^{\circ} \mathrm{C}$, appropriate for domestic and water-desalination applications. As for high-temperature concentrating photovoltaic/thermal systems, most of them have concentration ratios up to $1000 \mathrm{X}$, parabolic concentrators and use water (as the working fluid) at around 100-250 ${ }^{\circ} \mathrm{C}$. 
Moreover, in the field of high-temperature photovoltaic/thermal systems, most of the configurations are appropriate for building and industrial applications, and consist of triple-junction or silicon-based photovoltaic/thermal cells. In light of the issues mentioned above, a critical discussion and key challenges (in terms of materials, efficiencies, technologies, etc.) are presented.

Keywords: Photovoltaic/Thermal (PVT) systems; Low-temperature applications; Medium-temperature applications; High-temperature applications; Technologies with/without solar concentration; Buildings, industry, power plants

WORD COUNT (excluding title, author names and affiliations, keywords, abbreviations, table/figure captions, acknowledgments and references): 10891 words

\section{ABBREVIATIONS}

BA Building-Added

BA PVT Building-Added Photovoltaic/Thermal

BI Building-Integrated

BIPVT Building-Integrated Photovoltaic/Thermal

CdTe Cadmium Telluride

CIGS Copper Indium Gallium (di)Selenide

CIS Copper Indium Selenide

COP Coefficient of Performance

CPC Compound Parabolic Concentrator

CPV Concentrating Photovoltaic

CPVT Concentrating Photovoltaic/Thermal

CR Concentration Ratio

E Experimental

E-M Experimental and Modelling (both)

G Solar irradiance

HCE Heat Collection Element 
LCPVT-STC Low-Concentrating Photovoltaic/Thermal - Solar Thermal Collector

M Modelling

Mono-Si Monocrystalline silicon

NIP Normal Incidence Pyranometer

PCM Phase change material

Poly-Si Polycrystalline silicon

PV Photovoltaic

PVT Photovoltaic/Thermal

PVT/air Photovoltaic/Thermal with air as working fluid

PVT/water Photovoltaic/Thermal with water as working fluid

Re Reynolds number

$\mathrm{T}_{\mathrm{b}} \quad$ Temperature of the absorber plate

$\mathrm{T}_{\text {in }} \quad$ Inlet temperature

$\mathrm{T}_{\text {out }} \quad$ Outlet temperature

\section{INTRODUCTION}

Photovoltaic (PV) cells absorb and convert solar radiation into electricity [1]. However, the main part of the collected solar radiation is transformed into heat, increasing PV-cell temperature and, therefore, reducing PV-cell efficiency [2]. This undesirable phenomenon can be avoided by using a heat extraction device with fluid circulation. In this way, PV panels can work at a more satisfactory temperature. PV systems which combine PV modules with thermal units (involving the circulation of a fluid, e.g. air or water) are known as hybrid Photovoltaic/Thermal (PVT) systems and produce both electrical and thermal energy [1]. In other words, PVT installations provide higher total energy output (in comparison to PV modules which generate only electrical energy) and environmental advantages [3, 4]. 
PVT systems are appropriate for different kinds of applications (domestic, industrial, etc.). By placing emphasis on the working fluid, water-cooled PVT (PVT/water) and air-cooled PVT (PVT/air) systems are commonly used for water and indoor space heating, respectively [1].

The temperature of the working fluid plays a pivotal role and is associated with the type of application [5]. PVT systems appropriate for different temperatures/applications were developed: domestic hot water production, indoor space heating/cooling, desalination, pool heating, crop drying, industrial process heating and so on [6].

In the case of PVT applications in the building sector, it can be noted that there are two basic categories: 1) Building-Added Photovoltaic/Thermal (BA PVT) (for instance, these systems are mounted on the roof of a building), 2) Building-Integrated Photovoltaic/Thermal (BIPVT) (these systems form part of the building structure itself, e.g. façade- or roof-integrated configurations) [7].

There are articles that include reviews about PVT systems. In Table 1, the major references (with emphasis on review papers about PVT) are presented. It can be noticed that the majority of these studies focus on issues such as PVT design, performance, working fluids, applications, temperature effect and PV cooling.

Table 1. References about PVT systems with emphasis on review papers.

\begin{tabular}{ll}
\hline Study / year & Content \\
\hline Tripanagnostopoulos (2007) [1] & PVT systems: Literature review \\
& PVT applications \\
& PVT design improvements \\
& Dual PVT: Experimental study \\
& \\
\hline Charalambous et al. (2007) [8] & Different types of PVT modules \\
& PVT performance \\
& Evaluation of thermal/electrical output \\
\hline Zondag (2008) [9] & PVT history \\
& PVT liquid- and air-collectors (issues about the modules) \\
& Ventilated BIPV with heat recovery (issues about the modules) \\
& PVT systems \\
& PVT market \\
\hline Chow (2010) [10] & Groundwork and developments \\
\hline
\end{tabular}




\begin{tabular}{|c|c|}
\hline & $\begin{array}{l}\text { Developments (during the last decade) in flat-plate PVT systems } \\
\text { Developments (during the last decade) in Concentrating Photovoltaic/Thermal } \\
\text { (CPVT) designs } \\
\text { Developments (commercial, etc.) during the last decade }\end{array}$ \\
\hline Hasan and Sumathy (2010) [11] & $\begin{array}{l}\text { PVT development } \\
\text { PVT devices } \\
\text { PVT module concepts } \\
\text { Performance analysis } \\
\text { Techniques to improve PVT performance } \\
\text { Future prospects of PVT systems }\end{array}$ \\
\hline Ibrahim et al. (2011) [12] & $\begin{array}{l}\text { PVT design and performance evaluation } \\
\text { PVT future developments }\end{array}$ \\
\hline Avezov et al. (2011) [13] & $\begin{array}{l}\text { PVT/air modules } \\
\text { PVT/water modules }\end{array}$ \\
\hline Zhang et al. (2012a) [14] & $\begin{array}{l}\text { Traditional Concentrating Photovoltaic (CPV) systems } \\
\text { CPV cooling } \\
\text { PVT systems } \\
\text { Spectral-beam-splitting technology }\end{array}$ \\
\hline Zhang et al. (2012b) [15] & $\begin{array}{l}\text { PVT technology: Concept, theory, classification, performance, standards } \\
\text { PVT research/development and practical applications } \\
\text { Future studies }\end{array}$ \\
\hline Tyagi et al. (2012) [16] & $\begin{array}{l}\text { Solar thermal collectors } \\
\text { PV technology } \\
\text { PVT technology } \\
\text { PVT novel applications }\end{array}$ \\
\hline Vivar et al. (2012) [17] & $\begin{array}{l}\text { Standards for CPV systems: The case of active cooling } \\
\text { Standards for CPVT systems } \\
\text { A proposal for evaluating CPVT systems }\end{array}$ \\
\hline Chow et al. (2012) [18] & $\begin{array}{l}\text { PVT developments in the twentieth century } \\
\text { Flat-plate PVT systems: Recent developments } \\
\text { CPVT systems: Recent developments } \\
\text { Developments in recent years }\end{array}$ \\
\hline Shan et al. (2014) [19] & $\begin{array}{l}\text { PVT systems } \\
\text { BIPVT systems } \\
\text { CPVT systems } \\
\text { PVT systems with heat pumps } \\
\text { Case studies } \\
\text { Limitations and solutions }\end{array}$ \\
\hline Sharaf and Orhan (2015a) [20] & $\begin{array}{l}\text { Foundations and overview } \\
\text { Fundamentals and technological advances }\end{array}$ \\
\hline Sharaf and Orhan (2015b) [21] & $\begin{array}{l}\text { Literature about CPVT } \\
\text { Performance assessment } \\
\text { Overview - prospects }\end{array}$ \\
\hline Makki et al. (2015) [22] & $\begin{array}{l}\text { Temperature effect on PV-cell efficiency } \\
\text { PV cell cooling } \\
\text { PVT systems }\end{array}$ \\
\hline Lamnatou and Chemisana (2017) [7] & $\begin{array}{l}\text { Methods and indicators (from an environmental point of view) } \\
\text { Studies which include environmental issues about PVT: Literature review } \\
\text { Parameters which influence PVT environmental profile }\end{array}$ \\
\hline Ju et al. (2017a) [23] & $\begin{array}{l}\text { CPVT with waste-heat recovery: Literature review } \\
\text { Research studies about CPVT with waste-heat recovery: Current status }\end{array}$ \\
\hline Ju et al. (2017b) [24] & $\begin{array}{l}\text { Spectral-beam-splitting CPVT: } \\
\text { - General issues } \\
\text { - Developments } \\
\text { - Current status (in terms of research) }\end{array}$ \\
\hline Azarian et al. (2017) [25] & $\begin{array}{l}\text { CPVT concept } \\
\text { CPVT from a thermodynamic point of view } \\
\text { PV cells }\end{array}$ \\
\hline
\end{tabular}




\begin{tabular}{ll}
\hline & PV cells and thermal collector: Materials \\
& Heat-transfer fluid \\
& PV-cell temperature \\
& Heat-extraction system \\
& \\
\hline Joshi and Dhoble (2018) [6] & PVT concept \\
& PVT systems: Classification \\
& Non-concentrating PVT systems \\
& CPVT systems \\
& Spectral-beam-splitting PVT systems \\
& \\
\hline Sultan and Ervina Efzan (2018) [26] & Types of PVT modules \\
& Solar greenhouses with PVT modules \\
\hline Fudholi et al. (2019) [27] & Monofacial and bifacial PV cells \\
& Efficiency of bifacial PV modules \\
& PVT/air systems with monofacial PV cells \\
& PVT/air systems with bifacial PV cells \\
& PVT systems \\
& PVT systems with heat pumps \\
& PVT systems with heat pumps: Details about the components \\
Research and development \\
Future prospects \\
\hline Vaishak and Bhale (2019) [28]
\end{tabular}

The aforementioned issues indicate that in the literature about PVT there is a lack of review papers which place emphasis on working-fluid temperature. The present article provides an overview about different kinds of PVT systems, appropriate for buildings, industry, etc. Its main contribution is the classification of the PVT configurations according to the temperature of the working fluid. The classification criteria are as follows:

- Low-temperature systems: Working-fluid temperatures $<60{ }^{\circ} \mathrm{C}$

- Medium-temperature systems: $60{ }^{\circ} \mathrm{C} \leq$ working-fluid temperatures $\leq 90{ }^{\circ} \mathrm{C}$

- High-temperature systems: Working-fluid temperatures $>90{ }^{\circ} \mathrm{C}$

Furthermore, the PVT systems are categorised by taking into account additional criteria:

- Type of study (experimental, modelling, both experimental/modelling).

- Working fluid (air, water, nanofluids, etc.).

- Solar energy collection by means of concentrating or non-concentrating devices.

- Type of PV cells (mono-Si, poly-Si, etc.).

- Systems with or without thermoelectric elements.

- Efficiencies (electrical, thermal, etc.). 
- Type of application (buildings, industry, drying, desalination, etc.).

- Location/country where a certain system was evaluated.

In light of the issues mentioned above, it can be noted that the proposed framework provides the basis for identifying key challenges (in terms of materials, technologies, efficiencies and so on) that PVT systems are facing.

\section{LITERATURE REVIEW}

\subsection{PVT SYSTEMS FOR LOW-TEMPERATURE APPLICATIONS}

The present section deals with PVT systems with working fluids at low temperatures (less than $60{ }^{\circ} \mathrm{C}$ ). In the literature on PVT, there is a whole host of studies on this kind of systems and, therefore, three subcategories have been considered: 1) PVT/air, 2) PVT/water, 3) PVT with both air and water, PVT with nanofluids, etc.

In Table 2, selected references about PVT/air systems for low-temperature use are presented. The results show that:

- The majority of the references are about modelling or experimental/modelling studies on systems without solar concentration.

- Most of the systems do not have thermoelectric elements.

- A large number of investigations include mono-Si or poly-Si PV cells.

- In most cases, the maximum temperature of the working fluid (air) ranges from around 30 to $55^{\circ} \mathrm{C}$.

- Thermal efficiencies range from 10 to $90 \%$. Moreover, many systems show PV conversion efficiencies around 6-16\%. In certain cases, high overall efficiencies (80\% or higher) were found.

- Regarding the type of application, a large number of investigations are about building-integrated configurations whereas there are a few studies on dryers. 
- A large majority of the references are about systems with PCM appropriate for BI applications.

- In most cases, the systems were investigated for the climatic conditions of Europe and India.

In terms of the achievement of high efficiencies, it is worth mentioning the study by Nazri et al. [54] (PVT/air with a thermoelectric element) on the grounds that a maximum thermal efficiency of $84 \%$ was found. It was noted that mass flow rate considerably influences thermal-efficiency results. It is also worth mentioning the study by Kamthania and Tiwari [35]. Multiple silicon-based and non-silicon-based BIPVT/air modules were investigated and the findings show that the Heterojunction with Intrinsic Thin Layer (HIT) system has the highest: i) module efficiency, ii) net annual electrical energy, iii) overall annual thermal energy, iv) exergy output.

Regarding BIPVT, Assoa and Ménézo [34] investigated a roof-integrated PVT/air system. A model was developed and validated with data of an experimental setup near Lyon, in France. It was found that forced ventilation offers advantages from a thermalproduction point of view. However, natural ventilation provides adequate cooling of the PV panels. In Figure 1, the experimental building with the prototype roof-integrated PVT/air system is illustrated.

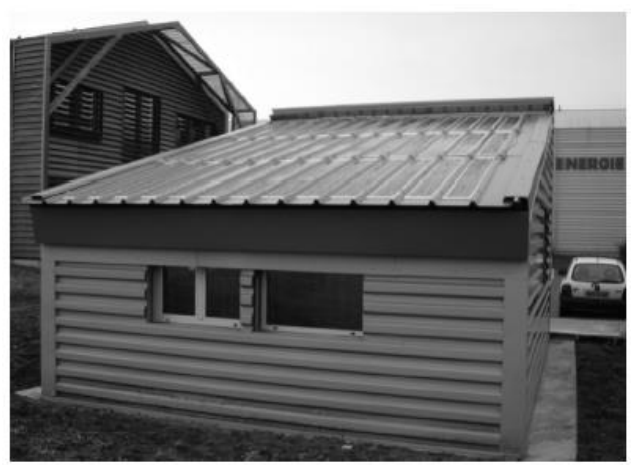

Figure 1. The roof-integrated PVT/air system studied by Assoa and Ménézo [34]. An experimental building at TENESOL company site. Source: Assoa and Ménézo [34].

Table 2. PVT/air systems: working fluid at low-temperatures. 


\begin{tabular}{|c|c|c|c|c|c|c|c|c|}
\hline $\begin{array}{l}\text { Study / } \\
\text { year }\end{array}$ & $\begin{array}{l}\text { Type } \\
\text { of } \\
\text { study }\end{array}$ & $\begin{array}{l}\text { Solar } \\
\text { concentration }\end{array}$ & $\begin{array}{l}\text { Type of } \\
\text { PV cells }\end{array}$ & $\begin{array}{l}\text { Thermoelect } \\
\text { ric element }\end{array}$ & $\begin{array}{l}\text { Temperature } \\
\text { of the working } \\
\text { fluid: Low }\end{array}$ & Efficiencies & $\begin{array}{l}\text { Type of } \\
\text { application: } \\
\text { - Buildings } \\
\text { - Etc. }\end{array}$ & $\begin{array}{l}\text { Location } \\
\text { of the } \\
\text { study }\end{array}$ \\
\hline $\begin{array}{l}\text { Candan } \\
\text { edo } \\
\text { and } \\
\text { Athieni } \\
\text { tis } \\
(2009) \\
{[29]}\end{array}$ & E-M & No & $\begin{array}{l}\text { Not } \\
\text { directly } \\
\text { stated }\end{array}$ & No & $\begin{array}{l}\text { Higher than } \\
30^{\circ} \mathrm{C}\end{array}$ & $\begin{array}{l}\text { Not directly } \\
\text { stated }\end{array}$ & $\begin{array}{l}\text { BIPVT (roof- } \\
\text { integrated); } \\
\text { Net-zero energy } \\
\text { solar house }\end{array}$ & Canada \\
\hline $\begin{array}{l}\text { Vats } \\
\text { and } \\
\text { Tiwari } \\
(2012) \\
{[30]}\end{array}$ & $\mathrm{M}$ & No & $\begin{array}{l}\text { Mono-Si; } \\
\text { poly-Si; } \\
\text { amorphous } \\
\text { silicon; } \\
\text { CdTe; } \\
\text { CIGS; HIT }\end{array}$ & No & $\begin{array}{l}22{ }^{\circ} \mathrm{C} \\
\text { (maximum) }\end{array}$ & $\begin{array}{l}16 \% \text { for HIT, } \\
6 \% \text { for } \\
\text { amorphous } \\
\text { silicon }\end{array}$ & $\begin{array}{l}\text { BIPVT (roof- } \\
\text { integrated, } \\
\text { semi- } \\
\text { transparent) }\end{array}$ & India \\
\hline $\begin{array}{l}\text { Sopian } \\
\text { et al. } \\
\text { (2013) } \\
{[31]}\end{array}$ & M & $\begin{array}{l}\text { Yes (there is a } \\
\text { reflector below } \\
\text { the PV cells) }\end{array}$ & Bifacial & No & $\begin{array}{l}\text { Air-flow } \\
\text { temperature } \\
\text { along the length } \\
\text { of the panel: } \\
\text { around } 29.5^{\circ} \mathrm{C} \\
\text { (maximum) }\end{array}$ & $\begin{array}{l}\text { Total: around } \\
78 \% \\
\text { (maximum) for } \\
\text { the double-path } \\
\text { mode }\end{array}$ & $\begin{array}{l}\text { BI with bifacial } \\
\text { PV cells and } \\
\text { reflectors }\end{array}$ & $\begin{array}{l}\text { Not directly } \\
\text { stated }\end{array}$ \\
\hline $\begin{array}{l}\text { Rajoria } \\
\text { et al. } \\
\text { (2013) } \\
{[32]}\end{array}$ & M & No & $\begin{array}{l}\text { Not } \\
\text { directly } \\
\text { stated }\end{array}$ & No & $\begin{array}{l}\text { Outlet air } \\
\text { temperature: } \\
\text { around } 59^{\circ} \mathrm{C} \\
\text { (maximum); } \\
\text { Case 2: Delhi, } \\
\text { January }\end{array}$ & $\begin{array}{l}\text { PV cell: around } \\
11.8 \% \\
\text { (maximum); } \\
\text { Case 1: Delhi, } \\
\text { January }\end{array}$ & BIPVT (tiles) & India \\
\hline $\begin{array}{l}\text { Aelene } \\
i \text { and } \\
\text { Pereira } \\
(2013) \\
{[33]}\end{array}$ & $\mathrm{M}$ & No & $\begin{array}{l}\text { Not } \\
\text { directly } \\
\text { stated }\end{array}$ & No & $\begin{array}{l}\text { Air inside the } \\
\text { cavity: } 43^{\circ} \mathrm{C} \\
\text { and } 54{ }^{\circ} \mathrm{C} \text {, with } \\
\text { and without } \\
\text { PCM, } \\
\text { respectively }\end{array}$ & $\begin{array}{l}\text { Systems at } 9.00 \\
\text { a.m.: around } \\
22 \% \\
\text { (maximum); } \\
\text { ventilated } \\
\text { BIPVT without } \\
\text { PCM }\end{array}$ & $\begin{array}{l}\text { BIPVT (façade- } \\
\text { integrated) } \\
\text { with/without } \\
\text { PCM }\end{array}$ & Portugal \\
\hline $\begin{array}{l}\text { Assoa } \\
\text { and } \\
\text { Ménéz } \\
\text { o } \\
(2014) \\
{[34]}\end{array}$ & E-M & No & Poly-Si & No & $\begin{array}{l}\text { Air temperature } \\
\text { (outlet of the air } \\
\text { gap): around } \\
35^{\circ} \mathrm{C} \\
\text { (maximum) }\end{array}$ & $\begin{array}{l}\text { Reference, } \\
\text { PV cell: } 12 \%\end{array}$ & $\begin{array}{l}\text { BIPVT (roof- } \\
\text { integrated) }\end{array}$ & France \\
\hline $\begin{array}{l}\text { Kamth } \\
\text { ania } \\
\text { and } \\
\text { Tiwari } \\
\text { (2014) } \\
{[35]}\end{array}$ & E-M & No & $\begin{array}{l}\text { Mono-Si, } \\
\text { poly-Si, } \\
\text { ribbon, } \\
\text { amorphous } \\
\text { silicon, } \\
\text { CdTe, } \\
\text { CIGS, } \\
\text { CIS, HIT }\end{array}$ & No & $\begin{array}{l}\text { Outlet air } \\
\text { temperature: } \\
20.5^{\circ} \mathrm{C} \\
\text { (maximum) at } \\
12 \mathrm{pm}\end{array}$ & $\begin{array}{l}\text { Hourly } \\
\text { variation of } \\
\text { electrical } \\
\text { efficiency: from } \\
\text { around } 6 \% \text { to } \\
18 \% \text {, depending } \\
\text { on the PV } \\
\text { module }\end{array}$ & $\begin{array}{l}\text { BIPVT (façade- } \\
\text { integrated) }\end{array}$ & India \\
\hline $\begin{array}{l}\text { Aelene } \\
\text { i et al. } \\
\text { (2014a } \\
\text { ) [36] }\end{array}$ & E-M & No & Poly-Si & No & $\begin{array}{l}\text { Air-gap } \\
\text { maximum } \\
\text { temperature: } \\
\text { around } 50^{\circ} \mathrm{C}\end{array}$ & $\begin{array}{l}\text { For }\left(\mathrm{T}_{\mathrm{in}}-\mathrm{T}_{\text {out }}\right) / \mathrm{G} \\
=0.01: \text { thermal } \\
\text { around } \\
10 \%, \text { overall } \\
\text { around } 20 \%\end{array}$ & $\begin{array}{l}\text { BIPVT (façade- } \\
\text { integrated) with } \\
\text { PCM }\end{array}$ & Portugal \\
\hline $\begin{array}{l}\text { Aelene } \\
\text { i et al. } \\
\text { (2014b } \\
\text { ) [37] }\end{array}$ & E-M & No & Poly-Si & No & $\begin{array}{l}\text { Air-cavity } \\
\text { maximum } \\
\text { temperature: } \\
\text { around } 47^{\circ} \mathrm{C}\end{array}$ & $\begin{array}{l}\text { Not directly } \\
\text { stated }\end{array}$ & $\begin{array}{l}\text { BIPVT (façade- } \\
\text { integrated) with } \\
\text { PCM }\end{array}$ & Portugal \\
\hline $\begin{array}{l}\text { Sohel } \\
\text { et al. } \\
(2014) \\
{[38]}\end{array}$ & E-M & No & $\begin{array}{l}\text { Not } \\
\text { directly } \\
\text { stated }\end{array}$ & No & $\begin{array}{l}\text { Air outlet } \\
\text { temperature: } \\
\text { around } 58^{\circ} \mathrm{C} \\
\text { (maximum) }\end{array}$ & $\begin{array}{l}\text { Electrical: } \\
\text { around 9-10\% } \\
\text { (maximum); } \\
\text { Thermal: } \\
\text { around 90\% } \\
\text { (maximum) } \\
\end{array}$ & $\begin{array}{l}\text { Net-zero energy } \\
\text { buildings; Solar } \\
\text { Decathlon } \\
\text { house }\end{array}$ & $\begin{array}{l}\text { Australia; } \\
\text { China }\end{array}$ \\
\hline
\end{tabular}




\begin{tabular}{|c|c|c|c|c|c|c|c|c|}
\hline $\begin{array}{l}\text { Machni } \\
\text { ewicz } \\
\text { et al. } \\
(2015) \\
{[39]}\end{array}$ & M & No & $\begin{array}{l}\text { Thin-film } \\
\text { CIS }\end{array}$ & No & $\begin{array}{l}\text { The most } \\
\text { effective } \\
\text { performance: } \\
\text { PCM transition } \\
\text { temperatures of } \\
18 \text { and } 25^{\circ} \mathrm{C}\end{array}$ & $\begin{array}{l}\text { The } \\
\text { incorporation of } \\
\text { PCM into the } \\
\text { back surface of } \\
\text { the PV module } \\
\text { has little effect } \\
\text { on the power } \\
\text { production } \\
\text { efficiency }\end{array}$ & $\begin{array}{l}\text { BIPVT (façade- } \\
\text { integrated) with } \\
\text { PCM }\end{array}$ & $\begin{array}{l}\text { Central } \\
\text { Europe }\end{array}$ \\
\hline $\begin{array}{l}\text { Xiang } \\
\text { and } \\
\text { Gan } \\
(2015) \\
{[40]}\end{array}$ & E-M & No & Mono-Si & No & $\begin{array}{l}\text { Maximum } \\
\text { temperature at } \\
\text { the top side of } \\
\text { the model: } \\
\text { around } 37^{\circ} \mathrm{C}\end{array}$ & $\begin{array}{l}\text { Not directly } \\
\text { stated }\end{array}$ & $\begin{array}{l}\text { BIPVT (wall) } \\
\text { with PCM }\end{array}$ & UK \\
\hline $\begin{array}{l}\text { Li et } \\
\text { al. } \\
(2015 \mathrm{a} \\
)[41]\end{array}$ & $\mathrm{M}$ & No & $\begin{array}{l}\text { Not } \\
\text { directly } \\
\text { stated }\end{array}$ & No & $\begin{array}{l}\text { Scenario: a } \\
\text { cloudy day after } \\
\text { two consecutive } \\
\text { sunny days, } \\
\text { maximum tank- } \\
\text { temperature } \\
\text { around } 41^{\circ} \mathrm{C}\end{array}$ & $\begin{array}{l}\text { Not directly } \\
\text { stated }\end{array}$ & $\begin{array}{l}\text { BIPVT with air- } \\
\text { to-water heat } \\
\text { pump }\end{array}$ & USA \\
\hline $\begin{array}{l}\text { Sliman } \\
\text { i et al. } \\
(2016) \\
{[42]}\end{array}$ & $\mathrm{M}$ & No & Mono-Si & No & $\begin{array}{l}\text { Outlet air } \\
\text { temperature: } \\
\text { a maximum } \\
\text { value of } 50^{\circ} \mathrm{C} \\
\text { at } 12: 00 \text { was } \\
\text { found }\end{array}$ & $\begin{array}{l}\text { Electrical: } \\
\text { around } 10.5 \% \\
\text { (maximum); } \\
\text { Thermal: } \\
\text { around } 70 \% \\
\text { (maximum) }\end{array}$ & $\begin{array}{l}\text { Drying of } \\
\text { agricultural } \\
\text { products }\end{array}$ & India \\
\hline $\begin{array}{l}\text { Delisle } \\
\text { and } \\
\text { Kumm } \\
\text { ert } \\
(2016) \\
{[43]}\end{array}$ & $\mathrm{M}$ & No & Mono-Si & No & $\begin{array}{l}\text { The heat-pump- } \\
\text { water-heater } \\
\text { temperature was } \\
\text { set at } 55^{\circ} \mathrm{C}\end{array}$ & $\begin{array}{l}\text { Electrical: } \\
15.2 \% \text { (at } \\
\text { reference } \\
\text { conditions) }\end{array}$ & $\begin{array}{l}\text { BIPVT (roof- } \\
\text { integrated) with } \\
\text { air-to-water } \\
\text { heat pump }\end{array}$ & Canada \\
\hline $\begin{array}{l}\text { Lin et } \\
\text { al. } \\
(2016) \\
{[44]}\end{array}$ & $\mathrm{M}$ & No & $\begin{array}{l}\text { Not } \\
\text { directly } \\
\text { stated }\end{array}$ & No & $\begin{array}{l}\text { Maximum } \\
\text { enclosure } \\
\text { temperature: } \\
\text { around } 29^{\circ} \mathrm{C}\end{array}$ & $\begin{array}{l}\text { Not directly } \\
\text { stated }\end{array}$ & $\begin{array}{l}\text { BIPVT } \\
\text { combined with } \\
\text { PCM wall }\end{array}$ & Australia \\
\hline $\begin{array}{l}\text { Favoin } \\
\text { o et al. } \\
(2016) \\
{[45]}\end{array}$ & $E$ & No & $\begin{array}{l}\text { Amorphou } \\
\text { s silicon }\end{array}$ & No & $\begin{array}{l}\text { Up to } 45 \text { and } \\
50^{\circ} \mathrm{C} \text { : indoor } \\
\text { glass surface } \\
\text { of the aerogel- } \\
\text { filled } \\
\text { configuration in } \\
\text { winter and } \\
\text { summer, } \\
\text { respectively }\end{array}$ & $\begin{array}{l}\text { PV cell: } 6 \% \\
\text { (nominal } \\
\text { efficiency); } \\
\text { peak efficiency } \\
\text { of the latent- } \\
\text { heat-thermal- } \\
\text { energy-storage } \\
\text { system: } 60-70 \%\end{array}$ & $\begin{array}{l}\text { BIPVT (façade- } \\
\text { integrated) with } \\
\text { PCM }\end{array}$ & Italy \\
\hline $\begin{array}{l}\text { Hadda } \\
\text { d et al. } \\
(2016) \\
{[46]}\end{array}$ & $E$ & Yes & Mono-Si & No & $\begin{array}{l}\text { Hourly } \\
\text { temperature } \\
\text { (PVT/air } \\
\text { collector } \\
\text { without } \\
\text { reflector): } \\
\text { around } \\
40^{\circ} \mathrm{C} \\
\text { (maximum) }\end{array}$ & $\begin{array}{l}\text { Not directly } \\
\text { stated }\end{array}$ & $\begin{array}{l}\text { PVT } \\
\text { applications } \\
\text { with reflectors }\end{array}$ & Algeria \\
\hline $\begin{array}{l}\text { Tiwari } \\
\text { et al. } \\
\text { (2016a } \\
\text { ) [47] }\end{array}$ & E-M & No & $\begin{array}{l}\text { Semi- } \\
\text { transparent }\end{array}$ & No & $\begin{array}{l}\text { Maximum } \\
\text { drying-chamber } \\
\text { temperature: } \\
\text { around } 45^{\circ} \mathrm{C}\end{array}$ & $\begin{array}{l}\text { PV cell: around } \\
13.5 \% \\
\text { (maximum) }\end{array}$ & $\begin{array}{l}\text { PVT integrated } \\
\text { into a } \\
\text { greenhouse } \\
\text { dryer (crop } \\
\text { drying) }\end{array}$ & India \\
\hline $\begin{array}{l}\text { Oliveir } \\
\text { a } \\
(2016) \\
{[48]}\end{array}$ & $\mathrm{M}$ & No & Mono-Si & $\begin{array}{l}\text { Yes } \\
\text { (thermoelectri } \\
\text { c heat pumps) }\end{array}$ & $\begin{array}{l}\text { Not directly } \\
\text { stated }\end{array}$ & $\begin{array}{l}\text { Goals for } 1000 \\
\text { W/m² incident } \\
\text { solar radiation: } \\
\text { PV-module } \\
\text { efficiency } \geq\end{array}$ & $\begin{array}{l}\text { BIPVT (façade- } \\
\text { integrated) with } \\
\text { natural or } \\
\text { forced air }\end{array}$ & $\begin{array}{l}\text { Europe, } \\
\text { Portugal }\end{array}$ \\
\hline
\end{tabular}




\begin{tabular}{|c|c|c|c|c|c|c|c|c|}
\hline & & & & & & $\begin{array}{l}15 \% ; \text { System } \\
\text { heating } \\
\text { efficiency } \geq \\
40 \% ; \text { System } \\
\text { cooling } \\
\text { efficiency } \geq \\
15 \%\end{array}$ & $\begin{array}{l}\text { circulation and } \\
\text { heat pumps }\end{array}$ & \\
\hline $\begin{array}{l}\text { Tripath } \\
\text { y et al. } \\
(2017) \\
{[49]}\end{array}$ & M & No & $\begin{array}{l}\text { Mono-Si } \\
\text { (semi- } \\
\text { transparent } \\
\text { ) }\end{array}$ & No & $\begin{array}{l}\text { Solar-cell } \\
\text { temperature: } \\
\text { around } 44^{\circ} \mathrm{C} \\
\text { (maximum) }\end{array}$ & $\begin{array}{l}\text { Electrical: } \\
\text { around } 11.7 \% \\
\text { (maximum) }\end{array}$ & $\begin{array}{l}\text { BIPVT (roof- } \\
\text { integrated) }\end{array}$ & India \\
\hline $\begin{array}{l}\text { Liu et } \\
\text { al. } \\
(2017) \\
{[50]}\end{array}$ & E-M & No & $\begin{array}{l}\text { Not } \\
\text { directly } \\
\text { stated }\end{array}$ & $\begin{array}{l}\text { Yes } \\
\text { (thermoelectri } \\
\text { c ventilator) }\end{array}$ & $\begin{array}{l}\text { Fresh air } \\
\text { temperature: } \\
\text { between } 18.3 \\
\text { and } 31{ }^{\circ} \mathrm{C}\end{array}$ & $\begin{array}{l}\text { Electrical (for } \\
\text { the system): } \\
\text { around } 12.6 \% \\
\text { (maximum); } \\
\text { Coefficient of } \\
\text { Performance } \\
\text { (COP): } 3.35 \\
\text { (maximum) }\end{array}$ & Buildings & China \\
\hline $\begin{array}{l}\text { Dimri } \\
\text { et al. } \\
(2017) \\
{[51]}\end{array}$ & $\mathrm{M}$ & No & $\begin{array}{l}\text { Semi- } \\
\text { transparent }\end{array}$ & $\begin{array}{l}\text { Yes } \\
\text { (thermoelectri } \\
\text { c cooler) }\end{array}$ & $\begin{array}{l}\text { Fluid outlet } \\
\text { temperature: } \\
\text { around } 57^{\circ} \mathrm{C} \\
\text { (maximum) }\end{array}$ & $\begin{array}{l}\text { Overall } \\
\text { electrical (in } \\
\text { fraction): } \\
\text { around } 13.5 \% \\
\text { (maximum) }\end{array}$ & $\begin{array}{l}\text { Indoor space } \\
\text { heating or } \\
\text { drying of } \\
\text { agricultural } \\
\text { products }\end{array}$ & India \\
\hline $\begin{array}{l}\text { Liu et } \\
\text { al. } \\
\text { (2018a } \\
)[52]\end{array}$ & E-M & No & Mono-Si & $\begin{array}{l}\text { Yes } \\
\text { (thermoelectri } \\
\text { c ventilator) }\end{array}$ & $\begin{array}{l}\text { Fresh air outlet } \\
\text { temperature of } \\
\text { the PVT- } \\
\text { thermoelectric } \\
\text { ventilator } \\
\text { system: around } \\
34^{\circ} \mathrm{C} \\
\text { (maximum) }\end{array}$ & $\begin{array}{l}\text { Electrical: } \\
\text { around } 16 \% \\
\text { (maximum); } \\
\text { Thermal: } \\
\text { around } 55 \% \\
\text { (maximum) }\end{array}$ & $\begin{array}{l}\text { Buildings: } \\
\text { power } \\
\text { production, } \\
\text { waste heat } \\
\text { recovery, air } \\
\text { supply, etc. }\end{array}$ & China \\
\hline $\begin{array}{l}\text { Agatho } \\
\text { kleous } \\
\text { et al. } \\
(2018) \\
{[53]}\end{array}$ & E-M & No & Poly-Si & No & $\begin{array}{l}\text { Maximum } \\
\text { temperature: } \\
\text { around } 35^{\circ} \mathrm{C} \\
\text { (air outlet: the } \\
\text { duct between } \\
\text { the PV module } \\
\text { and the brick } \\
\text { wall) }\end{array}$ & $\begin{array}{l}\text { Overall energy } \\
\text { efficiency of the } \\
\text { system: } 25.5- \\
33.5 \% \text {; } \\
\text { Electrical } \\
\text { efficiency of the } \\
\text { system: } 24- \\
28.5 \% \text { (PV- } \\
\text { module } \\
\text { temperature: } \\
30-57^{\circ} \mathrm{C} \text { ) }\end{array}$ & $\begin{array}{l}\text { BIPVT (façade- } \\
\text { integrated) } \\
\text { applications: } \\
\text { Naturally } \\
\text { ventilated }\end{array}$ & Cyprus \\
\hline $\begin{array}{l}\text { Nazri } \\
\text { et al. } \\
\text { (2018a } \\
\text { ) [54] }\end{array}$ & $\mathrm{M}$ & No & Mono-Si & Yes & $\begin{array}{l}\text { Back } \\
\text { plate and air } \\
\text { temperatures in } \\
\text { the channels: } 20 \\
\text { and } 10^{\circ} \mathrm{C} \\
\text { higher than } \\
\text { the ambient } \\
\text { temperature, } \\
\text { respectively }\end{array}$ & $\begin{array}{l}\text { Thermal: } 84 \% \\
\text { (maximum); } \\
\text { Electrical: } 12 \% \\
\text { (maximum) }\end{array}$ & $\begin{array}{l}\text { Drying of } \\
\text { agricultural } \\
\text { products }\end{array}$ & $\begin{array}{l}\text { Not directly } \\
\text { stated }\end{array}$ \\
\hline $\begin{array}{l}\text { Liu et } \\
\text { al. } \\
(2018 b \\
)[55]\end{array}$ & $\mathrm{E}$ & No & $\begin{array}{l}\text { Not } \\
\text { directly } \\
\text { stated }\end{array}$ & $\begin{array}{l}\text { Yes } \\
\text { (thermoelectri } \\
\text { c ventilator) }\end{array}$ & $\begin{array}{l}\text { Maximum } \\
\text { outlet air } \\
\text { temperature: } \\
28.5^{\circ} \mathrm{C}\end{array}$ & $\begin{array}{l}\text { PVT average } \\
\text { electrical } \\
\text { efficiency: } 10 \% \\
\text { (sunny day); } \\
\text { average thermal } \\
\text { efficiency of } \\
\text { the } \\
\text { PVT/thermoelec } \\
\text { tric: } 26.7 \%\end{array}$ & Buildings & China \\
\hline $\begin{array}{l}\text { Nazri } \\
\text { et al. } \\
(2018 b \\
\text { [56] }\end{array}$ & $\mathrm{E}$ & No & Mono-Si & $\begin{array}{l}\text { Yes } \\
\text { (thermoelectri } \\
\text { c generators) }\end{array}$ & $\begin{array}{l}\text { Outlet air } \\
\text { temperature: } \\
40^{\circ} \mathrm{C} \\
\text { (maximum); } \\
\text { mass flow rate: } \\
0.02 \mathrm{~kg} / \mathrm{s} \text {; }\end{array}$ & $\begin{array}{l}\text { For mass flow } \\
\text { rate } 0.09 \mathrm{~kg} / \mathrm{s} \text { : } \\
\text { thermal around } \\
60 \% \\
\text { (maximum), } \\
\text { electrical }\end{array}$ & $\begin{array}{l}\text { Temperature } \\
\text { control }\end{array}$ & Malaysia \\
\hline
\end{tabular}




\begin{tabular}{|c|c|c|c|c|c|c|c|c|}
\hline & & & & & $\begin{array}{l}\text { maximum } \\
\text { radiation } \\
\text { intensity }\end{array}$ & $\begin{array}{l}\text { around } 12 \% \\
\text { (maximum) }\end{array}$ & & \\
\hline $\begin{array}{l}\text { Irshad } \\
\text { et al. } \\
(2019) \\
{[57]}\end{array}$ & E-M & No & $\begin{array}{l}\text { Not } \\
\text { directly } \\
\text { stated }\end{array}$ & $\begin{array}{l}\text { Yes } \\
\text { (thermoelectri } \\
\text { c air cooling) }\end{array}$ & $\begin{array}{l}\text { Working } \\
\text { temperature of } \\
\text { the } \\
\text { thermoelectric } \\
\text { air-cooling } \\
\text { system: } \\
24-38^{\circ} \mathrm{C}\end{array}$ & $\begin{array}{l}\text { PV panel: } \\
14.6 \%\end{array}$ & $\begin{array}{l}\text { BIPVT } \\
\text { applications } \\
\text { with air } \\
\text { conditioners }\end{array}$ & Malaysia \\
\hline $\begin{array}{l}\text { Pereira } \\
\text { and } \\
\text { Aelene } \\
\mathrm{i} \\
(2019) \\
{[58]}\end{array}$ & E-M & No & Poly-Si & No & $\begin{array}{l}\text { Air-cavity } \\
\text { temperature: } \\
\text { around } 43^{\circ} \mathrm{C} \\
\text { (maximum) }\end{array}$ & $\begin{array}{l}\text { Optimised } \\
\text { scenario: } 10 \% \\
\text { electrical and } \\
54 \% \text { thermal }\end{array}$ & $\begin{array}{l}\text { BIPVT (façade- } \\
\text { integrated) with } \\
\text { PCM }\end{array}$ & Portugal \\
\hline $\begin{array}{l}\text { Pal } \\
\text { Singh } \\
\text { et al. } \\
(2019) \\
{[59]}\end{array}$ & $\mathrm{M}$ & No & $\begin{array}{l}\text { Not } \\
\text { directly } \\
\text { stated }\end{array}$ & No & $\begin{array}{l}\text { Maximum } \\
\text { output } \\
\text { temperature: } \\
\text { around } 27.5^{\circ} \mathrm{C}\end{array}$ & $\begin{array}{l}\text { Thermal: } \\
\text { around } 45 \% \\
\text { (maximum) }\end{array}$ & $\begin{array}{l}\text { PVT } \\
\text { applications } \\
\text { with curved } \\
\text { grooved } \\
\text { absorber plates }\end{array}$ & $\begin{array}{l}\text { Not directly } \\
\text { stated }\end{array}$ \\
\hline $\begin{array}{l}\text { Kalkan } \\
\text { et al. } \\
\text { (2019) } \\
{[60]}\end{array}$ & $\mathrm{M}$ & No & $\begin{array}{l}\text { Crystalline } \\
\text { silicon }\end{array}$ & No & $\begin{array}{l}\text { For air velocity } \\
1 \mathrm{~m} / \mathrm{s}, 400,800 \\
\text { and } 1000 \mathrm{~W} / \mathrm{m}^{2} \text {, } \\
\text { maximum outlet } \\
\text { air } \\
\text { temperatures: } \\
33,47 \text { and } 54 \\
{ }^{\circ} \mathrm{C} \text {, respectively }\end{array}$ & $\begin{array}{l}\text { For the optimal } \\
\text { design, overall: } \\
53.4 \%\end{array}$ & Buildings & Turkey \\
\hline
\end{tabular}

In Table 3, selected references about PVT/water systems for low-temperature applications are presented. The results demonstrate that:

- A large number of investigations include both modelling and experiments on systems without solar concentration.

- In most cases, the systems do not include thermoelectric components.

- The majority of the studies about concentrating systems refer to CRs less than 10X and include a whole host of configurations (with Compound Parabolic Concentrators (CPCs), Fresnel lenses, micro-concentrators, parabolic-trough concentrators, etc.).

- In most cases, mono-Si and poly-Si PV cells were used.

- The majority of thermal efficiencies are around $50-85 \%$ and electrical/PV efficiencies are approximately $12-15 \%$. 
- Many references are about BI configurations and, in general, about systems for buildings and domestic use whereas there are a few studies about agricultural applications (e.g. greenhouses, dryers of agricultural products).

- There are a few investigations about PVT systems with PCMs, integratedcollector-storage, heat pipes, chillers, desiccants and polymer PVT collectors.

- Most of the systems were evaluated for the climatic conditions of Europe and China, operating at around $50-60{ }^{\circ} \mathrm{C}$ working-fluid temperatures.

Regarding the achievement of high efficiencies, Alves et al. [102] investigated a PVT/water with a Solarus reflector (CR: 1.7X) and mono-Si PV cells. The system is appropriate for domestic water heating and, in the case of Sweden, showed an electrical efficiency of $19.1 \%$. Alves et al. [102] noted that by increasing the water flow rate, more heat (from the receiver) is removed. This means that there is a reduction in PV-cell temperature and increase in PV efficiency. Moreover, Khelifa et al. [84] studied a PVT/water system (without solar concentration). In certain cases, high thermal efficiencies (around 94\%: maximum) were found and, in relation to these high efficiencies, it was highlighted that the collector is perfectly insulated and covered by a flat glass [84]. 
Table 3. PVT/water systems: working fluid at low-temperatures.

\begin{tabular}{|c|c|c|c|c|c|c|c|c|}
\hline $\begin{array}{l}\text { Study / } \\
\text { year }\end{array}$ & $\begin{array}{l}\text { Type } \\
\text { of } \\
\text { study }\end{array}$ & $\begin{array}{l}\text { Solar } \\
\text { concentration }\end{array}$ & $\begin{array}{l}\text { Type of } \\
\text { PV cells }\end{array}$ & $\begin{array}{l}\text { Thermoelect } \\
\text { ric element }\end{array}$ & $\begin{array}{l}\text { Temperature } \\
\text { of the working } \\
\text { fluid: Low }\end{array}$ & Efficiencies & $\begin{array}{l}\text { Type of } \\
\text { application: } \\
\text { - Buildings } \\
\text { - Etc. }\end{array}$ & $\begin{array}{l}\text { Location } \\
\text { of the } \\
\text { study }\end{array}$ \\
\hline $\begin{array}{l}\text { Ibrahi } \\
\text { m et al. } \\
(2009) \\
{[61]}\end{array}$ & $\mathrm{M}$ & No & Poly-Si & No & $\begin{array}{l}\text { Water } \\
\text { temperature } \\
\text { (outlet): around } \\
31^{\circ} \mathrm{C} \\
\text { (maximum) }\end{array}$ & $\begin{array}{l}\text { Thermal: } \\
\text { around 50\% } \\
\text { (maximum); PV } \\
\text { cell: around } \\
12 \% \\
\text { (maximum) }\end{array}$ & $\begin{array}{l}\text { Domestic } \\
\text { applications }\end{array}$ & $\begin{array}{l}\text { Not directly } \\
\text { stated }\end{array}$ \\
\hline $\begin{array}{l}\text { da } \\
\text { Silva } \\
\text { and } \\
\text { Fernan } \\
\text { des } \\
(2010) \\
{[62]}\end{array}$ & $\mathrm{M}$ & No & Mono-Si & No & $\begin{array}{l}\text { Maximum tank } \\
\text { temperature: } \\
\text { around } 50^{\circ} \mathrm{C}\end{array}$ & $\begin{array}{l}\text { Global annual } \\
\text { energy: } 24 \% \\
\text { (15\% thermal; } \\
9 \% \text { electrical) }\end{array}$ & $\begin{array}{l}\text { Domestic hot } \\
\text { water } \\
\text { production }\end{array}$ & Portugal \\
\hline $\begin{array}{l}\text { Chemis } \\
\text { ana et } \\
\text { al. } \\
(2011) \\
{[63]}\end{array}$ & E-M & $\begin{array}{l}\text { Yes } \\
\text { (CRs: 7-10X) }\end{array}$ & $\begin{array}{l}\text { Crystalline } \\
\text { silicon }\end{array}$ & No & $\begin{array}{l}\text { Maximum } \\
\text { water } \\
\text { temperature: } \\
\text { around } 33^{\circ} \mathrm{C} \\
(\operatorname{Re}=125 ; \\
\text { channel } \\
\text { height/width = } \\
2.43 ; \text { module } \\
\text { length = } 1 \mathrm{~m})\end{array}$ & $\begin{array}{l}\text { Thermal: } \\
\text { around } 65 \% \\
\text { (maximum) }\end{array}$ & $\begin{array}{l}\text { BIPVT } \\
\text { applications } \\
\text { with Fresnel } \\
\text { linear } \\
\text { concentrators }\end{array}$ & Spain \\
\hline $\begin{array}{l}\text { Sonnev } \\
\text { eld et } \\
\text { al. } \\
(2011) \\
{[64]}\end{array}$ & $\mathrm{E}$ & $\begin{array}{l}\text { Yes } \\
(\mathrm{CR}: 25 \mathrm{X})\end{array}$ & Mono-Si & No & $\begin{array}{l}\text { Incoming water } \\
\text { temperature: } \\
22.4^{\circ} \mathrm{C} \text {; } \\
\text { outgoing water } \\
\text { temperature: } \\
25.8^{\circ} \mathrm{C} \text {; flow: } \\
18.6 \mathrm{~kg} / \mathrm{s} \text {; } \\
\text { module length: } \\
1.55 \mathrm{~m}\end{array}$ & $\begin{array}{l}\text { Thermal: } 56 \% \\
\text { Electrical: } 11 \%\end{array}$ & $\begin{array}{l}\text { Greenhouses } \\
\text { with Fresnel } \\
\text { lenses } \\
\text { (cultivation of } \\
\text { ornamental } \\
\text { plants) }\end{array}$ & Netherlands \\
\hline $\begin{array}{l}\text { Cristof } \\
\text { ari et } \\
\text { al. } \\
(2012) \\
{[65]}\end{array}$ & $\mathrm{M}$ & No & Poly-Si & No & $\begin{array}{l}\text { PV-cell } \\
\text { temperature for } \\
\text { the PVT: } \\
30.6{ }^{\circ} \mathrm{C} \\
\text { (maximum) }\end{array}$ & $\begin{array}{l}\text { Average } \\
\text { efficiencies } \\
\text { (PVT without } \\
\text { air layer): } 29 \% \\
\text { for the thermal } \\
\text { and } 14 \% \text { for the } \\
\text { PV }\end{array}$ & $\begin{array}{l}\text { Domestic hot } \\
\text { water } \\
\text { production by } \\
\text { using polymer } \\
\text { PVT collectors }\end{array}$ & $\begin{array}{l}\text { Mediterran } \\
\text { ean }\end{array}$ \\
\hline $\begin{array}{l}\text { Redpat } \\
\text { h et al. } \\
(2012) \\
{[66]}\end{array}$ & $E$ & $\begin{array}{l}\text { Yes } \\
\text { (CR: } 1.8 \mathrm{X} \text {; a } \\
\text { configuration } \\
\text { without } \\
\text { concentration was } \\
\text { also studied) }\end{array}$ & Poly-Si & No & $\begin{array}{l}\text { Outlet } \\
\text { temperature: } \\
\text { around } 57^{\circ} \mathrm{C} \\
\text { (maximum) for } \\
\text { the PVT with } \\
\text { CPC }\end{array}$ & $\begin{array}{l}\text { Thermal: } \\
\text { around } 50-60 \% \text {, } \\
\text { depending on } \\
\text { the system; } \\
\text { Electrical: } \\
\text { around } 8-10 \% \text {, } \\
\text { depending on } \\
\text { the system }\end{array}$ & $\begin{array}{l}\text { PVT } \\
\text { with/without } \\
\text { CPCs for } \\
\text { domestic and } \\
\text { industrial } \\
\text { applications }\end{array}$ & UK \\
\hline $\begin{array}{l}\text { Gang } \\
\text { et al. } \\
(2012) \\
{[67]}\end{array}$ & $\mathrm{M}$ & No & Mono-Si & No & $\begin{array}{l}\text { Water } \\
\text { temperature: } \\
45^{\circ} \mathrm{C} \text { (or } \\
\text { higher) }\end{array}$ & $\begin{array}{l}\text { Standard } \\
\text { electrical } \\
\text { efficiency (PV } \\
\text { module): } 15 \%\end{array}$ & $\begin{array}{l}\text { Domestic } \\
\text { applications: } \\
\text { PVT with heat } \\
\text { pipes }\end{array}$ & China \\
\hline $\begin{array}{l}\text { Chávez } \\
\text { Urbiola } \\
\text { and } \\
\text { Vorobi } \\
\text { ev } \\
(2013) \\
{[68]}\end{array}$ & E-M & $\begin{array}{l}\text { Yes } \\
\text { (CR: around 52X) }\end{array}$ & $\begin{array}{l}\text { Not } \\
\text { directly } \\
\text { stated }\end{array}$ & $\begin{array}{l}\text { Yes } \\
\text { (thermoelectri } \\
\text { c generators) }\end{array}$ & $\begin{array}{l}\text { Thermal energy } \\
\text { stored in water } \\
\text { at a temperature } \\
\text { of } 50{ }^{\circ} \mathrm{C} \\
\text { (approximately) }\end{array}$ & $\begin{array}{l}\text { Electrical } \\
\text { efficiency } \\
\text { of the system: } \\
5 \% \text {; Thermal: } \\
50 \%\end{array}$ & $\begin{array}{l}\text { Domestic } \\
\text { applications }\end{array}$ & Mexico \\
\hline
\end{tabular}




\begin{tabular}{|c|c|c|c|c|c|c|c|c|}
\hline $\begin{array}{l}\text { Yin et } \\
\text { al. } \\
(2013) \\
{[69]}\end{array}$ & E-M & No & Mono-Si & $\begin{array}{l}\text { No (but it is } \\
\text { noted that a } \\
\text { case with } \\
\text { thermoelectri } \\
\text { c element } \\
\text { could be } \\
\text { examined } \\
\text { (future } \\
\text { prospect)) }\end{array}$ & $\begin{array}{l}\text { Equilibrium } \\
\text { temperature } \\
\text { with water flow: } \\
\text { around } 40{ }^{\circ} \mathrm{C}\end{array}$ & $\begin{array}{l}\text { At } 25^{\circ} \mathrm{C}, \mathrm{PV} \\
\text { cell efficiencies: } \\
15.1 \% \text { and } \\
11.9 \% \text {, for } 850 \\
\text { and } 1100 \mathrm{~W} / \mathrm{m}^{2} \text {, } \\
\text { respectively; } \\
\text { Thermal } \\
\text { efficiency: } \\
53.9 \% \text { (1100 } \\
\mathrm{W} / \mathrm{m}^{2}, 66 \\
\mathrm{ml} / \mathrm{min} \text { water } \\
\text { flow) }\end{array}$ & $\begin{array}{l}\text { BIPVT (roof- } \\
\text { integrated) with } \\
\text { PCM }\end{array}$ & USA \\
\hline $\begin{array}{l}\text { Amriza } \\
1 \text { et al. } \\
(2013) \\
{[70]}\end{array}$ & E-M & $\begin{array}{l}\text { Yes (PVT: } 2 \text { lines } \\
\text { of } 26 \text { series } \\
\text { connected PV } \\
\text { cells optimised } \\
\text { for concentrating } \\
\text { systems) }\end{array}$ & $\begin{array}{l}\text { Crystalline } \\
\text { silicon }\end{array}$ & No & $\begin{array}{l}\text { Maximum } \\
\text { outlet } \\
\text { temperature: } \\
\text { around } 53^{\circ} \mathrm{C}\end{array}$ & $\begin{array}{l}\text { PV cell: } 14.3 \% \\
\text { (standard } \\
\text { conditions) }\end{array}$ & Buildings & Spain \\
\hline $\begin{array}{l}\text { He et } \\
\text { al. } \\
(2013) \\
{[71]}\end{array}$ & E-M & No & $\begin{array}{l}\text { Not } \\
\text { directly } \\
\text { stated }\end{array}$ & $\begin{array}{l}\text { Yes (cooling } \\
\text { and heating } \\
\text { system) }\end{array}$ & $\begin{array}{l}\text { Maximum } \\
\text { water } \\
\text { temperature in } \\
\text { the storage tank: } \\
\text { around } 32-34^{\circ} \mathrm{C}\end{array}$ & $\begin{array}{l}\text { System COP: } \\
\text { higher } \\
\text { than } 0.45 \text {; } \\
\text { Thermal } \\
\text { (experimental): } \\
12.06 \% \text {; } \\
\text { Electrical } \\
\text { (experimental): } \\
10.27 \%\end{array}$ & $\begin{array}{l}\text { Domestic } \\
\text { applications }\end{array}$ & China \\
\hline $\begin{array}{l}\text { Shan et } \\
\text { al. } \\
(2013) \\
{[72]}\end{array}$ & M & No & $\begin{array}{l}\text { Not } \\
\text { directly } \\
\text { stated }\end{array}$ & No & $\begin{array}{l}\text { Maximum } \\
\text { outlet } \\
\text { temperature: } \\
56.3^{\circ} \mathrm{C}\end{array}$ & $\begin{array}{l}\text { PV: around } \\
12.5 \% \\
\text { (maximum) }\end{array}$ & $\begin{array}{l}\text { Appropriate for } \\
\text { BIPVT } \\
\text { applications }\end{array}$ & China \\
\hline $\begin{array}{l}\text { Vivar } \\
\text { et al. } \\
(2013) \\
{[73]}\end{array}$ & $E$ & $\begin{array}{l}\text { Yes } \\
\text { (CR: 38X) }\end{array}$ & Mono-Si & No & $\begin{array}{l}\text { Fluid } \\
\text { temperature: not } \\
\text { exceeding } 60^{\circ} \mathrm{C}\end{array}$ & $\begin{array}{l}\text { The combined } \\
\text { efficiency of the } \\
\text { system can } \\
\text { exceed } \\
70 \% \text {; Average } \\
\text { electrical: } 8 \% \text {; } \\
\text { Average } \\
\text { thermal: } 50 \%\end{array}$ & $\begin{array}{l}\text { Domestic } \\
\text { applications } \\
\text { with PVT with } \\
\text { micro- } \\
\text { concentrators } \\
\text { (Fresnel } \\
\text { mirrors) }\end{array}$ & Australia \\
\hline $\begin{array}{l}\text { El- } \\
\text { Seesy } \\
\text { and } \\
\text { Khalil } \\
(2014) \\
{[74]}\end{array}$ & $E$ & $\begin{array}{l}\text { Yes } \\
\text { (geometric } \\
\text { CR: 4X) }\end{array}$ & Mono-Si & No & $\begin{array}{l}\text { Hot water } \\
\text { average } \\
\text { temperature: } \\
53^{\circ} \mathrm{C}\end{array}$ & $\begin{array}{l}\text { Not directly } \\
\text { stated }\end{array}$ & $\begin{array}{l}\text { PVT } \\
\text { applications } \\
\text { with low-cost } \\
\text { mirrors }\end{array}$ & Egypt \\
\hline $\begin{array}{l}\text { Ibrahi } \\
\text { m et al. } \\
(2014) \\
{[75]}\end{array}$ & $\mathrm{E}$ & No & Poly-Si & No & $\begin{array}{l}\text { Outlet } \\
\text { temperature: } \\
\text { around } 50{ }^{\circ} \mathrm{C} \\
\text { (maximum) }\end{array}$ & $\begin{array}{l}\text { PV: } 10.4- \\
11.3 \% \text {; } \\
\text { Thermal: } \\
44-51 \%\end{array}$ & BIPVT & Malaysia \\
\hline $\begin{array}{l}\text { Buker } \\
\text { et al. } \\
(2014) \\
{[76]}\end{array}$ & E-M & No & Mono-Si & No & $\begin{array}{l}\text { Water } \\
\text { temperature: } \\
\text { around } 35^{\circ} \mathrm{C} \\
\text { (maximum) }\end{array}$ & $\begin{array}{l}\text { System thermal: } \\
\text { around } 20 \% \\
\text { (maximum); } \\
\text { PV: around } \\
15 \% \\
\text { (maximum) }\end{array}$ & $\begin{array}{l}\text { BIPVT (roof- } \\
\text { integrated) }\end{array}$ & UK \\
\hline $\begin{array}{l}\text { Buker } \\
\text { et al. } \\
(2015) \\
{[77]}\end{array}$ & E-M & No & Mono-Si & No & $\begin{array}{l}\text { One of the case } \\
\text { studies: roof } \\
\text { with an average } \\
\text { water } \\
\text { temperature of } \\
30.25^{\circ} \mathrm{C} \text { (mass } \\
\text { flow rate: } 6 \\
1 / \text { min) }\end{array}$ & $\begin{array}{l}\text { PV: around } \\
15 \% \\
\text { (maximum); } \\
\text { Overall thermal } \\
\text { efficiency (PVT } \\
\text { system): around } \\
20 \% \\
\text { (maximum) }\end{array}$ & $\begin{array}{l}\text { BIPVT (roof- } \\
\text { integrated) with } \\
\text { desiccant }\end{array}$ & UK \\
\hline $\begin{array}{l}\text { Evola } \\
\text { and } \\
\text { Marlett }\end{array}$ & $\mathrm{M}$ & No & Poly-Si & No & $\begin{array}{l}\text { Outlet } \\
\text { temperature: } 40 \\
{ }^{\circ} \mathrm{C} \text { (inlet }\end{array}$ & $\begin{array}{l}\text { Electrical: } \\
\text { around } 13.5 \% \text {; } \\
\text { Thermal }\end{array}$ & Industrial & Italy \\
\hline
\end{tabular}




\begin{tabular}{|c|c|c|c|c|c|c|c|}
\hline $\begin{array}{l}\text { a } \\
(2014) \\
{[78]}\end{array}$ & & & & $\begin{array}{l}\text { temperature }= \\
\left.35^{\circ} \mathrm{C}\right)\end{array}$ & $\begin{array}{l}\text { (maximum): } \\
\text { around } 59 \% \text { (for } \\
\text { inlet } \\
\text { temperature = } \\
20^{\circ} \mathrm{C} \text { ) }\end{array}$ & $\begin{array}{l}\text { premises: } \\
\text { Integration on } \\
\text { concrete roofs }\end{array}$ & \\
\hline $\begin{array}{l}\text { Kroiß } \quad \text { E } \\
\text { et al. } \\
(2014) \\
{[79]}\end{array}$ & No & Poly-Si & No & $\begin{array}{l}\text { Fluid outlet } \\
\text { temperature: } \\
\text { around } 22^{\circ} \mathrm{C} \\
\text { (maximum) }\end{array}$ & $\begin{array}{l}\text { Electrical (PVT } \\
\text { system): } 14 \% \\
\text { (standard test } \\
\text { conditions); } \\
\text { Mean thermal } \\
\text { (PVT system): } \\
69 \%\end{array}$ & $\begin{array}{l}\text { Desalination by } \\
\text { using polymer } \\
\text { PVT collectors }\end{array}$ & Germany \\
\hline $\begin{array}{l}\text { He et } \\
\text { al. } \\
(2014) \\
{[80]}\end{array}$ & No & $\begin{array}{l}\text { Not } \\
\text { directly } \\
\text { stated }\end{array}$ & $\begin{array}{l}\text { Yes (cooling } \\
\text { and heating } \\
\text { systems) }\end{array}$ & $\begin{array}{l}\text { Water } \\
\text { temperature: } \\
21^{\circ} \mathrm{C} \text { (average) }\end{array}$ & $\begin{array}{l}\text { Electrical } \\
\text { (of the heat-pipe } \\
\text { PVT): } \\
\text { approximately } \\
16.7 \% \text {; Thermal } \\
\text { (of the system): } \\
\text { around } 23.5 \%\end{array}$ & $\begin{array}{l}\text { Building } \\
\text { applications } \\
\text { with heat-pipe } \\
\text { PVT systems }\end{array}$ & China \\
\hline $\begin{array}{l}\text { Kim et } \\
\text { al. } \\
(2014) \\
{[81]}\end{array}$ & No & Mono-Si & No & $\begin{array}{l}\text { Outlet } \\
\text { temperature: } \\
\text { around } 44^{\circ} \mathrm{C}\end{array}$ & $\begin{array}{l}\text { Thermal and } \\
\text { electrical } \\
\text { efficiencies } \\
\text { (average) of the } \\
\text { BIPVT } \\
\text { collector: } 30 \% \\
\text { and } 17 \% \text {, } \\
\text { respectively }\end{array}$ & $\begin{array}{l}\text { BIPVT (roof- } \\
\text { integrated) }\end{array}$ & Korea \\
\hline $\begin{array}{l}\text { Ziapou } \quad \text { M } \\
\text { r et al. } \\
\text { (2014) } \\
{[82]}\end{array}$ & No & Poly-Si & No & $\begin{array}{l}\text { For } 120 \mathrm{~kg} \text { of } \\
\text { water in the } \\
\text { tank and } \\
\text { collector area } \\
1.5 \mathrm{~m}^{2} \text { : tank } \\
\text { water } \\
\text { temperature } \\
45.9^{\circ} \mathrm{C}\end{array}$ & $\begin{array}{l}\text { For } 120 \mathrm{~kg} \text { of } \\
\text { water in the } \\
\text { tank and } \\
\text { collector area } \\
1.5 \mathrm{~m}^{2} \text { : } \\
\text { electrical } \\
\text { (overall) } \\
12.5 \% \text {, thermal } \\
\text { (overall) } 36.1 \%\end{array}$ & $\begin{array}{l}\text { Domestic } \\
\text { applications } \\
\text { with integrated- } \\
\text { collector- } \\
\text { storage solar } \\
\text { water heater }\end{array}$ & $\begin{array}{l}\text { Different } \\
\text { cases were } \\
\text { examined }\end{array}$ \\
\hline $\begin{array}{l}\text { Brown } \\
\text { e et al. } \\
(2016) \\
{[83]}\end{array}$ & No & Mono-Si & No & $\begin{array}{l}\text { Temperature at } \\
\text { the outlet pipes: } \\
\text { around } 24^{\circ} \mathrm{C} \\
\text { (maximum) }\end{array}$ & $\begin{array}{l}\text { Not directly } \\
\text { stated }\end{array}$ & $\begin{array}{l}\text { Buildings: PVT } \\
\text { applications } \\
\text { with PCM }\end{array}$ & Ireland \\
\hline $\begin{array}{l}\text { Khelifa } \quad \text { E-M } \\
\text { et al. } \\
\text { (2016) } \\
{[84]}\end{array}$ & No & $\begin{array}{l}\text { Not } \\
\text { directly } \\
\text { stated }\end{array}$ & No & $\begin{array}{l}\text { Outlet } \\
\text { temperature: } \\
39^{\circ} \mathrm{C} \\
\text { (maximum) }\end{array}$ & $\begin{array}{l}\text { Thermal: } \\
\text { around 94\% } \\
\text { (maximum) }\end{array}$ & $\begin{array}{l}\text { Water heating, } \\
\text { drying, air } \\
\text { conditioning, } \\
\text { etc. }\end{array}$ & Algeria \\
\hline $\begin{array}{l}\text { Adeilla } \quad \text { E } \\
\text { et al. } \\
(2016) \\
{[85]}\end{array}$ & Yes & $\begin{array}{l}\text { Not } \\
\text { directly } \\
\text { stated }\end{array}$ & No & $\begin{array}{l}\text { Output } \\
\text { temperature: } \\
\text { around } 36^{\circ} \mathrm{C} \\
\text { (maximum) }\end{array}$ & $\begin{array}{l}\text { Electrical: } 17 \% \text {; } \\
\text { Thermal: } 83 \%\end{array}$ & BIPVT & $\begin{array}{l}\text { Indoor } \\
\text { testing by } \\
\text { means of a } \\
\text { solar- } \\
\text { simulator }\end{array}$ \\
\hline $\begin{array}{l}\text { He et } \\
\text { al. } \\
(2016) \\
{[86]}\end{array}$ & $\begin{array}{l}\text { Yes } \\
\text { (CR less than 2X) }\end{array}$ & $\begin{array}{l}\text { Silicon- } \\
\text { based }\end{array}$ & No & $\begin{array}{l}\text { Maximum hot- } \\
\text { water } \\
\text { temperature for } \\
\text { the PVT with } \\
\text { concentrator: } \\
58^{\circ} \mathrm{C}\end{array}$ & $\begin{array}{l}\text { Not directly } \\
\text { stated }\end{array}$ & $\begin{array}{l}\text { PVT } \\
\text { applications } \\
\text { with diffuse- } \\
\text { reflection } \\
\text { concentrators }\end{array}$ & China \\
\hline $\begin{array}{l}\text { Rosa- } \quad \text { E } \\
\text { Clot et } \\
\text { al. } \\
(2016) \\
{[87]}\end{array}$ & No & Poly-Si & No & $\begin{array}{l}\text { Maximum daily } \\
\text { water } \\
\text { temperatures: } \\
47 \text { and } 55^{\circ} \mathrm{C} \text {, } \\
\text { depending on } \\
\text { the case }\end{array}$ & $\begin{array}{l}\text { Average } \\
\text { electrical } \\
\text { efficiencies of } \\
\text { systems A } \\
\text { and B: } 8.8 \% \\
\text { and } 13.2 \% \text {, } \\
\text { respectively }\end{array}$ & $\begin{array}{l}\text { Buildings and } \\
\text { industrial } \\
\text { applications }\end{array}$ & Italy \\
\hline $\begin{array}{ll}\text { Finocc } & \text { E-M } \\
\text { hiaro et } & \\
\text { al. } & \\
\end{array}$ & No & $\begin{array}{l}\text { Not } \\
\text { directly } \\
\text { stated }\end{array}$ & No & $\begin{array}{l}\text { Maximum } \\
\text { temperature: } \\
\text { around } 58^{\circ} \mathrm{C} \\
\end{array}$ & $\begin{array}{l}\text { Under cooling } \\
\text { conditions an } \\
\text { energy- }\end{array}$ & $\begin{array}{l}\text { BA PVT } \\
\text { combined with } \\
\text { desiccant } \\
\end{array}$ & Italy \\
\hline
\end{tabular}




\begin{tabular}{|c|c|c|c|c|c|c|c|c|}
\hline $\begin{array}{l}(2016) \\
{[88]}\end{array}$ & & & & & $\begin{array}{l}\text { (psychrometric } \\
\text { chart) }\end{array}$ & $\begin{array}{l}\text { efficiency-ratio } \\
\text { of } 12.8 \text { was } \\
\text { found (this ratio } \\
\text { is } 50.7 \text { if } \mathrm{PV} \\
\text { generation is } \\
\text { taken into } \\
\text { account) }\end{array}$ & & \\
\hline $\begin{array}{l}\text { Jouhar } \\
\text { a et al. } \\
(2016) \\
{[89]}\end{array}$ & $\mathrm{E}$ & No & $\begin{array}{l}\text { Not } \\
\text { directly } \\
\text { stated }\end{array}$ & No & $\begin{array}{l}\text { PVT module } \\
\text { temperature: } \\
\text { between } 28 \text { and } \\
33^{\circ} \mathrm{C}\end{array}$ & $\begin{array}{l}\text { Energy } \\
\text { conversion } \\
\text { efficiency: } 50 \% \\
\text { for the PVT } \\
\text { configuration }\end{array}$ & $\begin{array}{l}\text { BIPVT (roof- } \\
\text { integrated) }\end{array}$ & UK \\
\hline $\begin{array}{l}\text { Wang } \\
\text { et al. } \\
\text { (2016a } \\
\text { ) }[90]\end{array}$ & $\mathrm{E}$ & No & Poly-Si & No & $\begin{array}{l}\text { Tank water } \\
\text { temperature } \\
\text { maximum: } \\
47.2^{\circ} \mathrm{C} \\
\text { (simulated:900 } \\
\mathrm{W} / \mathrm{m}^{2} \text {; water } \\
\text { flow rate } 600 \\
\mathrm{~L} / \mathrm{h} \text { ) }\end{array}$ & $\begin{array}{l}\text { Daily average } \\
\text { thermal, } \\
\text { electrical and } \\
\text { total } \\
\text { efficiencies of } \\
\text { the system: } \\
61.1 \%, 7.8 \% \\
\text { and } 68.9 \% \text {, } \\
\text { respectively } \\
\text { (simulated:900 } \\
\text { W/m²; water } \\
\text { flow rate } 600 \\
\mathrm{~L} / \mathrm{h} \text { ) }\end{array}$ & $\begin{array}{l}\text { Heat-pipe } \\
\text { BIPVT }\end{array}$ & China \\
\hline $\begin{array}{l}\text { Wang } \\
\text { et al. } \\
\text { (2016b } \\
\text { ) [91] }\end{array}$ & $\mathrm{E}$ & No & Poly-Si & No & $\begin{array}{l}\text { Maximum tank- } \\
\text { water } \\
\text { temperature: } \\
53.83{ }^{\circ} \mathrm{C} \\
\text { (simulated:900 } \\
\mathrm{W} / \mathrm{m}^{2} \text {; water } \\
\text { flow rate } 200 \\
\mathrm{~L} / \mathrm{h} \text { ) }\end{array}$ & $\begin{array}{l}\text { Maximum } \\
\text { thermal: } 44 \% \\
\text { (simulated:300 } \\
\mathrm{W} / \mathrm{m}^{2} \text {; water } \\
\text { flow rate } 200 \\
\mathrm{~L} / \mathrm{h} \text { ); Maximum } \\
\text { electrical: } 7.9 \%\end{array}$ & $\begin{array}{l}\text { Heat-pipe } \\
\text { BIPVT; } \\
\text { potential of } \\
\text { building } \\
\text { integration: } \\
\text { walls, roofs, } \\
\text { balconies }\end{array}$ & China \\
\hline $\begin{array}{l}\text { Chemis } \\
\text { ana et } \\
\text { al. } \\
(2016) \\
{[92]}\end{array}$ & $\mathrm{E}$ & $\begin{array}{l}\text { Yes (geometric } \\
\text { CR: } 10.32 \mathrm{X} \text { ) }\end{array}$ & $\begin{array}{l}\text { Crystalline } \\
\text { silicon }\end{array}$ & No & $\begin{array}{l}\text { Outlet water } \\
\text { temperature: } \\
52{ }^{\circ} \mathrm{C}\end{array}$ & $\begin{array}{l}\text { Mean optical } \\
\text { efficiency: } 51 \%\end{array}$ & $\begin{array}{l}\text { BIPVT (façade- } \\
\text { integrated) with } \\
\text { Fresnel } \\
\text { reflectors }\end{array}$ & Spain \\
\hline $\begin{array}{l}\text { Karimi } \\
\text { et al. } \\
(2017) \\
{[93]}\end{array}$ & $\mathrm{E}$ & $\begin{array}{l}\text { Yes } \\
(\mathrm{CR}: 5.85 \mathrm{X})\end{array}$ & Mono-Si & No & $\begin{array}{l}\text { Water- } \\
\text { temperature in } \\
\text { the tank (for the } \\
\text { CPVT system): } \\
33.1^{\circ} \mathrm{C} \text { (final), } \\
15^{\circ} \mathrm{C} \text { (initial) }\end{array}$ & $\begin{array}{l}\text { For the CPVT } \\
\text { system (one of } \\
\text { the cases): } \\
\text { Thermal } 40.8 \% \\
\text { and electrical } \\
14.7 \%\end{array}$ & $\begin{array}{l}\text { Buildings: PVT } \\
\text { with Fresnel } \\
\text { lenses }\end{array}$ & China \\
\hline $\begin{array}{l}\text { Jaaz et } \\
\text { al. } \\
(2017) \\
{[94]}\end{array}$ & $\mathrm{E}$ & Yes & Poly-Si & No & $\begin{array}{l}\text { Maximum PV- } \\
\text { cell temperature } \\
\text { (PVT with } \\
\mathrm{CPC}): 67^{\circ} \mathrm{C}\end{array}$ & $\begin{array}{l}\text { Electrical: } \\
14.5 \% \\
\text { (maximum) }\end{array}$ & PVT with CPCs & Malaysia \\
\hline $\begin{array}{l}\text { Asaee } \\
\text { et al. } \\
(2017) \\
{[95]}\end{array}$ & $\mathrm{M}$ & No & $\begin{array}{l}\text { Crystalline } \\
\text { silicon }\end{array}$ & No & $\begin{array}{l}\text { Maximum } \\
\text { water } \\
\text { temperature: } \\
55^{\circ} \mathrm{C}\end{array}$ & $\begin{array}{l}\text { User-defined } \\
\text { efficiency of the } \\
\text { PV panels: } \\
11.7 \%\end{array}$ & $\begin{array}{l}\text { BIPVT (roof- } \\
\text { integrated) }\end{array}$ & Canada \\
\hline $\begin{array}{l}\text { Gauta } \\
\mathrm{m} \text { and } \\
\text { Andres } \\
\text { en } \\
(2017) \\
{[96]}\end{array}$ & M & No & $\begin{array}{l}\text { Not } \\
\text { directly } \\
\text { stated }\end{array}$ & No & $\begin{array}{l}\text { At the top of the } \\
\text { tank: } 55^{\circ} \mathrm{C} \text { to } \\
\text { prevent the } \\
\text { growth of } \\
\text { Legionella } \\
\text { pneumophila }\end{array}$ & $\begin{array}{l}\text { Electrical: } \\
\text { around } 11.4 \% \\
\text { (maximum, for } \\
\text { the BIPVT in } \\
\text { Spain) }\end{array}$ & $\begin{array}{l}\text { BIPVT (façade- } \\
\text { integrated) with } \\
\text { direct flow } \\
\text { (boxed) } \\
\text { absorber }\end{array}$ & $\begin{array}{l}\text { Denmark; } \\
\text { Spain }\end{array}$ \\
\hline $\begin{array}{l}\text { Buono } \\
\text { mano } \\
\text { et al. } \\
(2017) \\
{[97]}\end{array}$ & $\mathrm{M}$ & No & Poly-Si & No & $\begin{array}{l}\text { Domestic-hot- } \\
\text { water set point } \\
\text { temperature: } \\
45^{\circ} \mathrm{C}\end{array}$ & $\begin{array}{l}\text { PV (reference): } \\
12 \% \text {; PVT } \\
\text { winter: around } \\
9 \%\end{array}$ & $\begin{array}{l}\text { BIPVT (roof- } \\
\text { integrated) with } \\
\text { chiller }\end{array}$ & Italy \\
\hline
\end{tabular}




\begin{tabular}{|c|c|c|c|c|c|c|c|c|}
\hline $\begin{array}{l}\text { Li et } \\
\text { al. } \\
(2017) \\
{[98]}\end{array}$ & E-M & $\begin{array}{l}\text { Yes } \\
\text { (CR: 3.6X) }\end{array}$ & Si-based & No & $\begin{array}{l}\text { Maximum } \\
\text { temperature: } \\
\text { around } 41{ }^{\circ} \mathrm{C} \text { at } \\
\text { the inlet of the } \\
\text { first heat } \\
\text { exchanger of } \\
\text { the CPVT; } \\
\text { rooftop (case: } \\
\text { Spain) }\end{array}$ & $\begin{array}{l}\text { In one of the } \\
\text { cases: optical } \\
\text { efficiency of the } \\
\text { CPCs } 84 \%\end{array}$ & $\begin{array}{l}\text { PVT for } \\
\text { buildings: CPCs } \\
\text { vs. flat modules }\end{array}$ & $\begin{array}{l}\text { Spain; } \\
\text { Scotland; } \\
\text { UK }\end{array}$ \\
\hline $\begin{array}{l}\text { Soltani } \\
\text { et al. } \\
(2018) \\
{[99]}\end{array}$ & $\mathrm{M}$ & $\begin{array}{l}\text { Yes } \\
(\mathrm{CR}: 8 \mathrm{X})\end{array}$ & $\begin{array}{l}\text { Crystalline } \\
\text { silicon }\end{array}$ & Yes & $\begin{array}{l}\text { Maximum } \\
\text { temperatures of } \\
\text { the two sides of } \\
\text { the } \\
\text { thermoelectric } \\
\text { generator: } \\
89.97 \text { and } \\
45^{\circ} \mathrm{C}\end{array}$ & $\begin{array}{l}\text { Thermal: } \\
\text { around 57\% } \\
\text { (maximum); } \\
\text { electrical } \\
\text { (thermoelectric } \\
\text { generator): } \\
\text { about } 0.5 \% \\
\text { (maximum) }\end{array}$ & $\begin{array}{l}\text { PVT with } \\
\text { parabolic- } \\
\text { trough } \\
\text { collectors }\end{array}$ & $\begin{array}{l}\text { Not directly } \\
\text { stated }\end{array}$ \\
\hline $\begin{array}{l}\text { Yang } \\
\text { et al. } \\
(2018) \\
{[100]}\end{array}$ & E-M & $\begin{array}{l}\text { Yes } \\
(\mathrm{CR}: 8 \mathrm{X})\end{array}$ & Mono-Si & No & $\begin{array}{l}\text { Glass-cover- } \\
\text { plate } \\
\text { temperature: } \\
\text { around } 60^{\circ} \mathrm{C} \\
\text { (maximum) }\end{array}$ & $\begin{array}{l}\text { Overall (CPVT } \\
\text { system): 55.6- } \\
59 \% \text {; Electrical } \\
\text { efficiencies } \\
\text { (system): 16.6- } \\
20 \% \\
\text { (experimental); } \\
\text { Optical } \\
\text { efficiency and } \\
\text { mirror } \\
\text { utilisation } \\
\text { (concentrator): } \\
94.4 \%\end{array}$ & $\begin{array}{l}\text { PVT with quasi- } \\
\text { parabolic } \\
\text { concentrators }\end{array}$ & China \\
\hline $\begin{array}{l}\text { Fayaz } \\
\text { et al. } \\
(2019) \\
{[101]}\end{array}$ & E-M & No & Poly-Si & No & $\begin{array}{l}\text { Maximum } \\
\text { output } \\
\text { temperature } \\
(\mathrm{PVT}): 57.4{ }^{\circ} \mathrm{C} \\
\text { and } 56{ }^{\circ} \mathrm{C} \\
\text { (numerical and } \\
\text { experimental } \\
\text { results, } \\
\text { respectively) }\end{array}$ & $\begin{array}{l}\text { Maximum } \\
\text { thermal (PVT } \\
\text { system): } 81 \% \\
\text { and } 77.36 \% \\
\text { (numerical and } \\
\text { experimental } \\
\text { results, } \\
\text { respectively); } \\
\text { Electrical: } \\
12.75 \% \\
\text { improved } \\
\text { experimentally } \\
\text { for the PVT- } \\
\text { PCM }\end{array}$ & $\begin{array}{l}\text { PVT with } \\
\text { PCMs }\end{array}$ & Malaysia \\
\hline $\begin{array}{l}\text { Maadi } \\
\text { et al. } \\
(2019) \\
{[102]}\end{array}$ & $\mathrm{M}$ & No & Poly-Si & No & $\begin{array}{l}\text { Output } \\
\text { temperature: } \\
\text { around } 43{ }^{\circ} \mathrm{C} \\
\text { (considering the } \\
\text { greenhouse } \\
\text { effect) }\end{array}$ & $\begin{array}{l}\text { If the } \\
\text { greenhouse } \\
\text { effect is } \\
\text { considered, } \\
\text { there is an } \\
\text { increase of } 12 \% \\
\text { in thermal } \\
\text { efficiency (case: } \\
300 \mathrm{~W} / \mathrm{m}^{2} \text { ) }\end{array}$ & Buildings & $\begin{array}{l}\text { Not directly } \\
\text { stated }\end{array}$ \\
\hline $\begin{array}{l}\text { Alves } \\
\text { et al. } \\
(2019) \\
{[103]}\end{array}$ & E-M & $\begin{array}{l}\text { Yes } \\
\text { (CR: 1.7X) }\end{array}$ & Mono-Si & No & $\begin{array}{l}\text { Test 2: water } \\
\text { outlet } \\
\text { temperature } \\
\text { (average): } \\
49^{\circ} \mathrm{C} \\
\text { (experimental), } \\
48.7^{\circ} \mathrm{C} \\
\text { (modelled) }\end{array}$ & $\begin{array}{l}\text { For Sweden, } \\
\text { electrical: } \\
\text { 19.1\%; For } \\
\text { Portugal, } \\
\text { electrical: } \\
\text { 18.9\%; } \\
\text { Thermal: } \\
\text { around 63\% } \\
\text { (maximum) }\end{array}$ & $\begin{array}{l}\text { PVT with } \\
\text { reflector/concen } \\
\text { trator; Domestic } \\
\text { water heating }\end{array}$ & $\begin{array}{l}\text { Sweden; } \\
\text { Portugal }\end{array}$ \\
\hline
\end{tabular}

With respect to PVT based on nanofluids, Wu et al. [104] investigated a CPVT system with thermoelectric elements (figure 2). Glazed and unglazed configurations were 
examined. In order to improve heat removal, nanofluid was used as a heat sink. It was noted that nanofluid shows better performance in comparison to water (for instance, from a heat-transfer point of view). .

a)

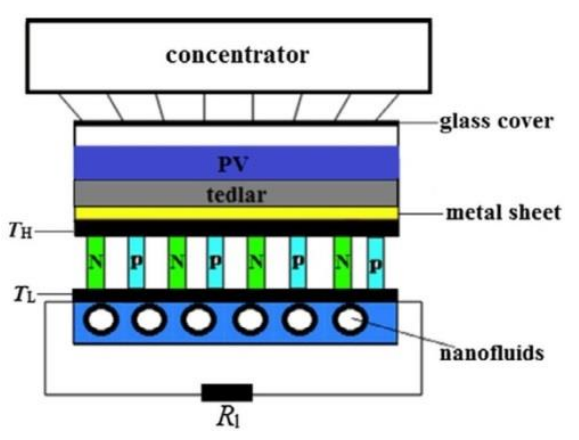

b)

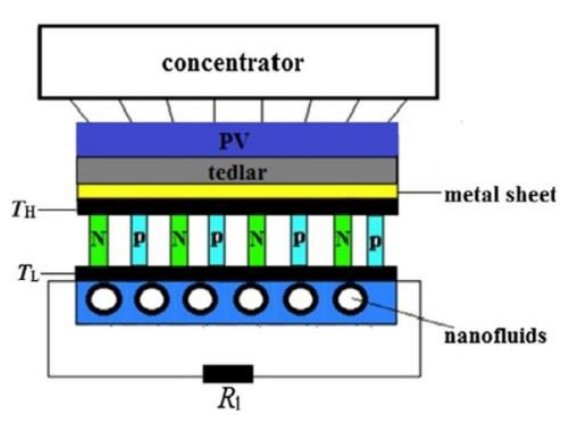

Figure 2. The low-temperature CPVT system studied by Wu et al. [104]: a) system with a thermoelectric component, b) nanofluid cooling tubes. Source: Wu et al. [104].

In Table 4, studies about different kinds of low-temperature PVT systems (bifluid configurations or systems with fluids different to those included in Tables 2 and 3), are presented. The results show that:

- The majority of the references are experimental/modelling investigations without involving solar concentration and thermoelectric devices.

- In many cases, silicon-based PV cells were used.

- Most of the investigations about concentrating systems refer to CRs up to 20X, involving configurations such as CPCs and parabolic-trough concentrators.

- The majority of the PV efficiencies are 13-15\% (approximately). Moreover, in many cases, thermal efficiencies reach up to around $70 \%$. 
- Different types of applications were presented: by way of illustration, BI systems and configurations with PCM as storage material.

- A large majority of the studies are based on systems with working fluid temperatures around $40-55^{\circ} \mathrm{C}$.

- The systems were investigated for different climatic conditions.

Table 4. PVT systems: working fluids (nanofluids, air/water, etc.) at low-temperatures.

\begin{tabular}{|c|c|c|c|c|c|c|c|c|c|}
\hline $\begin{array}{l}\text { Study / } \\
\text { year }\end{array}$ & $\begin{array}{l}\text { Type } \\
\text { of } \\
\text { study }\end{array}$ & $\begin{array}{l}\text { Working } \\
\text { fluid }\end{array}$ & $\begin{array}{l}\text { Solar } \\
\text { concentration }\end{array}$ & $\begin{array}{l}\text { Type of } \\
\text { PV cells }\end{array}$ & $\begin{array}{l}\text { Thermoelect } \\
\text { ric element }\end{array}$ & $\begin{array}{l}\text { Temperature } \\
\text { of the working } \\
\text { fluid: Low }\end{array}$ & Efficiencies & $\begin{array}{l}\text { Type of } \\
\text { application: } \\
\text { - Buildings } \\
\text { - Etc. }\end{array}$ & $\begin{array}{l}\text { Location } \\
\text { of the } \\
\text { study }\end{array}$ \\
\hline $\begin{array}{l}\text { Wu et } \\
\text { al. } \\
(2015) \\
{[104]}\end{array}$ & $\mathrm{M}$ & Nanofluid & $\begin{array}{l}\text { Yes } \\
\text { (CRs up to 5X) }\end{array}$ & $\begin{array}{l}\text { Not } \\
\text { directly } \\
\text { stated }\end{array}$ & Yes & $\begin{array}{l}\text { PV cell: around } \\
53{ }^{\circ} \mathrm{C} \\
\text { (maximum) }\end{array}$ & $\begin{array}{l}\text { Thermal: } 54.3 \% \\
\text { (maximum; } \\
\text { theoretical) }\end{array}$ & $\begin{array}{l}\text { Engineering } \\
\text { applications }\end{array}$ & $\begin{array}{l}\text { Not directly } \\
\text { stated }\end{array}$ \\
\hline $\begin{array}{l}\text { Oruc et } \\
\text { al. } \\
(2016) \\
{[105]}\end{array}$ & M & $\begin{array}{l}\text { Water } \\
\text { electrolyze } \\
\mathrm{r}\end{array}$ & No & $\begin{array}{l}\text { Silicon- } \\
\text { based }\end{array}$ & No & $\begin{array}{l}\text { Average } \\
\text { temperature of } \\
\text { the electrolyte } \\
\text { in the chamber: } \\
53^{\circ} \mathrm{C}\end{array}$ & $\begin{array}{l}\text { Energetic } \\
\text { efficiencies of } \\
\text { the PVT } \\
\text { system: } 56- \\
59 \% \text {; Electrical: } \\
\text { around } 15 \% \\
\text { (maximum) }\end{array}$ & $\begin{array}{l}\text { Water and/or } \\
\text { room heating; } \\
\text { Powering fuel } \\
\text { cell-based } \\
\text { cars }\end{array}$ & USA \\
\hline $\begin{array}{l}\text { Su et } \\
\text { al. } \\
(2016) \\
{[106]}\end{array}$ & $\mathrm{M}$ & $\begin{array}{l}\text { Bifluid } \\
\text { (water- } \\
\text { water or } \\
\text { air-water } \\
\text { or water- } \\
\text { air or air- } \\
\text { air) }\end{array}$ & No & $\begin{array}{l}\text { Not } \\
\text { directly } \\
\text { stated }\end{array}$ & No & $\begin{array}{l}\text { Water-water } \\
\text { PVT: hot water } \\
\text { at } 39.4{ }^{\circ} \mathrm{C}(0.1 \\
\mathrm{kg} / \mathrm{s}) \text {; air-air } \\
\text { PVT: hot air at } \\
45.6^{\circ} \mathrm{C}(0.1 \\
\mathrm{kg} / \mathrm{s})\end{array}$ & $\begin{array}{l}\text { Water-water } \\
\text { PVT: electrical } \\
\text { and overall } \\
\text { efficiencies: } \\
7.8 \% \text { and } \\
84.2 \% \text {, } \\
\text { respectively } \\
(0.15 \mathrm{~kg} / \mathrm{s})\end{array}$ & $\begin{array}{l}\text { PVT with dual } \\
\text { channels for } \\
\text { different fluids }\end{array}$ & $\begin{array}{l}\text { China; } \\
\text { India }\end{array}$ \\
\hline $\begin{array}{l}\text { Jarimi } \\
\text { et al. } \\
(2016) \\
{[107]}\end{array}$ & E-M & $\begin{array}{l}\text { Bifluid } \\
\text { (air; water) }\end{array}$ & No & $\begin{array}{l}\text { Not } \\
\text { directly } \\
\text { stated }\end{array}$ & No & $\begin{array}{l}\text { With both fluids } \\
\text { operating (at the } \\
\text { same time), } \\
\text { mean PV-cell } \\
\text { temperature: } \\
51.4^{\circ} \mathrm{C} \text { (air } \\
\text { flow rate: } \\
0.0074 \mathrm{~kg} / \mathrm{s} \text { ) }\end{array}$ & $\begin{array}{l}\text { Electrical: } \\
\text { around } 4-4.5 \% \text {, } \\
\text { depending on } \\
\text { the case }\end{array}$ & $\begin{array}{l}\text { PVT-bifluid } \\
\text { applications }\end{array}$ & Malaysia \\
\hline $\begin{array}{l}\text { Othma } \\
\text { n et al. } \\
(2016) \\
{[108]}\end{array}$ & $E$ & $\begin{array}{l}\text { Air; } \\
\text { Water }\end{array}$ & No & $\begin{array}{l}\text { Transparen } \\
\mathrm{t}\end{array}$ & No & $\begin{array}{l}\text { Outlet } \\
\text { temperature } \\
44.6^{\circ} \mathrm{C}(0.01 \\
\mathrm{kg} / \mathrm{s} \text { air mass } \\
\text { flow rate; } 350 \\
\left.\mathrm{~W} / \mathrm{m}^{2}\right) \text {; Outlet } \\
\text { temperature } \\
32.2^{\circ} \mathrm{C}(0.02 \\
\mathrm{kg} / \mathrm{s} \text { water mass } \\
\text { flow rate; } 350 \\
\left.\mathrm{~W} / \mathrm{m}^{2}\right)\end{array}$ & $\begin{array}{l}\text { Optimum } \\
\text { results: } 0.05 \\
\mathrm{~kg} / \mathrm{s} \text { air mass } \\
\text { flow rate; } 0.02 \\
\mathrm{~kg} / \mathrm{s} \text { water mass } \\
\text { flow rate; total } \\
\text { thermal } \\
\text { efficiency } \\
\text { (combi system): } \\
76 \% \text {; average } \\
\text { outlet } \\
\text { temperature: } \\
27.4^{\circ} \mathrm{C} ; \\
\text { electrical } \\
\text { efficiency: } 17 \% \\
\left(800 \mathrm{~W} / \mathrm{m}^{2}\right)\end{array}$ & $\begin{array}{l}\text { PVT with air } \\
\text { and water } \\
\text { heating systems }\end{array}$ & Malaysia \\
\hline $\begin{array}{l}\text { Yazdan } \\
\text { ifard et } \\
\text { al. }\end{array}$ & $\mathrm{M}$ & $\begin{array}{l}\text { Water; } \\
\mathrm{TiO}_{2} / \text { water } \\
\text { nanofluid }\end{array}$ & $\begin{array}{l}\text { Yes } \\
\text { (CRs: 4X, 6X, } \\
\text { 8X, 10X, 12X, }\end{array}$ & GaAs & No & $\begin{array}{l}\text { Outlet water } \\
\text { temperature: } \\
37.4^{\circ} \mathrm{C}(0.008 \\
\end{array}$ & $\begin{array}{l}\text { Total energy } \\
\text { efficiency } 62 \% \\
\text { (in the case }\end{array}$ & $\begin{array}{l}\text { PVT with } \\
\text { parabolic- }\end{array}$ & $\begin{array}{l}\text { Not directly } \\
\text { stated }\end{array}$ \\
\hline
\end{tabular}




\begin{tabular}{|c|c|c|c|c|c|c|c|c|c|}
\hline $\begin{array}{l}(2017) \\
{[109]}\end{array}$ & & & $\begin{array}{l}14 X, 16 X, 18 X \\
20 X)\end{array}$ & & & $\begin{array}{l}\mathrm{kg} / \mathrm{s} ; 894.2 \\
\left.\mathrm{~W} / \mathrm{m}^{2}\right)\end{array}$ & $\begin{array}{l}\text { «laminar, } \\
\text { glazed, CR = } \\
20 \mathrm{X} »)\end{array}$ & $\begin{array}{l}\text { trough } \\
\text { collectors }\end{array}$ & \\
\hline $\begin{array}{l}\text { Sardara } \\
\text { badi et } \\
\text { al. } \\
(2017) \\
{[110]}\end{array}$ & $\mathrm{E}$ & $\begin{array}{l}\mathrm{ZnO} / \text { water } \\
\text { nanofluid }\end{array}$ & No & Mono-Si & No & $\begin{array}{l}\text { PV-surface } \\
\text { temperature, } \\
\text { PVT with PCM } \\
\text { and nanofluid: } \\
\text { around } 46^{\circ} \mathrm{C} \\
\text { (maximum) }\end{array}$ & $\begin{array}{l}\text { Overall exergy } \\
\text { (PVT with PCM } \\
\text { and nanofluid): } \\
13.42 \%\end{array}$ & $\begin{array}{l}\text { PVT with } \\
\text { nanofluid and } \\
\text { PCM }\end{array}$ & Iran \\
\hline $\begin{array}{l}\text { Riverol } \\
\text { a et al. } \\
(2018) \\
{[111]}\end{array}$ & E-M & $\begin{array}{l}\text { PV cells } \\
\text { immersed } \\
\text { in } \\
\text { deionised } \\
\text { water or } \\
\text { isopropyl } \\
\text { alcohol }\end{array}$ & $\begin{array}{l}\text { Yes } \\
\text { (geometric } \\
\text { CR: 10X) }\end{array}$ & Mono-Si & No & $\begin{array}{l}\text { Maximum } \\
\text { temperature: } \\
\text { around } 50^{\circ} \mathrm{C}\end{array}$ & $\begin{array}{l}\text { Isopropyl- } \\
\text { alcohol case } \\
\text { shows the } \\
\text { highest optical } \\
\text { efficiencies } \\
80-81 \% \\
\text { (maximum) }\end{array}$ & $\begin{array}{l}\text { BIPVT (façade- } \\
\text { integrated) with } \\
\text { PV cells } \\
\text { immersed in } \\
\text { liquid }\end{array}$ & Spain \\
\hline $\begin{array}{l}\text { Moren } \\
\text { o et al. } \\
(2018) \\
{[112]}\end{array}$ & E-M & $\begin{array}{l}\text { Deionised } \\
\text { water (PV } \\
\text { cells } \\
\text { immersed } \\
\text { in } \\
\text { deionised } \\
\text { water) }\end{array}$ & $\begin{array}{l}\text { Yes } \\
\text { (geometric } \\
\text { CR: 12X) }\end{array}$ & $\begin{array}{l}\text { Silicon- } \\
\text { based } \\
\text { passivated } \\
\text { emitter } \\
\text { rear cells }\end{array}$ & No & $\begin{array}{l}\text { Maximum } \\
\text { temperature: } \\
\text { around } 50{ }^{\circ} \mathrm{C}\end{array}$ & Optical: $76.14 \%$ & $\begin{array}{l}\text { BIPVT (façade- } \\
\text { integrated) with } \\
\text { PV cells } \\
\text { immersed in } \\
\text { liquid }\end{array}$ & $\begin{array}{l}\text { Spain; } \\
\text { Italy; } \\
\text { Portugal }\end{array}$ \\
\hline $\begin{array}{l}\text { Abdelr } \\
\text { azik et } \\
\text { al. } \\
(2019) \\
{[113]}\end{array}$ & M & $\begin{array}{l}\text { Water/grap } \\
\text { hene } \\
\text { nanofluid; } \\
\text { Water/ } \\
\text { silver }\end{array}$ & No & Poly-Si & No & $\begin{array}{l}\text { All the fluids } \\
\text { remain liquids } \\
\text { (phase of usage) } \\
\text { and the } \\
\text { temperature } \\
\text { is lower than } \\
60{ }^{\circ} \mathrm{C}\end{array}$ & $\begin{array}{l}\text { Electrical: 9.6- } \\
11.4 \% \\
\text { (depending on } \\
\text { the model); } \\
\text { Thermal: } \\
\text { around } 79 \% \\
\text { (maximum; } \\
\text { based on the } \\
\text { models studied) }\end{array}$ & $\begin{array}{l}\text { PVT with } \\
\text { nanofluids and } \\
\text { nano-PCM }\end{array}$ & $\begin{array}{l}\text { Not directly } \\
\text { stated }\end{array}$ \\
\hline $\begin{array}{l}\text { Dimri } \\
\text { et al. } \\
(2019) \\
{[114]}\end{array}$ & $\mathrm{M}$ & $\begin{array}{l}\text { Two } \\
\text { versions: } \\
\text { 1) air- } \\
\text { based, } \\
\text { 2) water- } \\
\text { based }\end{array}$ & No & $\begin{array}{l}\text { Not } \\
\text { directly } \\
\text { stated }\end{array}$ & $\begin{array}{l}\text { Yes } \\
\text { (thermoelectri } \\
\text { c cooler) }\end{array}$ & $\begin{array}{l}\text { Opaque PVT- } \\
\text { thermoelectric } \\
\text { air collector: } \\
\text { around } 38^{\circ} \mathrm{C} \\
\text { (maximum fluid } \\
\text { temperature) }\end{array}$ & $\begin{array}{l}\text { Opaque PVT- } \\
\text { thermoelectric } \\
\text { air collector: } \\
\text { overall } \\
\text { electrical } 14.2 \% \\
\text { (maximum) }\end{array}$ & Buildings & India \\
\hline
\end{tabular}

\subsection{PVT SYSTEMS FOR MEDIUM-TEMPERATURE APPLICATIONS}

In the literature about PVT systems with working-fluid temperatures between 60 and $90{ }^{\circ} \mathrm{C}$, there is a more balanced number of cases with/without solar concentration in comparison to the literature about PVT systems with low-temperature working fluids.

Table 5 presents studies about PVT systems without involving solar concentration and with using working fluids at medium temperatures. The results indicate that:

- A large number of references include experimental/modelling and modelling studies about systems without thermoelectric components.

- In most cases, silicon-based PV cells were utilised. 
- The majority of the thermal efficiencies are around 55-60\% and electrical/PV efficiencies are approximately $13-15 \%$.

- A large majority of the investigations are about PVT/water and PVT/air configurations, for industrial and domestic applications (including BI systems).

- There are a few references about configurations with PCMs, heat pumps, ethylene-tetrafluoroethylene cushions and polymeric PVT collectors.

- In the vast majority of cases, the working-fluid temperatures are approximately $60-70{ }^{\circ} \mathrm{C}$.

- The systems were evaluated for different climatic conditions.

Ren et al. [133] investigated an amorphous silicon PVT/water configuration appropriate for medium-temperature applications, verifying that this kind of PV technology is feasible from a technical/thermodynamic point of view (for mediumtemperature applications). The experiments were conducted in Hefei, in China. In Figure 3, the PVT system and experimental/numerical results are illustrated. 
a)

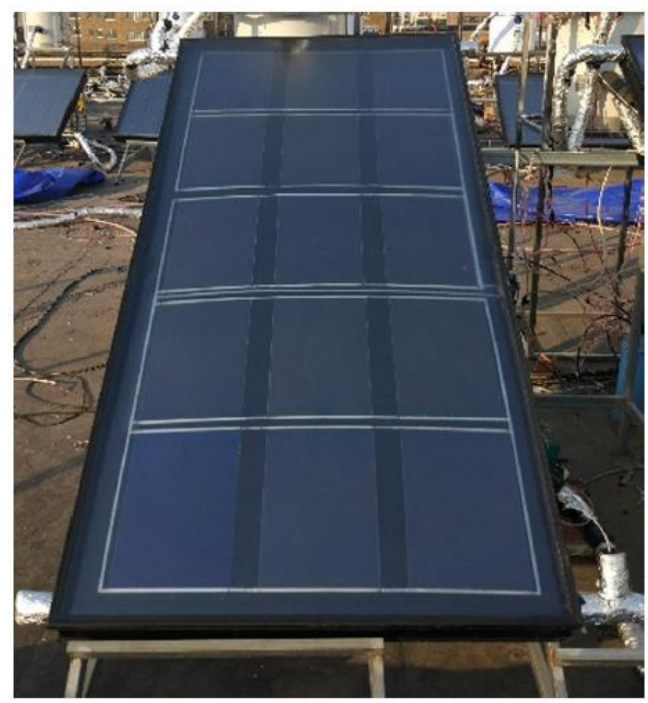

b)

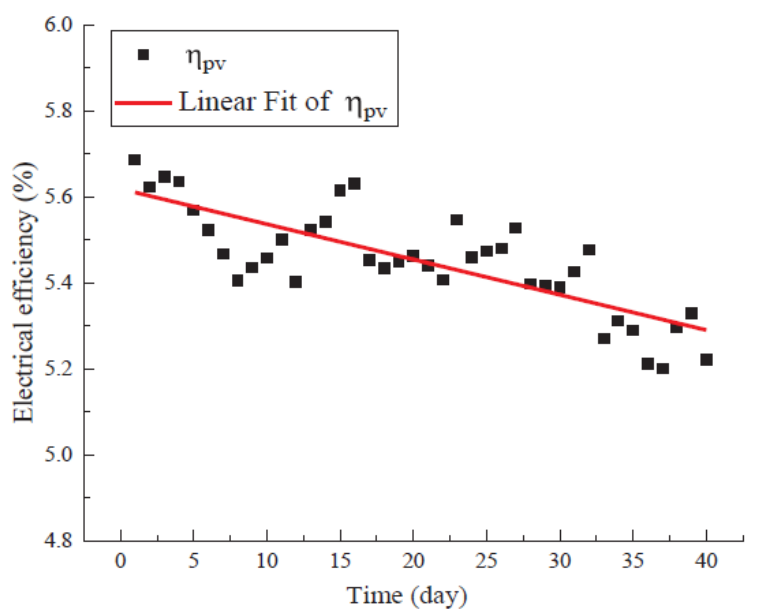

c)

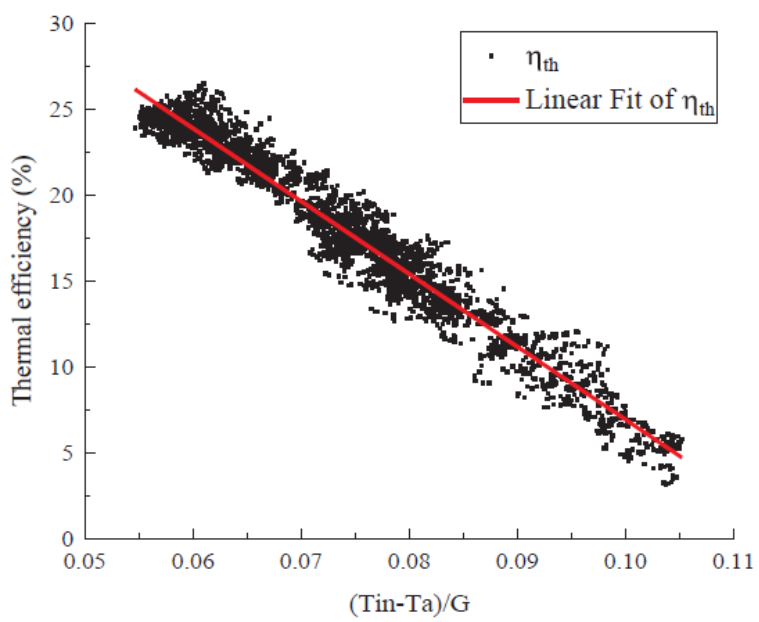


d)

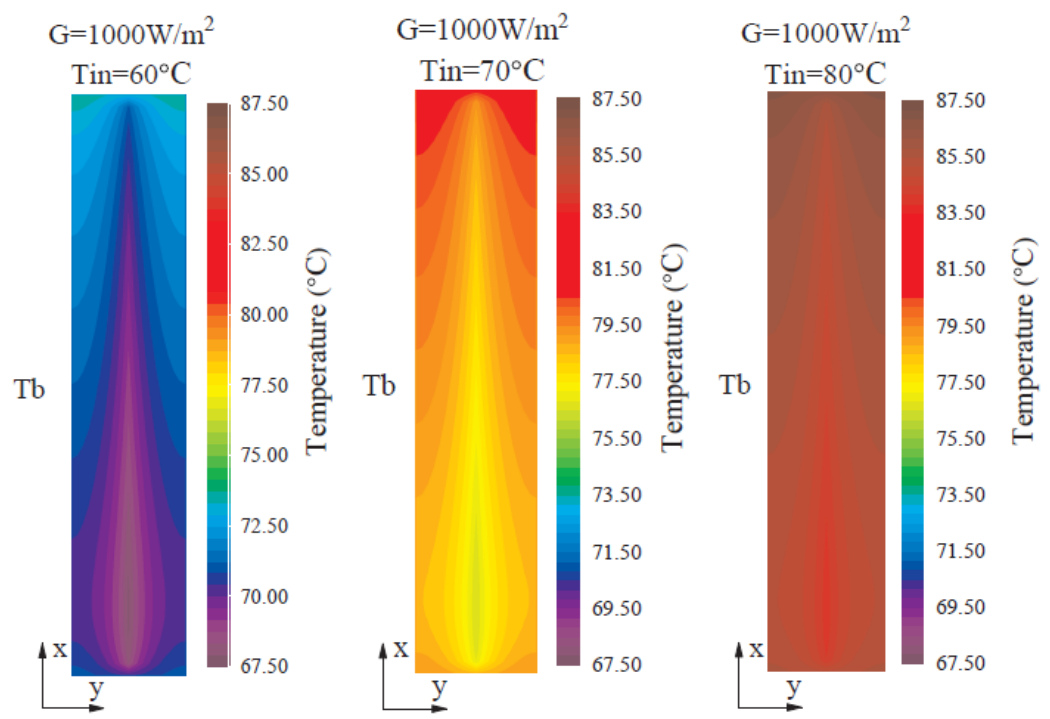

Figure 3. The amorphous silicon PVT/water system studied by Ren et al. [133]: a) experimental setup, b) electrical efficiency (experimental results), c) thermal efficiency (experimental results), d) temperature distribution of the absorber plate $\left(\mathrm{T}_{\mathrm{b}}\right)$ (numerical results; different inlet temperatures $\left(\mathrm{T}_{\text {in }}\right)$ ). Source: Ren et al. [133].

Table 5. PVT systems without involving solar concentration: working fluids at medium temperatures.

\begin{tabular}{|c|c|c|c|c|c|c|c|c|}
\hline $\begin{array}{l}\text { Study / } \\
\text { year }\end{array}$ & $\begin{array}{l}\text { Type } \\
\text { of } \\
\text { study }\end{array}$ & $\begin{array}{l}\text { Working } \\
\text { fluid }\end{array}$ & $\begin{array}{l}\text { Type of } \\
\text { PV cells }\end{array}$ & $\begin{array}{l}\text { Thermoelect } \\
\text { ric element }\end{array}$ & $\begin{array}{l}\text { Temperature } \\
\text { of the working } \\
\text { fluid: Medium }\end{array}$ & Efficiencies & $\begin{array}{l}\text { Type of } \\
\text { application: } \\
\text { - Buildings } \\
\text { - Etc. }\end{array}$ & $\begin{array}{l}\text { Location } \\
\text { of the } \\
\text { study }\end{array}$ \\
\hline $\begin{array}{l}\text { Cristof } \\
\text { ari et } \\
\text { al. } \\
(2009) \\
{[115]}\end{array}$ & E-M & Water & Poly-Si & No & $\begin{array}{l}\text { Solar-collector } \\
\text { output: } 62{ }^{\circ} \mathrm{C} \\
\text { (maximum) }\end{array}$ & $\begin{array}{l}\text { Average: } 55.5 \% \\
\text { (thermal), } \\
12.7 \%(\mathrm{PV})\end{array}$ & $\begin{array}{l}\text { Polymeric PVT } \\
\text { for domestic } \\
\text { applications }\end{array}$ & France \\
\hline $\begin{array}{l}\text { Rajoria } \\
\text { et al. } \\
(2012) \\
{[116]}\end{array}$ & $\mathrm{M}$ & Air & $\begin{array}{l}\text { Not } \\
\text { directly } \\
\text { stated }\end{array}$ & No & $\begin{array}{l}\text { Outlet air } \\
\text { temperature: } \\
\text { around } 70^{\circ} \mathrm{C} \\
\text { (maximum; } \\
\text { case III) }\end{array}$ & $\begin{array}{l}\text { Electrical } \\
\text { (average): } \\
11.3 \%\end{array}$ & $\begin{array}{l}\text { System } \\
\text { appropriate for } \\
\text { BI applications }\end{array}$ & India \\
\hline $\begin{array}{l}\text { Kalogir } \\
\text { ou et } \\
\text { al. } \\
(2014) \\
{[117]}\end{array}$ & $\mathrm{M}$ & Air & Poly-Si & No & $\begin{array}{l}\text { Air-gap } \\
\text { temperature } \\
\text { around } 77^{\circ} \mathrm{C} \\
\text { (maximum): for } \\
\text { an air gap of } \\
0.02 \mathrm{~m} \text { and a } \\
\text { steady flow } \\
\text { velocity of } 0.05 \\
\mathrm{~m} / \mathrm{s}\end{array}$ & PV cell: $15 \%$ & BIPVT & Cyprus \\
\hline $\begin{array}{l}\text { Herran } \\
\text { do et } \\
\text { al. } \\
(2014) \\
{[118]}\end{array}$ & $\mathrm{M}$ & Water & Mono-Si & No & $\begin{array}{l}\text { Constant hot } \\
\text { water supply } \\
\text { temperature: } \\
60{ }^{\circ} \mathrm{C}\end{array}$ & $\begin{array}{l}\text { PV module: } \\
15.4 \% \\
\text { (maximum) }\end{array}$ & $\begin{array}{l}\text { Domestic } \\
\text { applications }\end{array}$ & UK \\
\hline $\begin{array}{l}\text { Canelli } \\
\text { et al. } \\
(2015) \\
{[119]}\end{array}$ & $\mathrm{M}$ & Water & $\begin{array}{l}\text { Not } \\
\text { directly } \\
\text { stated }\end{array}$ & No & $\begin{array}{l}\text { Temperature of } \\
\text { the fluid for the } \\
\text { end user: set at } \\
60{ }^{\circ} \mathrm{C}\end{array}$ & $\begin{array}{l}\text { For the PVT } \\
\text { system: Not } \\
\text { directly stated }\end{array}$ & $\begin{array}{l}\text { Buildings: PVT } \\
\text { with chiller }\end{array}$ & $\begin{array}{l}\text { Italy; } \\
\text { Canada }\end{array}$ \\
\hline
\end{tabular}




\begin{tabular}{|c|c|c|c|c|c|c|c|c|}
\hline $\begin{array}{l}\text { Shyam } \\
\text { et al. } \\
(2016) \\
{[120]}\end{array}$ & E-M & Water & $\begin{array}{l}\text { Crystalline } \\
\text { silicon }\end{array}$ & No & $\begin{array}{l}\text { Outlet water } \\
\text { temperature: } \\
\text { around } 80^{\circ} \mathrm{C} \\
\text { (maximum; } \\
\text { clear sky) }\end{array}$ & $\begin{array}{l}\text { Module: around } \\
6 \% \text { (maximum) }\end{array}$ & $\begin{array}{l}\text { Domestic and } \\
\text { industrial } \\
\text { applications }\end{array}$ & India \\
\hline $\begin{array}{l}\text { Khanja } \\
\text { ri et al. } \\
\text { (2016) } \\
{[121]}\end{array}$ & $\mathrm{M}$ & $\begin{array}{l}\text { Pure water; } \\
\text { Ag-water } \\
\text { nanofluid; } \\
\text { Alumina- } \\
\text { water } \\
\text { nanofluid }\end{array}$ & $\begin{array}{l}\text { Not } \\
\text { directly } \\
\text { stated }\end{array}$ & No & $\begin{array}{l}\text { Maximum } \\
\text { outlet } \\
\text { temperature: } \\
\text { around } 65^{\circ} \mathrm{C} \text { in } \\
\text { one of the cases } \\
\text { (Ag- } \\
\text { nanoparticle) }\end{array}$ & $\begin{array}{l}\text { Thermal around } \\
84 \% \\
\text { (maximum) and } \\
\text { electrical } \\
\text { around } 11 \% \\
\text { (maximum) in } \\
\text { the case of Ag- } \\
\text { water nanofluid }\end{array}$ & $\begin{array}{l}\text { PVT with } \\
\text { nanofluids }\end{array}$ & $\begin{array}{l}\text { Not directly } \\
\text { stated }\end{array}$ \\
\hline $\begin{array}{l}\text { Sotehi } \\
\text { et al. } \\
(2016) \\
{[122]}\end{array}$ & E-M & Water & $\begin{array}{l}\text { Not } \\
\text { directly } \\
\text { stated }\end{array}$ & No & $\begin{array}{l}\text { Temperature of } \\
\text { the water in the } \\
\text { storage tank: } \\
60^{\circ} \mathrm{C} \text { in order } \\
\text { to reduce the } \\
\text { risk of } \\
\text { Legionella } \\
\text { growth }\end{array}$ & $\begin{array}{l}\text { Air } \\
\text { conditioning } \\
\text { system with } \\
\text { reverse cycle } \\
(\mathrm{COP}=2.8 ; \\
\text { compressor } \\
\text { electrical } \\
\text { efficiency: } \\
80 \%)\end{array}$ & $\begin{array}{l}\text { Desalination } \\
\text { with solar stills; } \\
\text { Net zero energy } \\
\text { buildings }\end{array}$ & Algeria \\
\hline $\begin{array}{l}\text { Tiwari } \\
\text { et al. } \\
(2016 \mathrm{~b} \\
)[123]\end{array}$ & E-M & Air & $\begin{array}{l}\text { Not } \\
\text { directly } \\
\text { stated }\end{array}$ & No & $\begin{array}{l}\text { Temperature } \\
\text { ranges from } \\
\text { around } 18^{\circ} \mathrm{C} \text { to } \\
63^{\circ} \mathrm{C}(\text { Room } 1, \\
\text { Room } 2)\end{array}$ & PV cell: $15 \%$ & $\begin{array}{l}\text { BIPVT (roof- } \\
\text { integrated) }\end{array}$ & India \\
\hline $\begin{array}{l}\text { Hu et } \\
\text { al. } \\
(2016) \\
{[124]}\end{array}$ & $\mathrm{E}$ & Air & $\begin{array}{l}\text { Amorphou } \\
\text { s silicon }\end{array}$ & No & $\begin{array}{l}\text { Maximum } \\
\text { temperature of } \\
\text { the air inside } \\
\text { the cushion: } \\
67.8^{\circ} \mathrm{C} \\
\text { (summer) }\end{array}$ & $\begin{array}{l}\text { Virtual system } \\
\text { efficiency } \\
\text { (electricity and } \\
\text { thermal } \\
\text { energy): } 25.5 \% \\
\text { (average } \\
\text { experimental } \\
\text { results, } \\
\text { approximate } \\
\text { method) }\end{array}$ & $\begin{array}{l}\text { Ethylene } \\
\text { tetrafluoroethyl } \\
\text { ene cushion } \\
\text { roof-integrated } \\
\text { PVT }\end{array}$ & China \\
\hline $\begin{array}{l}\text { Hasan } \\
\text { et al. } \\
(2017) \\
{[125]}\end{array}$ & E-M & $\begin{array}{l}\text { Nanopartic } \\
\text { les }(\mathrm{SiC} \text {, } \\
\mathrm{TiO}_{2} \text { and } \\
\left.\mathrm{SiO}_{2}\right) \text { with } \\
\text { water }\end{array}$ & Poly-Si & No & $\begin{array}{l}\text { Maximum PVT } \\
\text { plate } \\
\text { temperature: } \\
87^{\circ} \mathrm{C}\end{array}$ & $\begin{array}{l}\text { Electrical and } \\
\text { thermal } \\
\text { efficiencies: } \\
12.75 \% \text { and } \\
85 \% \text {, } \\
\text { respectively } \\
\left(1000 \mathrm{~W} / \mathrm{m}^{2} ;\right. \\
\text { flow rate: } 0.167 \\
\mathrm{~kg} / \mathrm{s}, \text { ambient } \\
\text { temperature: } \\
\left.\text { about } 30^{\circ} \mathrm{C}\right)\end{array}$ & $\begin{array}{l}\text { PVT with } \\
\text { nanofluids }\end{array}$ & Malaysia \\
\hline $\begin{array}{l}\text { Chialas } \\
\text { tri and } \\
\text { Isaacso } \\
\mathrm{n} \\
(2017) \\
{[126]}\end{array}$ & E-M & Air & Silicon & No & $\begin{array}{l}\text { Average output } \\
\text { temperature } \\
\text { (after the } \\
\text { optimisation): } \\
64.7^{\circ} \mathrm{C}\end{array}$ & $\begin{array}{l}\text { Thermal: } 25- \\
40 \% \text {; electrical: } \\
\text { around } 6-8 \%\end{array}$ & $\begin{array}{l}\text { BIPVT } \\
\text { (fenestration) }\end{array}$ & USA \\
\hline $\begin{array}{l}\text { Bigaila } \\
\text { and } \\
\text { Athieni } \\
\text { tis } \\
(2017) \\
{[127]}\end{array}$ & $\mathrm{M}$ & Air & $\begin{array}{l}\text { Silicon- } \\
\text { based }\end{array}$ & No & $\begin{array}{l}\text { Maximum } \\
\text { supply-water } \\
\text { temperature: } \\
100{ }^{\circ} \mathrm{C}\end{array}$ & $\begin{array}{l}\text { PV (standard } \\
\text { test conditions): } \\
15 \%\end{array}$ & $\begin{array}{l}\text { BIPVT (façade- } \\
\text { integrated) with } \\
\text { air-to-water } \\
\text { heat pump and } \\
\text { PCM }\end{array}$ & Canada \\
\hline $\begin{array}{l}\text { Gaur et } \\
\text { al. } \\
(2017) \\
{[128]}\end{array}$ & $\mathrm{M}$ & Water & Mono-Si & No & $\begin{array}{l}\text { Maximum } \\
\text { outlet } \\
\text { temperature: } \\
\text { around } 70^{\circ} \mathrm{C} \\
\text { (PVT without } \\
\text { PCM; summer) }\end{array}$ & $\begin{array}{l}\text { PV efficiency } \\
\text { with PCM: } \\
\text { around 17-19\% } \\
\text { (maximum); } \\
\text { Thermal } \\
\text { efficiencies } \\
\text { without PCM: }\end{array}$ & $\begin{array}{l}\text { PVT with PCM: } \\
\text { Industrial and } \\
\text { domestic } \\
\text { applications }\end{array}$ & France \\
\hline
\end{tabular}




\begin{tabular}{|c|c|c|c|c|c|c|c|c|}
\hline $\begin{array}{l}\text { Bellos } \\
\text { and } \\
\text { Tzivani } \\
\text { dis } \\
(2017) \\
{[129]}\end{array}$ & $\mathrm{M}$ & $\begin{array}{l}\text { Water with } \\
\text { nanoparticl } \\
\text { es }\end{array}$ & $\begin{array}{l}\text { Not } \\
\text { directly } \\
\text { stated }\end{array}$ & No & $\begin{array}{l}\text { Mean storage- } \\
\text { tank } \\
\text { temperature: } \\
\text { around } 64^{\circ} \mathrm{C} \\
\text { (maximum; at } \\
\text { the end of the } \\
\text { day; nanofluid } \\
\text { case) }\end{array}$ & $\begin{array}{l}\text { Mean yearly } \\
\text { efficiencies } \\
\text { (nanofluid): } \\
\text { thermal: } 43.8 \% \text {; } \\
\text { electrical: } \\
12.6 \%\end{array}$ & $\begin{array}{l}\text { Domestic } \\
\text { applications; } \\
\text { PVT with } \\
\text { nanofluid }\end{array}$ & Greece \\
\hline $\begin{array}{l}\text { Herran } \\
\text { do et } \\
\text { al. } \\
(2018) \\
{[130]}\end{array}$ & $\mathrm{M}$ & Water & Poly-Si & No & $\begin{array}{l}\text { Water is } \\
\text { extracted when } \\
\text { the temperature } \\
\text { at the top of the } \\
\text { tank is higher } \\
\text { than } 80^{\circ} \mathrm{C}\end{array}$ & $\begin{array}{l}\text { Thermal: } \\
\text { around } 70-73 \% \\
\text { (maximum); PV } \\
\text { module } \\
\text { (nominal): } \\
14.7 \%\end{array}$ & $\begin{array}{l}\text { Domestic } \\
\text { applications; } \\
\text { PVT with } \\
\text { polymeric } \\
\text { components }\end{array}$ & $\begin{array}{l}\text { Spain; } \\
\text { UK; } \\
\text { Greece }\end{array}$ \\
\hline $\begin{array}{l}\text { Zulak } \\
\text { mal et } \\
\text { al. } \\
(2019) \\
{[131]}\end{array}$ & $\mathrm{M}$ & Air & $\begin{array}{l}\text { Not } \\
\text { directly } \\
\text { stated }\end{array}$ & $\begin{array}{l}\text { Yes } \\
\text { (thermoelectri } \\
\text { c generators) }\end{array}$ & $\begin{array}{l}\mathrm{PV} \text {-panel initial } \\
\text { temperature: } \\
\text { around } 72^{\circ} \mathrm{C}\end{array}$ & $\begin{array}{l}\text { Efficiency } \\
\text { (maximum): } \\
4.6 \% \\
\text { (thermoelectric } \\
\text { generator) }\end{array}$ & $\begin{array}{l}\text { PVT with } \\
\text { thermoelectric } \\
\text { generators }\end{array}$ & $\begin{array}{l}\text { Not directly } \\
\text { stated }\end{array}$ \\
\hline $\begin{array}{l}\text { Xiao et } \\
\text { al. } \\
(2019) \\
{[132]}\end{array}$ & $\mathrm{M}$ & Water & $\begin{array}{l}\text { Not } \\
\text { directly } \\
\text { stated }\end{array}$ & No & $\begin{array}{l}\text { For depth of the } \\
\text { bottom channel } \\
=0.01 \mathrm{~m} \text {, the } \\
\text { maximum } \\
\text { temperature was } \\
\text { found to be } \\
83.5^{\circ} \mathrm{C} \text { at } 13: 30\end{array}$ & $\begin{array}{l}\text { Total thermal } \\
\text { efficiency of the } \\
\text { stepped PVT } \\
\text { solar still with a } \\
\text { bottom channel: } \\
50.6 \% \text {; } \\
\text { Electrical: } \\
\text { around } 10 \% \\
\text { (maximum) }\end{array}$ & $\begin{array}{l}\text { PVT with solar } \\
\text { stills for water } \\
\text { desalination }\end{array}$ & $\begin{array}{l}\text { Not directly } \\
\text { stated }\end{array}$ \\
\hline $\begin{array}{l}\text { Ren et } \\
\text { al. } \\
(2019) \\
{[133]}\end{array}$ & E-M & Water & $\begin{array}{l}\text { Amorphou } \\
\text { s silicon }\end{array}$ & No & $\begin{array}{l}\text { The } \\
\text { performance of } \\
\text { the system was } \\
\text { examined at } 60 \text {, } \\
70 \text { and } 80^{\circ} \mathrm{C} \\
\text { (operating } \\
\text { temperatures) }\end{array}$ & $\begin{array}{l}\text { Efficiencies at } \\
60,70 \text { and } 80^{\circ} \mathrm{C} \\
\text { (daily): thermal } \\
32.3 \%, 24.9 \% \\
\text { and } 17.2 \%, \\
\text { respectively; } \\
\text { Electrical: } \\
5.3 \%, 5.1 \% \text { and } \\
4.9 \%, \\
\text { respectively }\end{array}$ & Buildings & China \\
\hline $\begin{array}{l}\text { Nazri } \\
\text { et al. } \\
(2019) \\
{[134]}\end{array}$ & E-M & Air & Mono-Si & Yes & $\begin{array}{l}\text { Maximum } \\
\text { outlet-air } \\
\text { temperature: } \\
64.4^{\circ} \mathrm{C} \text { (mass } \\
\text { flow rate: } 0.001 \\
\mathrm{~kg} / \mathrm{s} \text { ) }\end{array}$ & $\begin{array}{l}\text { Optimum } \\
\text { exergy } \\
\text { efficiency of the } \\
\text { PVT/thermoelec } \\
\text { tric: around } \\
38 \%\end{array}$ & $\begin{array}{l}\text { Domestic and } \\
\text { industrial } \\
\text { applications }\end{array}$ & Malaysia \\
\hline $\begin{array}{l}\text { Bouma } \\
\text { araf et } \\
\text { al. } \\
(2020) \\
{[135]}\end{array}$ & E-M & Water & Poly-Si & No & $\begin{array}{l}\text { Maximum fluid } \\
\text { temperature: } \\
\text { around } \\
68-78^{\circ} \mathrm{C} \text {, } \\
\text { depending on } \\
\text { the } \\
\text { configuration }\end{array}$ & $\begin{array}{l}\text { For the water } \\
\text { glazed PVT } \\
\text { collector: } \\
\text { electrical } 6.3 \% \text {, } \\
\text { thermal } 57.7 \%\end{array}$ & $\begin{array}{l}\text { Domestic and } \\
\text { industrial } \\
\text { applications }\end{array}$ & Algeria \\
\hline
\end{tabular}

In terms of CPVT, Haiping et al. [136] developed and tested a flash tank integrated with a low-concentrating PVT system with CPCs (geometric CR: 4X; Figure 4), demonstrating the feasibility of this system for cogeneration of fresh water and electricity. The PVT panel is based on mono-Si PV cells, produces electricity and preheats saline 
water. A solar thermal collector is connected with the PVT module in order to enhance the heating of the saline water. The experimental findings revealed a vaporisation coefficient of $5 \%$ and an average electrical efficiency of $13.3 \%$.

a)

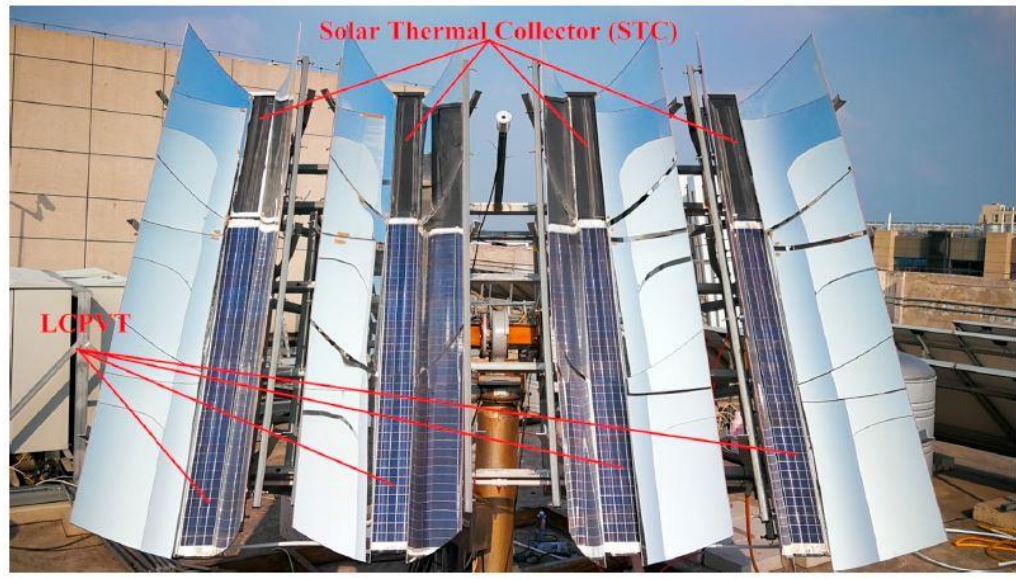

b)

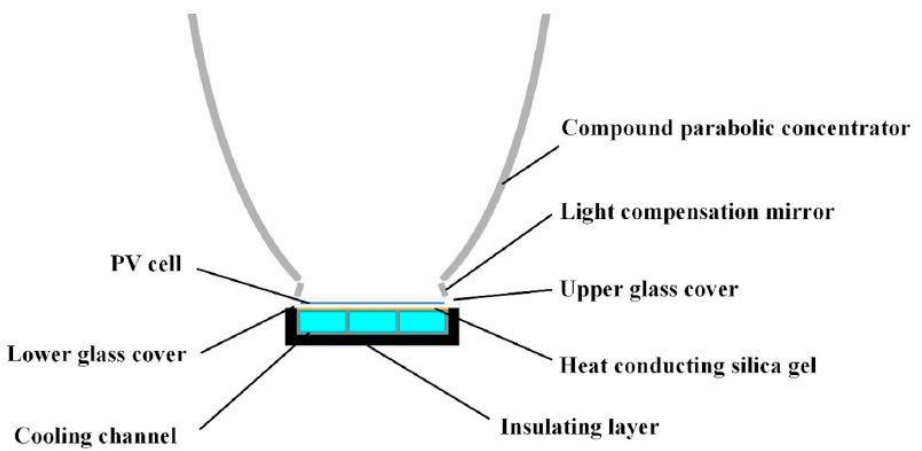

Figure 4. The medium-temperature CPVT studied by Haiping et al: a) The LowConcentrating Photovoltaic/Thermal - Solar Thermal Collector (LCPVT-STC) experimental set-up, b) details about the CPVT module. Source: Haiping et al. [136].

In Table 6, references about PVT systems involving solar concentration and using working fluids at medium temperatures are presented. The results suggest that:

- The majority of the references are about modelling and experimental/modelling investigations on PVT/water systems without thermoelectric elements. 
- In most cases, the CRs are up to $190 \mathrm{X}$ and the working-fluid temperatures are around $62-90{ }^{\circ} \mathrm{C}$.

- In most of the investigations, mono-Si and multi-/triple-junction PV cells were used.

- The majority of thermal efficiencies are approximately 50-68\%. In most cases, PV efficiencies are around 10-19\% and 35-38\%, depending on the PV cells (single-junction vs. multi-junction, etc.).

- A large number of investigations are about domestic applications and desalination whereas there are a few studies on greenhouses.

- The systems were examined for different climatic conditions.

Table 6. PVT systems involving solar concentration: working fluids at medium temperatures.

\begin{tabular}{|c|c|c|c|c|c|c|c|c|c|}
\hline $\begin{array}{l}\text { Study / } \\
\text { year }\end{array}$ & $\begin{array}{l}\text { Type } \\
\text { of } \\
\text { study }\end{array}$ & $\begin{array}{l}\text { Working } \\
\text { fluid }\end{array}$ & $\begin{array}{l}\text { Concentration } \\
\text { ratio }(\mathbf{C R})\end{array}$ & $\begin{array}{l}\text { Type of } \\
\text { PV cells }\end{array}$ & $\begin{array}{l}\text { Thermoelect } \\
\text { ric element }\end{array}$ & $\begin{array}{l}\text { Temperature } \\
\text { of the working } \\
\text { fluid: Medium }\end{array}$ & Efficiencies & $\begin{array}{l}\text { Type of } \\
\text { application: } \\
\text { - Buildings } \\
\text { - Etc. }\end{array}$ & $\begin{array}{l}\text { Location } \\
\text { of the } \\
\text { study }\end{array}$ \\
\hline $\begin{array}{l}\text { Sun } \\
\text { and Shi } \\
(2009) \\
{[137]}\end{array}$ & $\mathrm{M}$ & Air & $2 \mathrm{X}$ & $\begin{array}{l}\text { Not } \\
\text { directly } \\
\text { stated }\end{array}$ & No & $\begin{array}{l}\text { Temperature of } \\
\text { the PVT } \\
\text { system: around } \\
92^{\circ} \mathrm{C} \\
\text { (maximum) }\end{array}$ & $\begin{array}{l}\text { Combined } \\
\text { efficiency } \\
\text { (system with } \\
\text { CPC): around } \\
75 \% \\
\text { (maximum) }\end{array}$ & PVT with CPCs & $\begin{array}{l}\text { Not directly } \\
\text { stated }\end{array}$ \\
\hline $\begin{array}{l}\text { Cui et } \\
\text { al. } \\
(2010) \\
{[138]}\end{array}$ & $\mathrm{E}$ & Water & $\begin{array}{l}\text { Theoretical } \\
\text { maximum CR: } \\
5.1 \mathrm{X}\end{array}$ & Mono-Si & No & $\begin{array}{l}\text { PV cell: } 87.7^{\circ} \mathrm{C} \\
\left(907 \mathrm{~W} / \mathrm{m}^{2}\right)\end{array}$ & $\begin{array}{l}\text { PV cell: } 5.7 \% \\
\left(907 \mathrm{~W} / \mathrm{m}^{2}\right) ; \\
\text { total efficiency } \\
\text { of the CPVT } \\
\text { system: higher } \\
\text { than } 70 \%\end{array}$ & PVT with CPCs & China \\
\hline $\begin{array}{l}\text { Bernar } \\
\text { do et } \\
\text { al. } \\
(2011) \\
{[139]}\end{array}$ & E-M & Water & $\begin{array}{l}\text { Geometric CR: } \\
7.8 \mathrm{X}\end{array}$ & Mono-Si & No & $\begin{array}{l}\text { Water outlet } \\
\text { temperature: } \\
\text { around } 77^{\circ} \mathrm{C} \\
\text { (maximum) }\end{array}$ & $\begin{array}{l}\text { Measured } \\
\text { electrical: } 6.4 \% \\
\text { at } 25^{\circ} \mathrm{C} \text { water } \\
\text { outlet } \\
\text { temperature }\end{array}$ & $\begin{array}{l}\text { Domestic hot } \\
\text { water } \\
\text { production; } \\
\text { pool heating }\end{array}$ & $\begin{array}{l}\text { Sweden; } \\
\text { Portugal; } \\
\text { Zambia }\end{array}$ \\
\hline $\begin{array}{l}\text { Kerzm } \\
\text { ann } \\
\text { and } \\
\text { Schaef } \\
\text { er } \\
(2012) \\
{[140]}\end{array}$ & M & Water & $80 X$ & $\begin{array}{l}\text { Multi- } \\
\text { junction }\end{array}$ & No & $\begin{array}{l}\text { Bulk fluid } \\
\text { temperature: } \\
\text { around } 62^{\circ} \mathrm{C} \\
\text { (maximum; } \\
\text { July) }\end{array}$ & $\begin{array}{l}\text { Multi-junction } \\
\text { cell (average): } \\
34.7 \%\end{array}$ & $\begin{array}{l}\text { PVT with } \\
\text { Fresnel lenses }\end{array}$ & USA \\
\hline $\begin{array}{l}\text { Ong et } \\
\text { al. } \\
(2012) \\
{[141]}\end{array}$ & E-M & Water & CR up to $5000 \mathrm{X}$ & $\begin{array}{l}\text { Low- } \\
\text { thermal } \\
\text { resistance } \\
\text { multi PV } \\
\text { chip } \\
\text { receiver } \\
\text { package }\end{array}$ & No & $\begin{array}{l}\text { Deionised } \\
\text { water, pre- } \\
\text { heated to } \\
\text { around } 80{ }^{\circ} \mathrm{C} \text { : } \\
\text { evaporator }\end{array}$ & $\begin{array}{l}\text { Optical: around } \\
85 \%\end{array}$ & Desalination & $\begin{array}{l}\text { Switzerland } \\
\text {; Egypt }\end{array}$ \\
\hline
\end{tabular}




\begin{tabular}{|c|c|c|c|c|c|c|c|c|c|}
\hline $\begin{array}{l}\text { Jiang } \\
\text { et al. } \\
(2012) \\
{[142]}\end{array}$ & M & Water & CRs: $1.1 \mathrm{X}, 2 \mathrm{X}$ & Thin film & No & $\begin{array}{l}\text { Working-fluid } \\
\text { temperature: } \\
\text { around } 85^{\circ} \mathrm{C} \\
\text { (maximum) }\end{array}$ & $\begin{array}{l}\text { Optical: } 94 \% \\
\text { (average) }\end{array}$ & $\begin{array}{l}\text { PVT with } \\
\text { natural } \\
\text { convection; } \\
\text { PVT with CPCs }\end{array}$ & USA \\
\hline $\begin{array}{l}\text { Calise } \\
\text { et al. } \\
(2012) \\
{[143]}\end{array}$ & M & Water & $\begin{array}{l}\text { Future prospect: } \\
\text { combination of } \\
\text { solar } \\
\text { heating/cooling } \\
\text { with CPVT }\end{array}$ & $\begin{array}{l}\text { Crystalline } \\
\text { silicon } \\
\text { (future } \\
\text { prospect: } \\
\text { III-V PV } \\
\text { cells) }\end{array}$ & No & $\begin{array}{l}\text { PVT modules } \\
\text { operate up to } \\
80^{\circ} \mathrm{C}\end{array}$ & $\begin{array}{l}\text { PVT average } \\
\text { electrical: } \\
\text { slightly lower } \\
\text { than } 10 \%\end{array}$ & $\begin{array}{l}\text { Trigeneration } \\
\text { PVT system; } \\
\text { Domestic } \\
\text { applications }\end{array}$ & Italy \\
\hline $\begin{array}{l}\text { Petrucc } \\
\text { i et a. } \\
(2013) \\
{[144]}\end{array}$ & M & Water & $\begin{array}{l}\text { Not directly } \\
\text { stated }\end{array}$ & $\begin{array}{l}\text { Not } \\
\text { directly } \\
\text { stated }\end{array}$ & No & $\begin{array}{l}\text { Coolant exit } \\
\text { temperature: } \\
90^{\circ} \mathrm{C}\end{array}$ & $\begin{array}{l}\text { Electrical: } 18 \% \text {; } \\
\text { Thermal: } 62 \%\end{array}$ & Buildings & Portugal \\
\hline $\begin{array}{l}\text { Xu and } \\
\text { Kleinst } \\
\text { reuer } \\
(2014) \\
{[145]}\end{array}$ & M & $\begin{array}{l}\text { Water- } \\
\text { based } \\
\text { nanofluids }\end{array}$ & $100 \mathrm{X}$ & $\begin{array}{l}\text { Silicon- } \\
\text { based; } \\
\text { Triple- } \\
\text { junction }\end{array}$ & No & $\begin{array}{l}\text { Nanofluid outlet } \\
\text { temperature: set } \\
\text { at } 62{ }^{\circ} \mathrm{C}\end{array}$ & $\begin{array}{l}\text { For nanofluid } \\
\text { outlet } \\
\text { temperature } \\
62^{\circ} \mathrm{C} \text { : electrical } \\
11 \% \text {, thermal } \\
59 \%\end{array}$ & Domestic & USA \\
\hline $\begin{array}{l}\text { Jaffré } \\
\text { et al. } \\
(2014) \\
{[146]}\end{array}$ & $\mathrm{E}$ & Water & $\begin{array}{l}20 X \\
\text { (approximately) }\end{array}$ & Mono-Si & No & $\begin{array}{l}\text { Mean } \\
\text { temperature: } \\
\text { around } 62^{\circ} \mathrm{C} \\
\text { (maximum) }\end{array}$ & $\begin{array}{l}\begin{array}{l}\text { Lens optical } \\
\text { (measured): }\end{array} \\
77 \% \text {; PV cell: } \\
11 \%(\text { measured, } \\
\left.\text { at } 50^{\circ} \mathrm{C}\right) ; \\
\text { Thermal: } 50 \% \\
\text { (measured, at } \\
50^{\circ} \mathrm{C} \text { ) }\end{array}$ & $\begin{array}{l}\text { Domestic water } \\
\text { heating; PVT } \\
\text { with Fresnel } \\
\text { lenses }\end{array}$ & France \\
\hline $\begin{array}{l}\text { Tan et } \\
\text { al. } \\
(2014) \\
{[147]}\end{array}$ & $\mathrm{E}$ & Water & $\begin{array}{l}\text { Not directly } \\
\text { stated }\end{array}$ & $\begin{array}{l}\text { Crystalline } \\
\text { silicon }\end{array}$ & No & $\begin{array}{l}\text { In a specific } \\
\text { case: } 62.8^{\circ} \mathrm{C} \\
\text { working-fluid } \\
\text { temperature in } \\
\text { the tank }\end{array}$ & $\begin{array}{l}\text { PV cell } \\
\text { (maximum): } \\
5.21 \% \text { (with } \\
\text { concentration); } \\
\text { Mirror optical: } \\
70 \% \text {; } \\
\text { Maximum } \\
\text { instantaneous } \\
\text { thermal (metal } \\
\text { cavity heating): } \\
68.2 \%\end{array}$ & $\begin{array}{l}\text { PVT with } \\
\text { parabolic- } \\
\text { trough mirrors }\end{array}$ & China \\
\hline $\begin{array}{l}\text { Garcia- } \\
\text { Heller } \\
\text { et al. } \\
(2014) \\
{[148]}\end{array}$ & M & Water & $2000 X$ & $\begin{array}{l}\text { Triple- } \\
\text { junction }\end{array}$ & No & $\begin{array}{l}90^{\circ} \mathrm{C} \text { hot water } \\
\text { outflow }\end{array}$ & $\begin{array}{l}\text { The system } \\
\text { converts } 25 \% \text { of } \\
\text { the direct } \\
\text { normal } \\
\text { irradiance into } \\
\text { electrical } \\
\text { energy and } \\
62.5 \% \text { to low- } \\
\text { grade heat; } \\
\text { Combined } \\
\text { efficiency: } \\
87.5 \%\end{array}$ & $\begin{array}{l}\text { Indoor space } \\
\text { heating and } \\
\text { cooling; } \\
\text { Desalination }\end{array}$ & Algeria \\
\hline $\begin{array}{l}\text { Hughes } \\
\text { et al. } \\
\text { (2014) } \\
{[149]}\end{array}$ & E-M & Water & Around 500X & $\begin{array}{l}\text { III-V } \\
\text { multi- } \\
\text { junction }\end{array}$ & No & $\begin{array}{l}\text { Final } \\
\text { temperature of } \\
\text { the cooling } \\
\text { fluid: around } \\
81^{\circ} \mathrm{C} \\
\text { (maximum; } \\
\text { June) }\end{array}$ & $\begin{array}{l}\text { Evacuated-tube } \\
\text { collectors: } 65 \% \text {; } \\
\text { PV cells: } 36 \%\end{array}$ & $\begin{array}{l}\text { Desalination } \\
\text { with CPVT with } \\
\text { parabolic dish } \\
\text { and evacuated- } \\
\text { tube collectors }\end{array}$ & UK \\
\hline $\begin{array}{l}\text { Kiflem } \\
\text { ariam } \\
\text { et al. } \\
(2014) \\
{[150]}\end{array}$ & $\mathrm{M}$ & Air & $\begin{array}{l}\text { One of the cases: } \\
\text { CRs 2-5X }\end{array}$ & $\begin{array}{l}\text { Not } \\
\text { directly } \\
\text { stated }\end{array}$ & $\begin{array}{l}\text { Yes } \\
\text { (thermoelectri } \\
\text { c generator) }\end{array}$ & $\begin{array}{l}\text { Temperature } \\
\text { distribution for } \\
\mathrm{CR}=3 \mathrm{X} \text { and } \\
\text { wind velocity } 1 \text { - } \\
3 \mathrm{~m} / \mathrm{s}: 40-82^{\circ} \mathrm{C} \\
\text { (approximately) }\end{array}$ & $\begin{array}{l}\text { Not directly } \\
\text { stated }\end{array}$ & $\begin{array}{l}\text { PVT with } \\
\text { thermoelectric } \\
\text { generators }\end{array}$ & $\begin{array}{l}\text { Not directly } \\
\text { stated }\end{array}$ \\
\hline
\end{tabular}




\begin{tabular}{|c|c|c|c|c|c|c|c|c|c|}
\hline $\begin{array}{l}\text { Renno } \\
\text { and De } \\
\text { Giaco } \\
\text { mo } \\
(2014) \\
{[151]}\end{array}$ & $\mathrm{M}$ & Water & $500 X, 1000 X$ & $\begin{array}{l}\text { Triple- } \\
\text { junction } \\
\text { InGaP/InG } \\
\mathrm{aAs} / \mathrm{Ge}\end{array}$ & No & $\begin{array}{l}\text { One of the } \\
\text { cases: } 75.4^{\circ} \mathrm{C} \\
\text { fluid outlet } \\
\text { temperature } \\
\text { (average) }\end{array}$ & $\begin{array}{l}\text { PV cell: } 39.15 \% \\
\text { (maximum) }\end{array}$ & Domestic & Italy \\
\hline
\end{tabular}

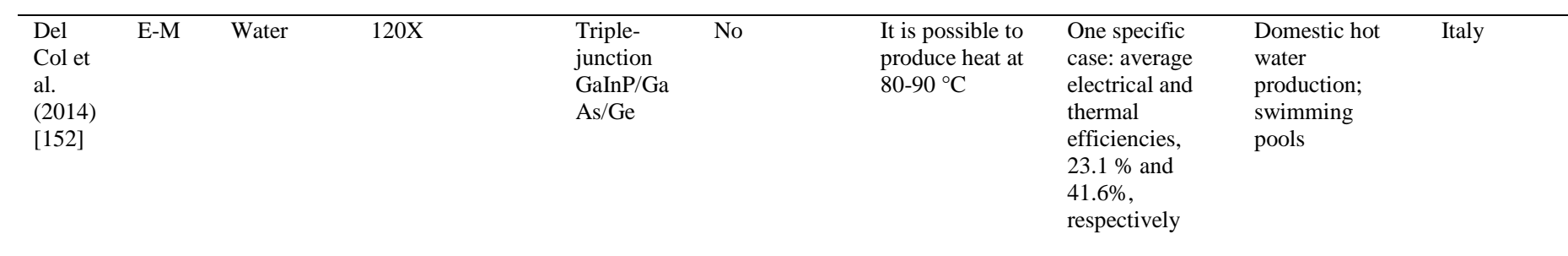

\begin{tabular}{|c|c|c|c|c|c|c|c|c|c|}
\hline $\begin{array}{l}\text { Atheay } \\
\text { a et al. } \\
(2015) \\
{[153]}\end{array}$ & M & Water & $\begin{array}{l}\text { Not directly } \\
\text { stated }\end{array}$ & $\begin{array}{l}\text { Not } \\
\text { directly } \\
\text { stated }\end{array}$ & No & $\begin{array}{l}\text { Working-fluid } \\
\text { output } \\
\text { temperature: } \\
\text { around } 88^{\circ} \mathrm{C} \\
\text { (maximum; for } \\
\text { mass flow rate } \\
0.002 \mathrm{~kg} / \mathrm{s} \text { ) }\end{array}$ & $\begin{array}{l}\text { Electrical: } \\
\text { around } 12.5 \% \\
\text { (maximum); } \\
\text { Thermal: } \\
\text { around } 42 \% \\
\text { (maximum; } \\
\text { case: partially } \\
\text { covered PVT- } \\
\text { CPC water } \\
\text { collector) }\end{array}$ & PVT with CPCs & India \\
\hline $\begin{array}{l}\text { Imtiaz } \\
\text { Hussai } \\
\mathrm{n} \text { and } \\
\text { Lee } \\
(2015) \\
{[154]}\end{array}$ & E-M & Water & $\begin{array}{l}\text { Not directly } \\
\text { stated }\end{array}$ & $\begin{array}{l}\text { Triple- } \\
\text { junction }\end{array}$ & No & $\begin{array}{l}\text { For } 0.5 \mathrm{~L} / \mathrm{min} \text {, } \\
30^{\circ} \mathrm{C} \text { ambient } \\
\text { temperature, } \\
900 \mathrm{~W} / \mathrm{m}^{2} \text { : } \\
\text { predicted } \\
\text { temperature } \\
75^{\circ} \mathrm{C}\end{array}$ & $\begin{array}{l}\text { Efficiency of } \\
\text { the U-shaped } \\
\text { collector: } \\
76 \% \\
\text { (maximum) at } \\
\text { zero } \\
\text { temperature } \\
\text { difference } \\
\text { between the } \\
\text { ambient and } \\
\text { working fluid }\end{array}$ & $\begin{array}{l}\text { PVT with } \\
\text { Fresnel lenses }\end{array}$ & Korea \\
\hline $\begin{array}{l}\text { Ghola } \\
\text { mi et } \\
\text { al. } \\
(2015) \\
{[155]}\end{array}$ & $\mathrm{M}$ & Water & $0-1000 X$ & $\begin{array}{l}\text { Triple- } \\
\text { junction }\end{array}$ & No & $\begin{array}{l}\text { One specific } \\
\text { case: maximum } \\
\text { fluid } \\
\text { temperature } \\
\text { around } 87^{\circ} \mathrm{C}\end{array}$ & $\begin{array}{l}\text { Electrical: } 38 \% \\
\text { (maximum; } \\
\text { under working } \\
\text { conditions); } \\
\text { thermal: } 48 \% \\
\text { (maximum; } \\
\text { under working } \\
\text { conditions) }\end{array}$ & $\begin{array}{l}\text { Domestic } \\
\text { applications; } \\
\text { CPVT with dish } \\
\text { concentrators }\end{array}$ & Iran \\
\hline
\end{tabular}

\begin{tabular}{|c|c|c|c|c|c|c|c|c|c|}
\hline $\begin{array}{l}\text { Li et } \\
\text { al. } \\
\text { (2015b } \\
)[156]\end{array}$ & E-M & Water & $\begin{array}{l}\text { Geometric CR: } \\
2.4 \mathrm{X}\end{array}$ & $\begin{array}{l}\text { Not } \\
\text { directly } \\
\text { stated }\end{array}$ & No & $\begin{array}{l}\text { Final water } \\
\text { temperature: } \\
70^{\circ} \mathrm{C}\end{array}$ & $\begin{array}{l}\text { Electrical and } \\
\text { thermal } \\
\text { efficiencies of } \\
\text { the system } \\
\text { during the test: } \\
6 \% \text { and } 35 \% \text {, } \\
\text { respectively (for } \\
\text { final water } \\
\text { temperature: } \\
70{ }^{\circ} \mathrm{C} \text { ) }\end{array}$ & $\begin{array}{l}\text { BIPVT with air- } \\
\text { gap-lens-walled } \\
\text { CPC }\end{array}$ & China \\
\hline $\begin{array}{l}\text { Wiesen } \\
\text { farth et } \\
\text { al. } \\
(2016) \\
{[157]}\end{array}$ & E-M & Water & $5000 X$ & $\begin{array}{l}\text { Multi- } \\
\text { junction }\end{array}$ & No & $\begin{array}{l}\text { Outlet } \\
\text { temperature } \\
\text { (receiver): fixed } \\
\text { at } 90{ }^{\circ} \mathrm{C}\end{array}$ & $\begin{array}{l}\text { Theoretical } \\
\text { maximum: } \\
79.2 \% \text { (for the } \\
\text { system) }\end{array}$ & $\begin{array}{l}\text { Desalination } \\
\text { with CPVT with } \\
\text { mirror dish }\end{array}$ & Germany \\
\hline $\begin{array}{l}\text { Imtiaz } \\
\text { Hussai } \\
\text { n et al. } \\
(2016) \\
{[158]}\end{array}$ & E-M & $\begin{array}{l}\text { A mixture } \\
\text { of } \\
\text { antifreeze } \\
\text { liquid and } \\
\text { water }\end{array}$ & $\begin{array}{l}\text { Not directly } \\
\text { stated }\end{array}$ & $\begin{array}{l}\text { Multi- } \\
\text { junction }\end{array}$ & No & $\begin{array}{l}\text { Temperature of } \\
\text { the fluid in the } \\
\text { pipe (with } \\
\text { enclosure): } \\
62.3^{\circ} \mathrm{C}\end{array}$ & $\begin{array}{l}\text { Global } \\
\text { efficiencies } \\
\text { (CPVT system; } \\
\text { average; steady } \\
\text { state): } 76 \% \text { with } \\
\text { enclosure, } 70 \% \\
\text { without } \\
\text { enclosure }\end{array}$ & $\begin{array}{l}\text { Greenhouses; } \\
\text { PVT with } \\
\text { Fresnel lenses }\end{array}$ & Korea \\
\hline
\end{tabular}




\begin{tabular}{|c|c|c|c|c|c|c|c|c|c|}
\hline $\begin{array}{l}\text { Ziapou } \\
\text { r et al. } \\
(2016) \\
{[159]}\end{array}$ & $\mathrm{M}$ & Water & $\begin{array}{l}\text { Not directly } \\
\text { stated }\end{array}$ & $\begin{array}{l}\text { Not } \\
\text { directly } \\
\text { stated }\end{array}$ & No & $\begin{array}{l}\text { Water storage- } \\
\text { tank } \\
\text { temperature: } \\
\text { around } 70^{\circ} \mathrm{C} \\
\text { (maximum) in } \\
\text { the case with } \\
\text { reflectors }\end{array}$ & $\begin{array}{l}\text { Solar cell: } \\
\text { around 13\% } \\
\text { (maximum } \\
\text { value in certain } \\
\text { cases) }\end{array}$ & $\begin{array}{l}\text { Domestic } \\
\text { applications; } \\
\text { PVT with } \\
\text { mirrors or } \\
\text { aluminium } \\
\text { reflectors }\end{array}$ & $\begin{array}{l}\text { Not directly } \\
\text { stated }\end{array}$ \\
\hline $\begin{array}{l}\text { Al } \\
\text { Imam } \\
\text { et al. } \\
(2016) \\
{[160]}\end{array}$ & E-M & Water & $\begin{array}{l}\text { Maximum CR: } \\
1.82 \mathrm{X}\end{array}$ & $\begin{array}{l}\text { Not } \\
\text { directly } \\
\text { stated }\end{array}$ & No & $\begin{array}{l}\text { Average plate } \\
\text { temperature: } \\
\text { around } 87{ }^{\circ} \mathrm{C} \\
\text { (clear days) }\end{array}$ & $\begin{array}{l}\text { Thermal: } \\
\text { around 50\% } \\
\text { (maximum); } \\
\text { Total: around } \\
63 \% \\
\text { (maximum) }\end{array}$ & $\begin{array}{l}\text { PVT with CPC } \\
\text { and PCM }\end{array}$ & Bangladesh \\
\hline $\begin{array}{l}\text { Mohse } \\
\text { nzadeh } \\
\text { et al. } \\
(2017) \\
{[161]}\end{array}$ & E-M & Water & $\begin{array}{l}\text { Geometric CR: } \\
8.34 \mathrm{X}\end{array}$ & Mono-Si & Yes & $\begin{array}{l}\text { Daily average } \\
\text { temperature of } \\
\text { the PV cells for } \\
\text { the mode } \\
\text { CPVT/thermoel } \\
\text { ectric with } \\
\text { cover (hybrid } \\
\text { system): } 93.8^{\circ} \mathrm{C}\end{array}$ & $\begin{array}{l}\text { CPVT/thermoel } \\
\text { ectric with } \\
\text { cover (hybrid } \\
\text { system): } \\
\text { thermal } 46.2 \% \text {, } \\
\text { electrical } \\
\text { (total): } 4.8 \%\end{array}$ & $\begin{array}{l}\text { PVT } \\
\text { applications } \\
\text { with parabolic- } \\
\text { trough } \\
\text { concentrators } \\
\text { and triangular } \\
\text { cooling ducts }\end{array}$ & Iran \\
\hline $\begin{array}{l}\text { Calise } \\
\text { et al. } \\
(2017) \\
{[162]}\end{array}$ & M & Water & $10 \mathrm{X}$ & $\begin{array}{l}\text { Triple- } \\
\text { junction } \\
\text { InGaP/InG } \\
\text { aAs/Ge }\end{array}$ & No & $\begin{array}{l}\text { CPVT set-point } \\
\text { temperatures: } \\
50^{\circ} \mathrm{C} \text { (winter), } \\
90^{\circ} \mathrm{C} \text { (summer) }\end{array}$ & $\begin{array}{l}\text { Thermal } \\
\text { (CPVT): } 63.4 \% \text {; } \\
\text { electrical } \\
\text { (CPVT): } 18.9 \%\end{array}$ & $\begin{array}{l}\text { Polygeneration } \\
\text { system: CPVT, } \\
\text { chiller, fuel } \\
\text { cells, etc. }\end{array}$ & Italy \\
\hline $\begin{array}{l}\text { Elsafi } \\
(2017) \\
{[163]}\end{array}$ & $\mathrm{M}$ & Air & $2 X$ & $\begin{array}{l}\text { Not } \\
\text { directly } \\
\text { stated }\end{array}$ & No & $\begin{array}{l}\text { Maximum air } \\
\text { temperature } \\
\text { (humidification- } \\
\text { dehumidificatio } \\
\text { n- } \\
\text { humidification/ } \\
\text { CPVT): around } \\
64{ }^{\circ} \mathrm{C} \text { (summer) }\end{array}$ & $\begin{array}{l}\text { Not directly } \\
\text { stated }\end{array}$ & $\begin{array}{l}\text { Desalination } \\
\text { based on PVT } \\
\text { with CPCs }\end{array}$ & $\begin{array}{l}\text { Saudi } \\
\text { Arabia }\end{array}$ \\
\hline $\begin{array}{l}\text { Akrami } \\
\text { et al. } \\
(2018) \\
{[164]}\end{array}$ & $\mathrm{M}$ & Water & $10 \mathrm{X}$ & $\begin{array}{l}\text { Not } \\
\text { directly } \\
\text { stated }\end{array}$ & No & $\begin{array}{l}\text { PV-cell } \\
\text { temperature: } \\
\text { around } 100{ }^{\circ} \mathrm{C}\end{array}$ & $\begin{array}{l}\text { Whole system: } \\
\text { overall exergy } \\
\text { efficiency } \\
11.3 \% \text {; CPVT } \\
\text { exergy } \\
\text { efficiency: less } \\
\text { than } 30 \%\end{array}$ & $\begin{array}{l}\text { Domestic } \\
\text { applications; } \\
\text { PVT with } \\
\text { reflectors, } \\
\text { chiller and } \\
\text { proton } \\
\text { exchange } \\
\text { membrane } \\
\text { electrolyser }\end{array}$ & $\begin{array}{l}\text { Not directly } \\
\text { stated }\end{array}$ \\
\hline $\begin{array}{l}\text { Guo et } \\
\text { al. } \\
(2018) \\
{[165]}\end{array}$ & $\mathrm{E}$ & Water & $\begin{array}{l}\text { Not directly } \\
\text { stated }\end{array}$ & $\begin{array}{l}\text { Not } \\
\text { directly } \\
\text { stated }\end{array}$ & No & $\begin{array}{l}\text { Maximum } \\
\text { temperature of } \\
\text { the inlet saline } \\
\text { water (vacuum } \\
\text { still): around } \\
70^{\circ} \mathrm{C}\end{array}$ & $\begin{array}{l}\text { Electrical: } \\
12.5 \% \\
\text { (maximum) }\end{array}$ & Desalination & China \\
\hline $\begin{array}{l}\text { Shadm } \\
\text { ehri et } \\
\text { al. } \\
(2018) \\
{[166]}\end{array}$ & $\mathrm{M}$ & Water & $\begin{array}{l}\text { Local } \\
\text { concentration } \\
\text { factor: 0-190 }\end{array}$ & Mono-Si & Yes & Medium & $\begin{array}{l}\text { PV cell: } \\
15.75 \% ; \\
\text { Thermal: } \\
\text { around } 47 \% \\
\text { (maximum; } \\
\text { numerical } \\
\text { simulation with } \\
\text { cover) }\end{array}$ & $\begin{array}{l}\text { Buildings, } \\
\text { industry; PVT } \\
\text { with triangular } \\
\text { cooling duct } \\
\text { and parabolic } \\
\text { reflector }\end{array}$ & $\begin{array}{l}\text { Not directly } \\
\text { stated }\end{array}$ \\
\hline $\begin{array}{l}\text { Kandil } \\
\text { et al. } \\
(2019) \\
{[167]}\end{array}$ & M & Water & Up to $1500 \mathrm{X}$ & $\begin{array}{l}\text { Triple- } \\
\text { junction } \\
\text { InGaP/InG } \\
\text { aAs/Ge }\end{array}$ & No & $\begin{array}{l}\text { For CRs higher } \\
\text { than } 400 \mathrm{X}, \\
\text { cooling-water } \\
\text { temperatures } \\
\text { higher than } \\
75^{\circ} \mathrm{C}\end{array}$ & $\begin{array}{l}\text { For CRs higher } \\
\text { than } 400 \mathrm{X} \text {, } \\
\text { thermal } \\
\text { efficiency } \\
\text { higher than } \\
65 \% \text {; electrical: } \\
34-42 \% \\
\text { (approximately) } \\
\text {, depending on } \\
\text { the CR (cell }\end{array}$ & $\begin{array}{l}\text { PVT with } \\
\text { Fresnel lenses } \\
\text { for hot climates }\end{array}$ & Kuwait \\
\hline
\end{tabular}




\begin{tabular}{|c|c|c|c|c|c|c|c|c|c|}
\hline & & & & & & & $\begin{array}{l}\text { temperatures: } \\
25 \text { and } 80^{\circ} \mathrm{C} \text { ) }\end{array}$ & & \\
\hline $\begin{array}{l}\text { Gomaa } \\
\text { et al. } \\
(2019) \\
{[168]}\end{array}$ & $\mathrm{E}$ & Water & $6 X, 10 X$ & Mono-Si & No & $\begin{array}{l}\text { Hot water } \\
\text { temperature at } \\
\text { the receiver exit } \\
\text { (maximum): } \\
74{ }^{\circ} \mathrm{C}(0.025 \\
\mathrm{L} / \mathrm{min} \text { flow rate, } \\
\text { ambient } \\
\text { temperature: } \\
37.6^{\circ} \mathrm{C} \text { ) }\end{array}$ & $\begin{array}{l}\text { Thermal } 61.3 \% \\
(0.025 \mathrm{~L} / \mathrm{min} \\
\text { flow rate, outlet } \\
\text { maximum } \\
\text { temperature } 57 \\
\left.{ }^{\circ} \mathrm{C}\right) \text {; for } \\
\text { geometric CR } \\
6 \mathrm{X} \text { and } 460 \\
\mathrm{~W} / \mathrm{m}^{2} \text {, electrical } \\
\text { efficiency } 11 \%\end{array}$ & $\begin{array}{l}\text { Domestic and } \\
\text { industrial } \\
\text { applications; } \\
\text { PVT with linear } \\
\text { Fresnel mirrors }\end{array}$ & Jordan \\
\hline $\begin{array}{l}\text { Haipin } \\
\text { g et al. } \\
(2019) \\
{[136]}\end{array}$ & $\mathrm{E}$ & Water & $\begin{array}{l}\text { Geometric CR: } \\
4 \mathrm{X}\end{array}$ & Mono-Si & No & $\begin{array}{l}\text { Flash-tank } \\
\text { design: } 90^{\circ} \mathrm{C} \\
\text { by regulating } \\
\text { the flow rate }\end{array}$ & $\begin{array}{l}\text { Electrical: about } \\
13.3 \% \text { (average) }\end{array}$ & $\begin{array}{l}\text { Desalination by } \\
\text { means of PVT } \\
\text { with CPCs }\end{array}$ & China \\
\hline
\end{tabular}

\subsection{PVT SYSTEMS FOR HIGH-TEMPERATURE APPLICATIONS}

In the field of PVT systems with the working fluids at high temperatures (higher than $90{ }^{\circ} \mathrm{C}$ ), one challenge is to cope with the reduction in PV-cell efficiency at high temperatures. Crisostomo et al. [169] noted that spectral beam splitting is a solution that allows PV cells to work at low temperatures whereas thermal receiver operates at high temperatures. However, in this case, the fraction of solar irradiation that without beam splitting would be converted into heat by the PV cell is lost. $\mathrm{SiN}_{\mathrm{x}} / \mathrm{SiO}_{2}$ multilayer thinfilm filters were used as beam splitting devices in a linear Fresnel mirror-based CPVT system with CR 10X. Indoor testing was conducted (involving filters, silicon-based PV cells, thermal sensor and solid-state plasma light source). The experiments revealed that the PV cells, illuminated by the light reflected by the filters, show $9.2 \%$ (absolute) higher efficiency in comparison to the same PV cells without the filters [169]. Widyolar et al. [170] investigated a spectrum splitting hybrid concentrating solar power/CPV collector (design, simulations, testing; geometric CR: 50X; Figure 5). Double-junction InGaP/GaAs solar cells were used. Experiments using a fluid with suspended solid (alumina based) particles heated up to $600{ }^{\circ} \mathrm{C}$ were conducted.

a) 


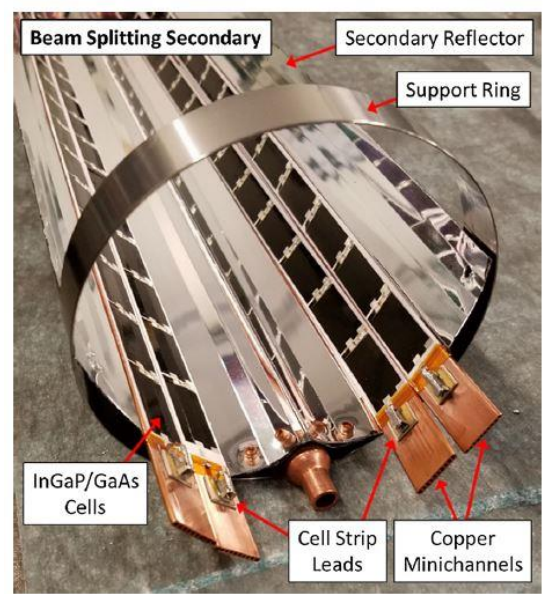

b)

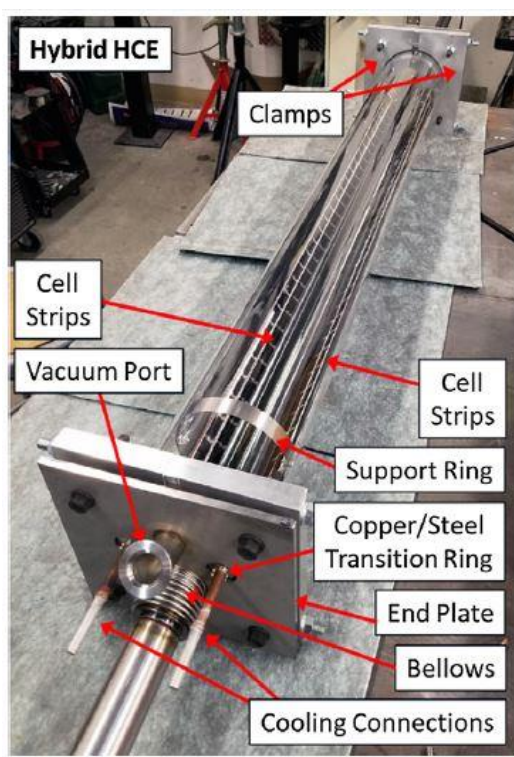

c)

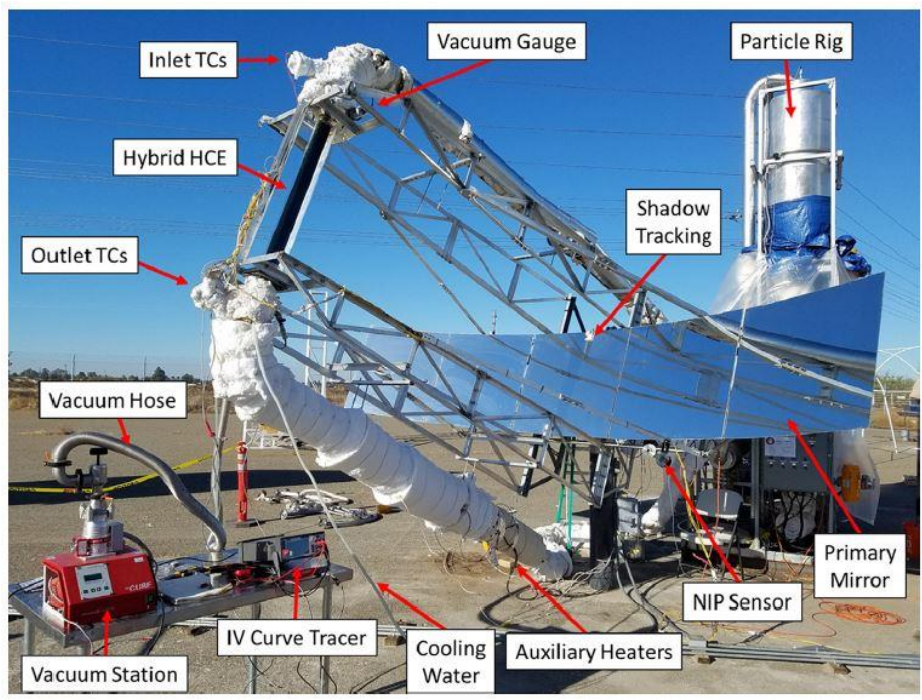

Figure 5. The high-temperature CPVT system studied by Widyolar et al. [170]: a) details about the secondary reflector, b) hybrid Heat Collection Element (HCE), c) primary mirror, Normal Incidence Pyranometer (NIP) sensor, shadow tracking, etc. Source: Widyolar et al. [170]. 
In Table 7, references about PVT systems with solar concentration for hightemperature use are presented. The analysis indicates that:

- The majority of the references are about modelling studies, suggesting that experimental developments are still in their early stages.

- In most cases: i) the systems do not include thermoelectric elements, ii) CRs are up to $1000 \mathrm{X}$, iii) the working fluid is water, iv) temperature spans are from around 100 to $250{ }^{\circ} \mathrm{C}$.

- There are a few investigations with working fluids such as oils, salts and nanofluids.

- Most of the systems have triple-junction or silicon-based PV cells.

- The majority of thermal efficiencies are around 50-60\% and electrical/PV efficiencies are approximately $20-30 \%$.

- Regarding applications, a large majority of the investigations refer to domestic installations, desalination, polygeneration and large-scale systems.

- A vast majority of the references are about configurations with parabolic concentrators.

- The systems were examined for different climatic conditions.

Riggs et al. [205] presented a study about high-temperature PVT systems (Figure 6: schematics), highlighting the fact that concentrating solar systems offer multiple applications such as industrial and commercial. Moreover, it was found that the energy produced offers cost savings, verifying that solar systems are competitive in comparison to conventional fuels such as propane and coal.

a) 


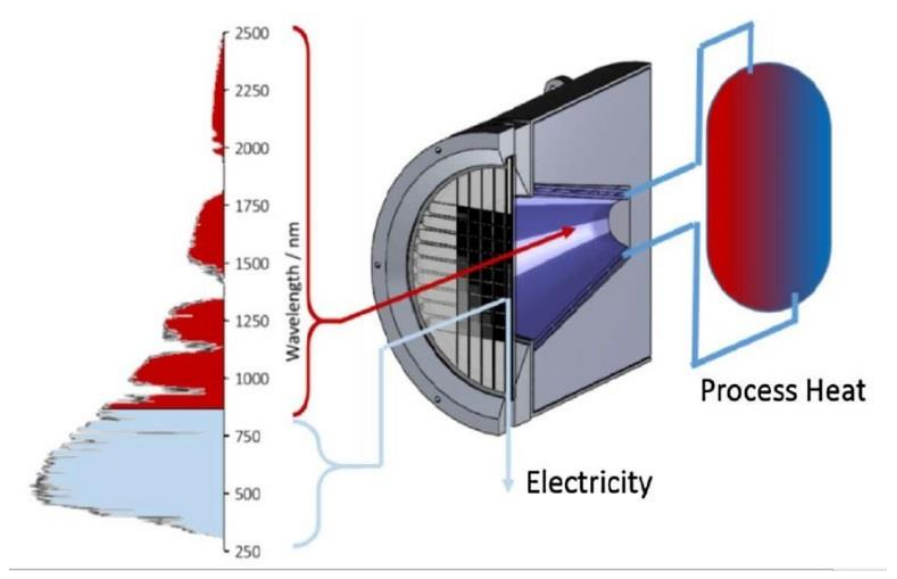

b)

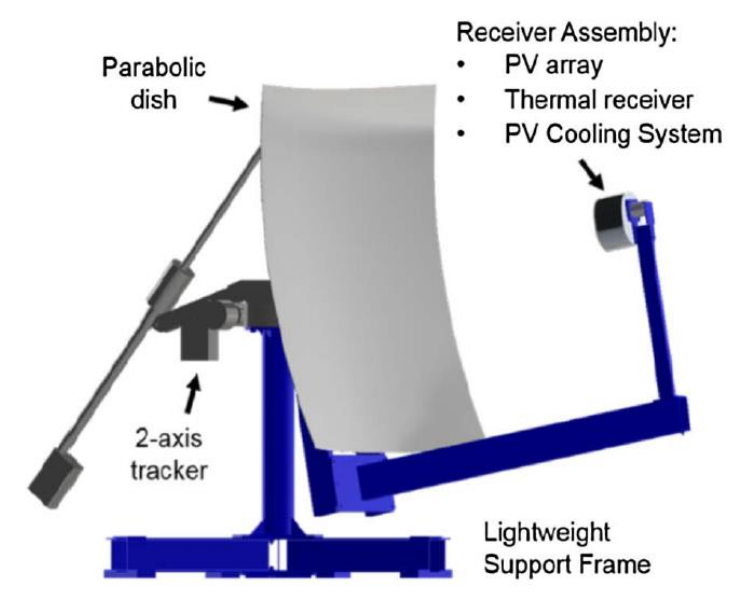

Figure 6. Schematics related to the study by Riggs et al. [205] about CPVT systems for high-temperature applications: a) energy conversion (hybrid receiver), b) CAD model of a dish-based CPVT system with 2-axis tracker. Source: Riggs et al. [205].

Table 7. PVT systems appropriate for high-temperature applications.

\begin{tabular}{|c|c|c|c|c|c|c|c|c|c|}
\hline $\begin{array}{l}\text { Study / } \\
\text { year }\end{array}$ & $\begin{array}{l}\text { Type } \\
\text { of } \\
\text { study }\end{array}$ & $\begin{array}{l}\text { Working } \\
\text { fluid }\end{array}$ & $\begin{array}{l}\text { Solar } \\
\text { concentration }\end{array}$ & $\begin{array}{l}\text { Type of } \\
\text { PV cells }\end{array}$ & $\begin{array}{l}\text { Thermoelect } \\
\text { ric element }\end{array}$ & $\begin{array}{l}\text { Temperature } \\
\text { of the working } \\
\text { fluid: High }\end{array}$ & Efficiencies & $\begin{array}{l}\text { Type of } \\
\text { application: } \\
\text { - Buildings } \\
\text { - etc. }\end{array}$ & $\begin{array}{l}\text { Location } \\
\text { of the } \\
\text { study }\end{array}$ \\
\hline $\begin{array}{l}\text { Mittel } \\
\text { man et } \\
\text { al. } \\
(2009) \\
{[171]}\end{array}$ & $\mathrm{M}$ & Water & $200 X$ & $\begin{array}{l}\text { Triple- } \\
\text { junction }\end{array}$ & No & $\begin{array}{l}\text { Coolant outlet } \\
\text { temperature: } \\
\text { around } 210^{\circ} \mathrm{C} \\
\text { (maximum) for } \\
\text { CR 200X }\end{array}$ & $\begin{array}{l}\text { For coolant } \\
\text { outlet } \\
\text { temperature: } \\
\text { around } 210^{\circ} \mathrm{C} \\
\text { and CR } 200 \mathrm{X} \text { : } \\
\text { thermal around } \\
59 \% \text {, electrical } \\
\text { around } 19 \%\end{array}$ & Desalination & $\begin{array}{l}\text { Not directly } \\
\text { stated }\end{array}$ \\
\hline $\begin{array}{l}\text { Otanic } \\
\text { ar et al. } \\
(2010) \\
{[172]}\end{array}$ & $\mathrm{M}$ & $\begin{array}{l}\text { Heat- } \\
\text { transfer } \\
\text { fluid }\end{array}$ & Up to $200 \mathrm{X}$ & $\begin{array}{l}\text { GaAs; } \\
\text { Silicon- } \\
\text { based }\end{array}$ & No & $\begin{array}{l}\text { Peak fluid } \\
\text { temperature: } \\
\text { around } 250{ }^{\circ} \mathrm{C}\end{array}$ & $\begin{array}{l}\text { Maximum } \\
\text { combined } \\
\text { efficiency: } \\
\text { around } 32.3 \% \\
\text { for solar } \\
\text { concentrations } \\
10-50 \text { and a } \\
\text { band-gap } 1.5- \\
2.0 \text { eV } \\
\text { (approximately) }\end{array}$ & $\begin{array}{l}\text { CPVT coupled } \\
\text { electrothermal } \\
\text { model }\end{array}$ & $\begin{array}{l}\text { Not directly } \\
\text { stated }\end{array}$ \\
\hline
\end{tabular}




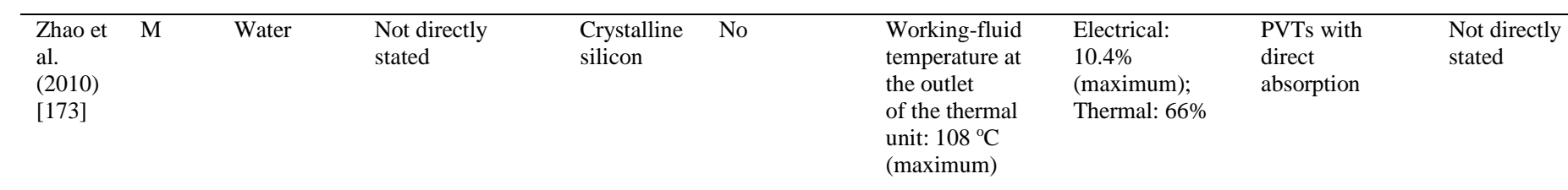

\begin{tabular}{|c|c|c|c|c|c|c|c|c|c|}
\hline $\begin{array}{l}\text { Jiang } \\
\text { et al. } \\
(2010) \\
{[174]}\end{array}$ & $\mathrm{M}$ & $\begin{array}{l}\text { Heat- } \\
\text { transfer } \\
\text { fluid }\end{array}$ & $\begin{array}{l}\text { Geometric CRs } \\
\text { up to around } 9 \mathrm{X} \\
\text { (evaluation } \\
\text { parameter: } 7 \mathrm{X} \text { ) }\end{array}$ & $\begin{array}{l}\text { Silicon- } \\
\text { based }\end{array}$ & No & $\begin{array}{l}\text { Heat energy of } \\
\text { about } \\
250-300{ }^{\circ} \mathrm{C} \text { can } \\
\text { be achieved }\end{array}$ & $\begin{array}{l}\text { Overall optical: } \\
76.4 \% \\
\text { (maximum) } \\
\text { with the } \\
\text { optimised } \\
\text { splitting coating }\end{array}$ & $\begin{array}{l}\text { Parabolic- } \\
\text { trough PVTwith } \\
\text { beam-splitting } \\
\text { filter and } \\
\text { evacuated-tube } \\
\text { collectors }\end{array}$ & $\begin{array}{l}\text { Not directly } \\
\text { stated }\end{array}$ \\
\hline $\begin{array}{l}\text { Al- } \\
\text { Alili et } \\
\text { al. } \\
(2012) \\
{[175]}\end{array}$ & $\mathrm{M}$ & Water & $\begin{array}{l}\text { Not directly } \\
\text { stated }\end{array}$ & $\begin{array}{l}\text { Not } \\
\text { directly } \\
\text { stated }\end{array}$ & No & $\begin{array}{l}\text { Tank } \\
\text { temperature } \\
\text { (average): } \\
\text { around } 99{ }^{\circ} \mathrm{C} \\
\text { (maximum) }\end{array}$ & $\begin{array}{l}\text { The COP of the } \\
\text { hybrid solar } \\
\text { air conditioner } \\
\text { is higher than } \\
\text { that of a } \\
\text { vapour- } \\
\text { compressor- } \\
\text { cycle (with } \\
\text { PVs; solar } \\
\text { absorption } \\
\text { cycle) }\end{array}$ & $\begin{array}{l}\text { PVT with } \\
\text { desiccant; } \\
\text { domestic-hot- } \\
\text { water } \\
\text { production }\end{array}$ & $\begin{array}{l}\text { United } \\
\text { Arab } \\
\text { Emirates }\end{array}$ \\
\hline
\end{tabular}

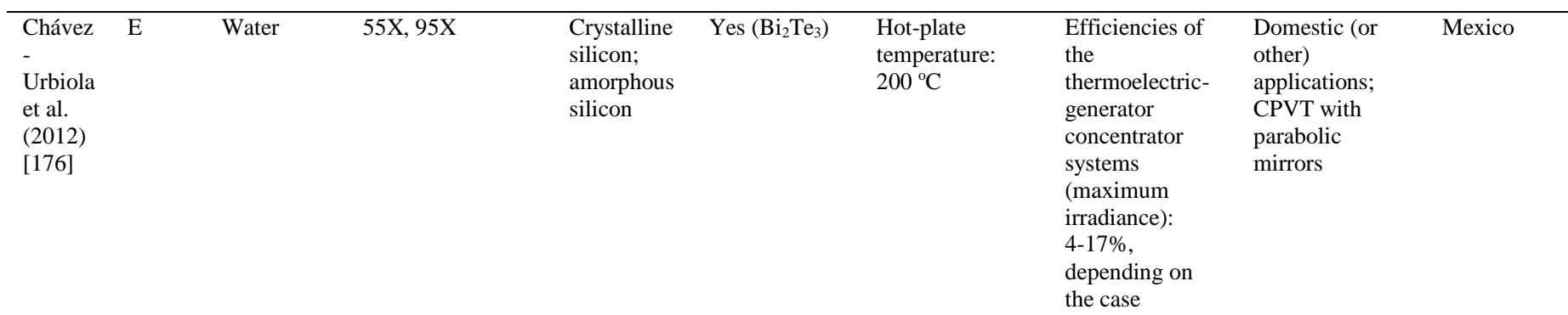

\begin{tabular}{|c|c|c|c|c|c|c|}
\hline $\begin{array}{l}\text { Buono } \\
\text { mano } \\
\text { et al. } \\
\text { (2013a } \\
\text { ) [177] }\end{array}$ & $\mathrm{M}$ & $\begin{array}{l}\text { Heat- } \\
\text { transfer } \\
\text { fluid }\end{array}$ & $\begin{array}{l}\text { Not directly } \\
\text { stated }\end{array}$ & $\begin{array}{l}\text { Triple- } \\
\text { junction }\end{array}$ & No & $\begin{array}{l}\text { Assumption: the } \\
\text { system operates } \\
\text { up to } 180^{\circ} \mathrm{C}\end{array}$ \\
\hline
\end{tabular}

$\begin{array}{lll}\text { Electrical (in } & \text { PVT with } & \begin{array}{l}\text { Not directly } \\ \text { one of the }\end{array} \\ \text { cases): 19-25\%; } & \text { for indoor space } \\ \text { optical: slightly } & \text { heating/cooling, } \\ \text { lower than 60\% } & \begin{array}{l}\text { domestic hot } \\ \text { water, } \\ \text { electricity }\end{array}\end{array}$

\begin{tabular}{|c|c|c|c|c|c|c|c|c|c|}
\hline $\begin{array}{l}\text { Buono } \\
\text { mano } \\
\text { et al. } \\
(2013 b \\
)[178]\end{array}$ & $\mathrm{M}$ & Water & $\begin{array}{l}\text { Geometric CR } \\
500 X\end{array}$ & $\begin{array}{l}\text { Triple- } \\
\text { junction }\end{array}$ & No & $\begin{array}{l}\text { Maximum } \\
\text { operating } \\
\text { temperature: } \\
100^{\circ} \mathrm{C}\end{array}$ & $\begin{array}{l}\text { PV cell: around } \\
35 \%\end{array}$ & $\begin{array}{l}\text { PVT with } \\
\text { parabolic dish } \\
\text { for indoor space } \\
\text { heating/cooling, } \\
\text { domestic hot } \\
\text { water, } \\
\text { electricity }\end{array}$ & Italy \\
\hline $\begin{array}{l}\text { Wu et } \\
\text { al. } \\
(2013) \\
{[179]}\end{array}$ & $\mathrm{E}$ & $\begin{array}{l}\text { Distilled } \\
\text { water; } \\
\text { Propylene } \\
\text { glycol; } \\
\text { Silicone } \\
\text { oil; } \\
\text { Mineral oil }\end{array}$ & $\begin{array}{l}\text { Geometric CRs: } \\
10-30 \mathrm{X}\end{array}$ & $\begin{array}{l}\text { Not } \\
\text { directly } \\
\text { stated }\end{array}$ & No & $\begin{array}{l}\text { Aim of the } \\
\text { project: } \\
\text { working fluid } \\
\text { up to } 150{ }^{\circ} \mathrm{C}\end{array}$ & $\begin{array}{l}\text { Not directly } \\
\text { stated }\end{array}$ & $\begin{array}{l}\text { High- } \\
\text { temperature } \\
\text { applications }\end{array}$ & Australia \\
\hline $\begin{array}{l}\text { Calise } \\
\text { et al. } \\
(2013) \\
{[180]}\end{array}$ & $\mathrm{M}$ & Water & $\begin{array}{l}\text { Not directly } \\
\text { stated }\end{array}$ & $\begin{array}{l}\text { Triple- } \\
\text { junction }\end{array}$ & No & $\begin{array}{l}\text { Maximum } \\
\text { output } \\
\text { temperature: } \\
\text { around } 175^{\circ} \mathrm{C} \\
\text { (summer); set } \\
\text { point: } 170^{\circ} \mathrm{C}\end{array}$ & $\begin{array}{l}\text { Based on the } \\
\text { beam radiation: } \\
\text { thermal } 50 \% \text {, } \\
\text { electrical } \\
20.8 \%\end{array}$ & $\begin{array}{l}\text { PVT with } \\
\text { parabolic dish } \\
\text { for indoor space } \\
\text { heating/cooling, } \\
\text { domestic hot } \\
\text { water, } \\
\text { electricity }\end{array}$ & Italy \\
\hline $\begin{array}{l}\text { Polons } \\
\text { ky et } \\
\text { al. } \\
(2013) \\
{[181]}\end{array}$ & $\mathrm{E}$ & Water & Around 400-450X & $\begin{array}{l}\text { Triple- } \\
\text { junction } \\
\text { GaInP/GaI } \\
\mathrm{nAs} / \mathrm{Ge}\end{array}$ & No & $\begin{array}{l}\text { PV cell: around } \\
120^{\circ} \mathrm{C} \\
\text { (maximum) }\end{array}$ & $\begin{array}{l}\text { Maximum } \\
\text { efficiency (for } \\
\text { the module): } \\
\text { around }\end{array}$ & $\begin{array}{l}\text { PVT with } \\
\text { parabolic dish } \\
\text { concentrators }\end{array}$ & $\begin{array}{l}\text { Israel; } \\
\text { Germany }\end{array}$ \\
\hline
\end{tabular}




\begin{tabular}{|c|c|c|c|c|c|c|c|c|c|}
\hline & & & & & & & $\begin{array}{l}22 \% \text { at } \mathrm{CR} \\
\text { about } 400 \mathrm{X} ; \\
\text { Optical } \\
\text { (measured): } \\
86.5 \%\end{array}$ & & \\
\hline $\begin{array}{l}\text { Helmer } \\
\text { s et al. } \\
(2014) \\
{[182]}\end{array}$ & $\mathrm{M}$ & Water & $\begin{array}{l}\text { Geometric CRs: } \\
10-2000 \mathrm{X}\end{array}$ & $\begin{array}{l}\text { Multi- } \\
\text { junction }\end{array}$ & No & $\begin{array}{l}\text { At CRs higher } \\
\text { than } 300 \mathrm{X}, \\
\text { thermal losses } \\
\text { are almost } \\
\text { negligible at } \\
\text { mean fluid } \\
\text { temperatures up } \\
\text { to } 160^{\circ} \mathrm{C}\end{array}$ & $\begin{array}{l}\text { For CRs higher } \\
\text { than } 300 X \text {, } \\
\text { system overall } \\
\text { efficiency: } \\
75 \% \text {; Maximum } \\
\text { electrical: } \\
\text { around } 29 \%\end{array}$ & Industrial & $\begin{array}{l}\text { Not directly } \\
\text { stated }\end{array}$ \\
\hline $\begin{array}{l}\text { Calise } \\
\text { et al. } \\
\text { (2014a } \\
)[183]\end{array}$ & $\mathrm{M}$ & Water & $\begin{array}{l}\text { Not directly } \\
\text { stated }\end{array}$ & $\begin{array}{l}\text { Triple- } \\
\text { junction }\end{array}$ & No & $\begin{array}{l}\text { CPVT outlet } \\
\text { temperature: } \\
100{ }^{\circ} \mathrm{C} \text { (or } \\
\text { higher) }\end{array}$ & $\begin{array}{l}\text { CPVT thermal: } \\
\text { up to } 60 \% \text {; } \\
\text { electrical: } \\
\text { around } 20 \%\end{array}$ & $\begin{array}{l}\text { Desalination; } \\
\text { polygeneration }\end{array}$ & Italy \\
\hline $\begin{array}{l}\text { Crisost } \\
\text { omo et } \\
\text { al. } \\
(2014) \\
{[169]}\end{array}$ & $\mathrm{E}$ & Water & $10 \mathrm{X}$ & $\begin{array}{l}\text { Front } \\
\text { junction } \\
\text { n-type } \\
\text { silicon }\end{array}$ & No & $\begin{array}{l}\text { Maximum } \\
\text { temperature } \\
\text { (thermal } \\
\text { output): it is } \\
\text { expected to } \\
\text { reach } 150^{\circ} \mathrm{C}\end{array}$ & $\begin{array}{l}\text { Thermal: } 75 \% \text {; } \\
\text { Maximum PV- } \\
\text { cell (hybrid } \\
\text { system with } \\
\text { filter): } 29.1 \%\end{array}$ & $\begin{array}{l}\text { PVT with } \\
\text { Fresnel mirrors } \\
\text { for commercial } \\
\text { and industrial } \\
\text { buildings }\end{array}$ & Australia \\
\hline $\begin{array}{l}\text { Gomes } \\
\text { et al. } \\
(2014) \\
{[184]}\end{array}$ & E-M & Water & $1.5 \mathrm{X}$ & Mono-Si & No & $\begin{array}{l}\text { Collector } \\
\text { stagnation } \\
\text { temperature: } \\
\text { about } 120^{\circ} \mathrm{C}\end{array}$ & PV panel: $15 \%$ & $\begin{array}{l}\text { Asymmetric } \\
\text { CPVT } \\
\text { collectors }\end{array}$ & Sweden \\
\hline $\begin{array}{l}\text { DeJarn } \\
\text { ette et } \\
\text { al. } \\
(2014) \\
{[185]}\end{array}$ & $\mathrm{M}$ & $\begin{array}{l}\text { Fluid with } \\
\text { plasmonic } \\
\text { nanoparticl } \\
\text { es }\end{array}$ & $\begin{array}{l}\text { Not directly } \\
\text { stated }\end{array}$ & GaAs & No & $\begin{array}{l}\text { Goal: to achieve } \\
\text { an operating } \\
\text { temperature of } \\
300{ }^{\circ} \mathrm{C}\end{array}$ & $\begin{array}{l}\text { Exergetic: } \\
\text { higher than } 40 \% \\
\left(\text { at } 300{ }^{\circ} \mathrm{C}\right)\end{array}$ & $\begin{array}{l}\text { PVT with } \\
\text { spectral fluid } \\
\text { filters and } \\
\text { plasmonic } \\
\text { nanoparticles }\end{array}$ & $\begin{array}{l}\text { Not directly } \\
\text { stated }\end{array}$ \\
\hline $\begin{array}{l}\text { Liu et } \\
\text { al. } \\
(2014) \\
{[186]}\end{array}$ & E-M & $\begin{array}{l}\text { Not } \\
\text { directly } \\
\text { stated }\end{array}$ & $\begin{array}{l}\text { Geometric CRs } \\
\text { from around } 3 \mathrm{X} \\
\text { to } 30 \mathrm{X} \\
\text { (approximately) }\end{array}$ & $\begin{array}{l}\text { Crystalline } \\
\text { silicon }\end{array}$ & No & $\begin{array}{l}\text { Operating } \\
\text { temperature of } \\
\text { the thermal } \\
\text { receiver: } 300^{\circ} \mathrm{C}\end{array}$ & $\begin{array}{l}\text { Efficiency of } \\
\text { the system: } \\
26.5 \% \text { (for solar } \\
\text { cell operating at } \\
25^{\circ} \mathrm{C} \text { ) }\end{array}$ & $\begin{array}{l}\text { Heat engine; } \\
\text { CPVT system } \\
\text { with beam } \\
\text { splitter and } \\
\text { linear Fresnel } \\
\text { reflector }\end{array}$ & China \\
\hline $\begin{array}{l}\text { Mojiri } \\
\text { et al. } \\
(2014) \\
{[187]}\end{array}$ & $\mathrm{M}$ & $\begin{array}{l}\text { Water; } \\
\text { Propylene } \\
\text { glycol; } \\
\text { Ethylene } \\
\text { glycol }\end{array}$ & $\begin{array}{l}\text { CRs: from } 10 X \text { to } \\
20 X\end{array}$ & $\begin{array}{l}\text { Crystalline } \\
\text { silicon }\end{array}$ & No & $\begin{array}{l}\text { Heat-transfer } \\
\text { liquids for } \\
\text { temperatures } \\
\text { higher than } 100 \\
{ }^{\circ} \mathrm{C}\end{array}$ & $\begin{array}{l}\text { Not directly } \\
\text { stated }\end{array}$ & $\begin{array}{l}\text { PVT rooftop } \\
\text { applications } \\
\text { with micro- } \\
\text { concentrators }\end{array}$ & $\begin{array}{l}\text { Not directly } \\
\text { stated }\end{array}$ \\
\hline $\begin{array}{l}\text { Calise } \\
\text { et al. } \\
\text { (2014b } \\
\text { ) [188] }\end{array}$ & $\mathrm{M}$ & Water & $\begin{array}{l}\text { Not directly } \\
\text { stated }\end{array}$ & $\begin{array}{l}\text { Triple- } \\
\text { junction }\end{array}$ & No & $\begin{array}{l}\text { The PVT can } \\
\text { operate at } \\
100^{\circ} \mathrm{C} \\
\text { (maximum) }\end{array}$ & $\begin{array}{l}\text { One specific } \\
\text { case: electrical } \\
20 \% \text {, thermal } \\
50 \% \text { (based on } \\
\text { beam radiation) }\end{array}$ & $\begin{array}{l}\text { Desalination; } \\
\text { trigeneration } \\
\text { system; PVT } \\
\text { with parabolic- } \\
\text { trough } \\
\text { collectors }\end{array}$ & Italy \\
\hline $\begin{array}{l}\text { Looser } \\
\text { et al. } \\
(2014) \\
{[189]}\end{array}$ & E-M & $\begin{array}{l}\text { Various } \\
\text { commercia } \\
1 \text { heat- } \\
\text { transfer } \\
\text { fluids }\end{array}$ & $\begin{array}{l}\text { Not directly } \\
\text { stated }\end{array}$ & $\begin{array}{l}\text { Silicon- } \\
\text { based }\end{array}$ & No & $\begin{array}{l}\text { Goal: heat } \\
\text { production at } \\
135^{\circ} \mathrm{C} \\
\text { (approximately) }\end{array}$ & $\begin{array}{l}\text { Goal: } \\
\text { enhancement of } \\
\text { system } \\
\text { efficiency } \\
\text { and reduction in } \\
\text { lifetime energy } \\
\text { costs }\end{array}$ & $\begin{array}{l}\text { Beam-splitting } \\
\text { applications; } \\
\text { PVT with } \\
\text { micro- } \\
\text { concentrators }\end{array}$ & Australia \\
\hline $\begin{array}{l}\text { Calise } \\
\text { et al. } \\
(2015) \\
{[190]}\end{array}$ & $\mathrm{M}$ & Water & $\begin{array}{l}\text { Not directly } \\
\text { stated }\end{array}$ & $\begin{array}{l}\text { Triple- } \\
\text { junction }\end{array}$ & No & $\begin{array}{l}\text { The system } \\
\text { includes one- } \\
\text { axis tracking } \\
\text { and can operate } \\
\text { at } 100^{\circ} \mathrm{C} \\
\text { (maximum) }\end{array}$ & $\begin{array}{l}\text { Exergy } \\
\text { efficiency } \\
\text { (summer day): } \\
\text { around } 20 \%\end{array}$ & $\begin{array}{l}\text { Desalination; } \\
\text { polygeneration; } \\
\text { PVT with } \\
\text { parabolic- } \\
\text { trough } \\
\text { collectors }\end{array}$ & Italy \\
\hline $\begin{array}{l}\text { Mojiri } \\
\text { et al. }\end{array}$ & $\mathrm{M}$ & $\begin{array}{l}\text { Water; } \\
\text { Propylene }\end{array}$ & $20 X$ & $\begin{array}{l}\text { Crystalline } \\
\text { silicon }\end{array}$ & No & $\begin{array}{l}\text { The hybrid } \\
\text { receiver has a }\end{array}$ & $\begin{array}{l}\text { PV cell } \\
\text { (baseline): }\end{array}$ & $\begin{array}{l}\text { Rooftop } \\
\text { applications }\end{array}$ & $\begin{array}{l}\text { Not directly } \\
\text { stated }\end{array}$ \\
\hline
\end{tabular}




\begin{tabular}{|c|c|c|c|c|c|c|c|c|c|}
\hline $\begin{array}{l}(2015) \\
{[191]}\end{array}$ & & $\begin{array}{l}\text { glycol; } \\
\text { Ethylene } \\
\text { glycol }\end{array}$ & & & & $\begin{array}{l}\text { high- } \\
\text { temperature } \\
\text { (higher than } 150 \\
{ }^{\circ} \mathrm{C} \text { ) liquid } \\
\text { channel }\end{array}$ & $\begin{array}{l}\text { around } 20.6 \% \\
\left(\mathrm{CR}: 1 \mathrm{X} ; 25^{\circ} \mathrm{C}\right)\end{array}$ & $\begin{array}{l}\text { with micro- } \\
\text { concentrators }\end{array}$ & \\
\hline $\begin{array}{l}\text { Otanic } \\
\text { ar et al. } \\
(2015) \\
{[192]}\end{array}$ & $\mathrm{M}$ & $\begin{array}{l}\text { Working } \\
\text { fluid }\end{array}$ & $\begin{array}{l}\text { Ranging from } \\
40 \mathrm{X} \text { to } 240 \mathrm{X} \text { or } \\
\text { from } 50 \mathrm{X} \text { to } \\
600 \mathrm{X} \text {, depending } \\
\text { on the case }\end{array}$ & $\begin{array}{l}\text { The values } \\
\text { selected } \\
\text { for the } \\
\text { bandgap } \\
\text { refer to: } \mathrm{Si} \text {, } \\
\text { GaAs, } \\
\mathrm{CdTe} \text {, } \\
\mathrm{InGaP}\end{array}$ & No & $\begin{array}{l}\text { Maximum heat- } \\
\text { transfer-fluid } \\
\text { outlet } \\
\text { temperature: } \\
600^{\circ} \mathrm{C}\end{array}$ & $\begin{array}{l}\text { For outlet fluid } \\
\text { temperature } \\
300^{\circ} \mathrm{C} \text { : thermal } \\
\text { around } 75 \% \\
\text { (maximum), } \\
\text { electrical } \\
\text { around } 28 \% \\
\text { (maximum) }\end{array}$ & $\begin{array}{l}\text { Applications } \\
\text { with spectral } \\
\text { filtering and } \\
\text { high- } \\
\text { temperature PV }\end{array}$ & $\begin{array}{l}\text { Not directly } \\
\text { stated }\end{array}$ \\
\hline $\begin{array}{l}\text { Renno } \\
\text { and } \\
\text { Petito } \\
(2015) \\
{[193]}\end{array}$ & $\mathrm{M}$ & $\begin{array}{l}\text { Water - } \\
\text { glycol }\end{array}$ & $100-900 \mathrm{X}$ & $\begin{array}{l}\text { Triple- } \\
\text { junction } \\
\text { InGaP/InG } \\
\text { aAs/Ge }\end{array}$ & No & $\begin{array}{l}\text { Maximum fluid } \\
\text { outlet } \\
\text { temperature } \\
\text { (summer): } \\
\text { around } 118^{\circ} \mathrm{C}\end{array}$ & $\begin{array}{l}\text { PVT system: } \\
\text { electrical } \\
\text { around } 25 \% \\
\text { (maximum),ther } \\
\text { mal around } 70 \% \\
\text { (maximum) }\end{array}$ & $\begin{array}{l}\text { Domestic } \\
\text { applications } \\
\text { with point-focus } \\
\text { parabolic- } \\
\text { concentrator } \\
\text { PVT }\end{array}$ & Italy \\
\hline $\begin{array}{l}\text { Crisost } \\
\text { omo et } \\
\text { al. } \\
(2015) \\
{[194]}\end{array}$ & $\mathrm{M}$ & Water & $10 \mathrm{X}$ & $\begin{array}{l}\mathrm{Si}, \mathrm{GaAs}, \\
\text { GaInP/Ga } \\
\text { As }\end{array}$ & No & $\begin{array}{l}\text { Hybrid- } \\
\text { collector goal: } \\
\text { pressurised } \\
\text { water at around } \\
140^{\circ} \mathrm{C}\end{array}$ & $\begin{array}{l}\text { Optical: } 71 \% \\
\text { (maximum); } \\
\text { Thermal: } 80 \% \\
\text { (maximum) }\end{array}$ & $\begin{array}{l}\text { Domestic or } \\
\text { industrial } \\
\text { applications; } \\
\text { PVT with } \\
\text { spectral beam } \\
\text { splitting and } \\
\text { Fresnel mirrors }\end{array}$ & $\begin{array}{l}\text { Not directly } \\
\text { stated }\end{array}$ \\
\hline $\begin{array}{l}\text { Abdelk } \\
\text { ader et } \\
\text { al. } \\
(2015) \\
{[195]}\end{array}$ & $\mathrm{M}$ & Water & $\begin{array}{l}100 X, 300 X, \\
500 X, 700 X, \\
900 X\end{array}$ & $\begin{array}{l}\text { Triple- } \\
\text { junction } \\
\text { InGaP/InG } \\
\text { aAs/Ge }\end{array}$ & No & $\begin{array}{l}\text { Maximum } \\
\text { output fluid } \\
\text { temperature: } \\
\text { around } 94^{\circ} \mathrm{C} \\
(\mathrm{CR}: 900 \mathrm{X})\end{array}$ & $\begin{array}{l}\text { Thermal: } \\
\text { around 59\% } \\
\text { (maximum); } \\
\text { Electrical: } \\
\text { around 22\% } \\
\text { (maximum) }\end{array}$ & $\begin{array}{l}\text { PVT with } \\
\text { parabolic mirror } \\
\text { concentrators }\end{array}$ & Libya \\
\hline $\begin{array}{l}\text { Atheay } \\
\text { a et al. } \\
(2016) \\
{[196]}\end{array}$ & $\mathrm{M}$ & Water & $\begin{array}{l}\text { Not directly } \\
\text { stated }\end{array}$ & $\begin{array}{l}\text { Not } \\
\text { directly } \\
\text { stated }\end{array}$ & No & $\begin{array}{l}\text { Outlet fluid } \\
\text { temperature: } \\
\text { around } 130{ }^{\circ} \mathrm{C} \\
\text { (maximum; } \\
\text { case: glazed } \\
\text { inverted } \\
\text { absorber } \\
\text { partially } \\
\text { covered PVT- } \\
\text { CPC) }\end{array}$ & $\begin{array}{l}\text { Electrical: } \\
\text { around } 13.2 \% \\
\text { (maximum; } \\
\text { case: partially } \\
\text { covered } \\
\text { horizontal PVT- } \\
\text { CPC); } \\
\text { instantaneous } \\
\text { thermal: around } \\
\text { 59\% } \\
\text { (maximum; } \\
\text { case: glazed } \\
\text { inverted } \\
\text { absorber } \\
\text { partially } \\
\text { covered PVT- } \\
\text { CPC) }\end{array}$ & PVT with CPCs & India \\
\hline $\begin{array}{l}\text { Sharaf } \\
\text { and } \\
\text { Orhan } \\
(2016) \\
{[197]}\end{array}$ & $\mathrm{M}$ & $\begin{array}{l}\text { Pure } \\
\text { water; } \\
\mathrm{Al}_{2} \mathrm{O}_{3} / \text { wate } \\
\mathrm{r} \\
\text { nanofluid; } \\
\mathrm{Al}_{2} \mathrm{O}_{3} / \text { synt } \\
\text { hetic oil } \\
\text { nanofluid }\end{array}$ & Up to $2000 \mathrm{X}$ & $\begin{array}{l}\text { Multi- } \\
\text { junction } \\
\text { InGaP/ } \\
\text { InGaAs/Ge }\end{array}$ & Yes & $\begin{array}{l}\text { One of the } \\
\text { cases: heat- } \\
\text { transfer-fluid } \\
\text { outlet } \\
\text { temperature: } \\
\text { around } \\
120-125^{\circ} \mathrm{C}\end{array}$ & $\begin{array}{l}\text { Multi-junction } \\
\text { PV cells } \\
\text { eliminate the } \\
\text { negative impact } \\
\text { of high } \\
\text { temperature on } \\
\text { conversion } \\
\text { efficiency } \\
\text { (for high CRs) }\end{array}$ & $\begin{array}{l}\text { PVT systems } \\
\text { with densely- } \\
\text { packed } \\
\text { receivers }\end{array}$ & $\begin{array}{l}\text { Not directly } \\
\text { stated }\end{array}$ \\
\hline $\begin{array}{l}\text { Stanley } \\
\text { et al. } \\
(2016) \\
{[198]}\end{array}$ & $\mathrm{E}$ & Water & $\begin{array}{l}\text { Geometric CR } \\
42 \mathrm{X}\end{array}$ & $\begin{array}{l}\text { Silicon- } \\
\text { based }\end{array}$ & No & $\begin{array}{l}\text { Receiver: } \\
\text { primary thermal } \\
\text { absorber inlet } \\
\text { temperature up } \\
\text { to } 200^{\circ} \mathrm{C}\end{array}$ & $\begin{array}{l}\text { Total (for the } \\
\text { system; at } \\
120{ }^{\circ} \mathrm{C} \text { receiver } \\
\text { temperature): } \\
50 \% \text {; Electrical: } \\
\text { about } 3.8 \% \\
\text { (relative to the } \\
\text { total incident } \\
\text { power) }\end{array}$ & $\begin{array}{l}\text { Spectral beam } \\
\text { splitting PVT } \\
\text { with linear } \\
\text { concentrators; } \\
\text { industrial } \\
\text { applications }\end{array}$ & Australia \\
\hline
\end{tabular}




\begin{tabular}{|c|c|c|c|c|c|c|c|c|c|}
\hline $\begin{array}{l}\text { Tripath } \\
\text { i and } \\
\text { Tiwari } \\
(2016) \\
{[199]}\end{array}$ & M & $\begin{array}{l}\text { Water; } \\
\text { Molten salt }\end{array}$ & $\begin{array}{l}\text { Not directly } \\
\text { stated }\end{array}$ & $\begin{array}{l}\text { Not } \\
\text { directly } \\
\text { stated }\end{array}$ & No & $\begin{array}{l}\text { Outlet fluid } \\
\text { temperature: } \\
190^{\circ} \mathrm{C} \\
\text { (maximum) }\end{array}$ & $\begin{array}{l}\text { PV module: } \\
\text { around } 12.5 \% \\
\text { (maximum) }\end{array}$ & PVT with CPCs & India \\
\hline $\begin{array}{l}\text { Tripath } \\
\text { i et al. } \\
(2016) \\
{[200]}\end{array}$ & M & Water & $\begin{array}{l}\text { Not directly } \\
\text { stated }\end{array}$ & $\begin{array}{l}\text { Not } \\
\text { directly } \\
\text { stated }\end{array}$ & No & $\begin{array}{l}\text { Outlet water } \\
\text { temperature: } \\
\text { around } 195{ }^{\circ} \mathrm{C} \\
\text { (maximum; } \\
\text { mass flow rate } \\
0.002 \mathrm{~kg} / \mathrm{s} \text {; } \\
\text { January) }\end{array}$ & $\begin{array}{l}\text { Electrical: } \\
\text { around } 13 \% \\
\text { (maximum) }\end{array}$ & PVT with CPCs & India \\
\hline $\begin{array}{l}\text { Hassan } \\
\text { i et al. } \\
(2016) \\
{[201]}\end{array}$ & M & $\begin{array}{l}\text { Water; } \\
\text { Ag/water } \\
\text { nanofluids }\end{array}$ & $\begin{array}{l}1 X, 2 X, 3 X, 4 X \\
5 X, 6 X, 7 X, 8 X \\
9 X, 10 X\end{array}$ & Mono-Si & No & $\begin{array}{l}\text { Maximum } \\
\text { working-fluid } \\
\text { temperatures: } \\
\text { around } 100^{\circ} \mathrm{C}\end{array}$ & $\begin{array}{l}\text { One of the } \\
\text { cases: electrical } \\
12.25 \% \text {, } \\
\text { thermal } \\
\text { exergetic } \\
1.72 \%\end{array}$ & Domestic & $\begin{array}{l}\text { Not directly } \\
\text { stated }\end{array}$ \\
\hline
\end{tabular}

\begin{tabular}{lllll}
\hline $\begin{array}{l}\text { Abdelh } \\
\text { amid et }\end{array}$ & E-M & Oil & $60 X$ & $\begin{array}{l}\text { Thin-film } \\
\text { single- }\end{array}$ \\
al. & & & junction \\
$(2016)$ & & & GaAs \\
{$[202]$} & & &
\end{tabular}

\begin{tabular}{|c|c|c|c|c|c|c|c|c|c|}
\hline $\begin{array}{l}\text { Radwa } \\
\text { n et al. } \\
(2016) \\
{[203]}\end{array}$ & M & Water & Up to $40 X$ & Poly-Si & No & $\begin{array}{l}\text { For CR 40X } \\
\text { and } R e=5, \\
\text { outlet water } \\
\text { temperature } \\
90.2^{\circ} \mathrm{C}\end{array}$ & $\begin{array}{l}\text { Electrical 16- } \\
19.5 \%, \text { thermal } \\
60.5-63 \%, \\
\text { depending on } \\
\text { the case (CR, } \\
R e)\end{array}$ & $\begin{array}{l}\text { PVT with point- } \\
\text { focus Fresnel- } \\
\text { lens } \\
\text { concentrators }\end{array}$ & Egypt \\
\hline $\begin{array}{l}\text { Singh } \\
\text { and } \\
\text { Tiwari } \\
(2017) \\
{[204]}\end{array}$ & M & Water & $\begin{array}{l}\text { Not directly } \\
\text { stated }\end{array}$ & $\begin{array}{l}\text { Not } \\
\text { directly } \\
\text { stated }\end{array}$ & No & $\begin{array}{l}\text { Outlet water } \\
\text { temperature: } \\
\text { around } 110{ }^{\circ} \mathrm{C} \\
\text { (maximum) }\end{array}$ & $\begin{array}{l}\text { Electrical: } \\
\text { around 12\% } \\
\text { (maximum); } \\
\text { annual } \\
\text { cogeneration: } \\
22.55 \%\end{array}$ & $\begin{array}{l}\text { PVT with CPCs } \\
\text { for water } \\
\text { distillation }\end{array}$ & India \\
\hline $\begin{array}{l}\text { Riggs } \\
\text { et al. } \\
(2017) \\
{[205]}\end{array}$ & M & Water & Up to $1800 \mathrm{X}$ & $\begin{array}{l}\text { Multi- } \\
\text { junction } \\
\text { GaAs }\end{array}$ & No & $\begin{array}{l}\text { Temperatures } \\
\text { up to } 650{ }^{\circ} \mathrm{C} \text { at } \\
\text { the surface of } \\
\text { the thermal } \\
\text { receiver }\end{array}$ & $\begin{array}{l}\text { PV cell: } 27- \\
33 \%\end{array}$ & $\begin{array}{l}\text { Domestic hot } \\
\text { water heating; } \\
\text { desalination; } \\
\text { food processing, } \\
\text { etc. }\end{array}$ & USA \\
\hline $\begin{array}{l}\text { Widyol } \\
\text { ar et al. } \\
(2017) \\
{[206]}\end{array}$ & E-M & $\begin{array}{l}\text { Heat- } \\
\text { transfer } \\
\text { fluid } \\
\text { (Therminol } \\
\text { VP-1) }\end{array}$ & $\begin{array}{l}\text { Geometric CR } \\
\text { around } 60 \mathrm{X}\end{array}$ & $\begin{array}{l}\text { Single- } \\
\text { junction } \\
\text { GaAs }\end{array}$ & No & $\begin{array}{l}\text { Maximum } \\
\text { outlet } \\
\text { temperature: } \\
365^{\circ} \mathrm{C}\end{array}$ & $\begin{array}{l}\text { Thermal } \\
\text { (experimental): } \\
\text { approximately } \\
37 \% \text {; Maximum } \\
\text { electrical: about } \\
8 \%\end{array}$ & PVT with CPCs & USA \\
\hline $\begin{array}{l}\text { Lamnat } \\
\text { ou et } \\
\text { al. } \\
(2018) \\
{[207]}\end{array}$ & $\mathrm{M}$ & Water & $\begin{array}{l}\text { Geometric CR } \\
\text { around } 13 \mathrm{X}\end{array}$ & Poly-Si & No & $\begin{array}{l}\text { Heat } \\
\text { production: at } \\
\text { about } 140^{\circ} \mathrm{C} \text { : } \\
\text { Lecoeuvre et al. } \\
(2018) \text { [208] }\end{array}$ & $\begin{array}{l}\text { Annual } \\
\text { production: } \\
996 \mathrm{kWh} \\
\text { electricity, } 2190 \\
\text { kWh thermal }\end{array}$ & $\begin{array}{l}\text { Buildings, etc.; } \\
\text { PV modules } \\
\text { with } \\
\text { concentrating } \\
\text { solar thermal } \\
\text { unit }\end{array}$ & France \\
\hline $\begin{array}{l}\text { Gomaa } \\
\text { et al. } \\
\text { (2018) } \\
{[209]}\end{array}$ & M & Water & $\begin{array}{l}\text { From around } 5 X \\
\text { to } 46 X \\
\text { (approximately) }\end{array}$ & $\begin{array}{l}\text { Silicon- } \\
\text { based }\end{array}$ & No & $\begin{array}{l}\text { Operation at } \\
150{ }^{\circ} \mathrm{C} \text { is } \\
\text { appropriate for } \\
\text { double-effect } \\
\text { absorption } \\
\text { refrigeration } \\
\text { and organic } \\
\text { Rankine cycle }\end{array}$ & $\begin{array}{l}\text { One specific } \\
\text { case: } 18 \% \\
\text { electrical, } 62 \% \\
\text { thermal }\end{array}$ & $\begin{array}{l}\text { Buildings; } \\
\text { industry }\end{array}$ & $\begin{array}{l}\text { Not directly } \\
\text { stated }\end{array}$ \\
\hline
\end{tabular}




\begin{tabular}{|c|c|c|c|c|c|c|c|c|c|}
\hline $\begin{array}{l}\text { Moale } \\
\text { man et } \\
\text { al. } \\
(2018) \\
{[210]}\end{array}$ & $\mathrm{M}$ & $\begin{array}{l}\text { Water- } \\
\text { ammonia } \\
\text { absorption } \\
\text { refrigeratio } \\
\text { n cycle }\end{array}$ & $15 X$ & Mono-Si & No & $\begin{array}{l}\text { Output fluid } \\
\text { from the panels: } \\
\text { around } \\
130-140{ }^{\circ} \mathrm{C} \\
\text { (maximum; } \\
\text { June, July) }\end{array}$ & $\begin{array}{l}\text { Electrical: } \\
12.8 \% \text { (average } \\
\text { annual); } \\
\text { Thermal: } 58 \% \\
\text { (average } \\
\text { annual) }\end{array}$ & $\begin{array}{l}\text { Buildings; } \\
\text { industry }\end{array}$ & Iran \\
\hline $\begin{array}{l}\text { Ben } \\
\text { Yousse } \\
\text { f et al. } \\
(2018) \\
{[211]}\end{array}$ & $\mathrm{M}$ & Water & $10 X, 20 X$ & $\begin{array}{l}\text { Triple- } \\
\text { junction } \\
\text { InGaP/InG } \\
\text { aAs/Ge }\end{array}$ & No & $\begin{array}{l}\text { Maximum } \\
\text { outlet hot water } \\
\text { temperature: } \\
220^{\circ} \mathrm{C} \\
\text { (midday) }\end{array}$ & $\begin{array}{l}\text { Electrical: } 21 \% \\
\text { (maximum); } \\
\text { Thermal: } 62 \% \\
\text { (maximum) }\end{array}$ & $\begin{array}{l}\text { Textile-industry } \\
\text { applications; } \\
\text { PVT with } \\
\text { parabolic- } \\
\text { trough } \\
\text { concentrators }\end{array}$ & Tunisia \\
\hline $\begin{array}{l}\text { Vossier } \\
\text { et al. } \\
(2018) \\
{[212]}\end{array}$ & $\mathrm{M}$ & Oil & $\begin{array}{l}\text { For line-focus: } \\
\text { 25-50X; for } \\
\text { point-focus: } \\
1000-2000 X\end{array}$ & $\begin{array}{l}\text { Single- } \\
\text { junction }\end{array}$ & No & $\begin{array}{l}\text { Maximum } \\
\text { temperatures: } \\
393^{\circ} \mathrm{C}, 550^{\circ} \mathrm{C}\end{array}$ & $\begin{array}{l}\text { Maximum } \\
\text { efficiency for } \\
\text { the high- } \\
\text { temperature PV } \\
\text { cell (for normal } \\
\text { global solar } \\
\text { radiation): } \\
42.3 \%\end{array}$ & Power plants & USA \\
\hline $\begin{array}{l}\text { Alayi } \\
\text { et al. } \\
(2019) \\
{[213]}\end{array}$ & $\mathrm{M}$ & $\begin{array}{l}\text { Heat- } \\
\text { transfer } \\
\text { fluid }\end{array}$ & $\begin{array}{l}\text { Not directly } \\
\text { stated }\end{array}$ & $\begin{array}{l}\text { Not } \\
\text { directly } \\
\text { stated }\end{array}$ & No & $\begin{array}{l}\text { Maximum } \\
\text { output } \\
\text { temperature of } \\
\text { the CPVT } \\
\text { collector: } \\
150^{\circ} \mathrm{C}\end{array}$ & $\begin{array}{l}\text { For the } \\
\text { simulations: } \\
\text { heat exchanger } \\
\text { with } 60 \% \\
\text { efficiency; } \\
\text { Collector fin } \\
\text { efficiency } \\
\text { factor: } 0.7\end{array}$ & $\begin{array}{l}\text { CPVT with } \\
\text { parabolic- } \\
\text { trough } \\
\text { concentrators } \\
\text { for buildings }\end{array}$ & Iran \\
\hline $\begin{array}{l}\text { Widyol } \\
\text { ar et al. } \\
(2019) \\
{[170]}\end{array}$ & E-M & $\begin{array}{l}\text { Water; } \\
\text { Heat- } \\
\text { transfer } \\
\text { fluid with } \\
\text { particles }\end{array}$ & $\begin{array}{l}\text { Geometric CR } \\
50 \mathrm{X}\end{array}$ & $\begin{array}{l}\text { Double- } \\
\text { junction } \\
\text { InGaP/Ga } \\
\text { As }\end{array}$ & No & $\begin{array}{l}\text { The system was } \\
\text { tested at } 600{ }^{\circ} \mathrm{C} \\
\text { (maximum) }\end{array}$ & $\begin{array}{l}\text { Simulations: } \\
\text { Optical } 64 \% \text {; } \\
\text { Thermal } 52 \% \\
\left.\text { (at } 600^{\circ} \mathrm{C}\right) ; \\
\text { Efficiency of } \\
\text { the back- } \\
\text { reflecting CPV } \\
\text { subsystem: } 6 \%\end{array}$ & $\begin{array}{l}\text { Power plants; } \\
\text { domestic or } \\
\text { commercial hot- } \\
\text { water } \\
\text { production }\end{array}$ & USA \\
\hline $\begin{array}{l}\text { Al } \\
\text { Nimr } \\
\text { and Al } \\
\text { Ammar } \\
\text { i } \\
(2019) \\
{[214]}\end{array}$ & M & $\begin{array}{l}\text { Organic } \\
\text { fluid (solar } \\
\text { cells } \\
\text { immersed } \\
\text { in the } \\
\text { fluid) }\end{array}$ & $\begin{array}{l}\text { Not directly } \\
\text { stated }\end{array}$ & $\begin{array}{l}\text { Not } \\
\text { directly } \\
\text { stated }\end{array}$ & No & $\begin{array}{l}\text { Outlet } \\
\text { temperature at } \\
\text { the exit of the } \\
\text { absorber tube: } \\
130^{\circ} \mathrm{C} \\
\text { (maximum) }\end{array}$ & $\begin{array}{l}\text { Based on the } \\
\text { designed } \\
\text { configuration: } \\
\text { PV-module } \\
\text { efficiency } \\
\text { around } 12 \% \text {; } \\
\text { absorber } \\
\text { efficiency } \\
64-75 \%\end{array}$ & $\begin{array}{l}\text { PVT based on } \\
\text { organic Rankine } \\
\text { cycle; PVT with } \\
\text { parabolic- } \\
\text { trough } \\
\text { concentrators }\end{array}$ & Jordan \\
\hline $\begin{array}{l}\text { Valiza } \\
\text { deh et } \\
\text { al. } \\
(2019) \\
{[215]}\end{array}$ & $\mathrm{M}$ & Water & $\begin{array}{l}\text { Not directly } \\
\text { stated }\end{array}$ & $\begin{array}{l}\text { Not } \\
\text { directly } \\
\text { stated }\end{array}$ & No & $\begin{array}{l}\text { Outlet fluid } \\
\text { temperature } \\
\text { (maximum): } \\
\text { around } 95^{\circ} \mathrm{C} \\
(0.1 \mathrm{~m} / \mathrm{s})\end{array}$ & $\begin{array}{l}\text { By increasing } \\
\text { the length of the } \\
\text { collector from } 3 \\
\text { to } 90 \mathrm{~m} \text { : } \\
\text { thermal } \\
\text { efficiency } \\
62.5 \% \text { and } \\
60 \% \text {; Electrical: } \\
\text { around } 20-22 \% \\
\text { (maximum) }\end{array}$ & $\begin{array}{l}\text { Domestic and } \\
\text { industrial } \\
\text { applications } \\
\text { with linear } \\
\text { parabolic- } \\
\text { trough } \\
\text { concentrators }\end{array}$ & $\begin{array}{l}\text { Not directly } \\
\text { stated }\end{array}$ \\
\hline
\end{tabular}




\section{CHALLENGES AND FUTURE PROSPECTS}

In light of the issues discussed in section 2, PVT systems for low- and mediumtemperature applications pose the following challenges:

- Development of PVT systems which are based on multiple kinds of PV cells (apart from the typical configurations with Si-based PV cells) and different types of working fluids (nanofluids, bi-fluid systems and so on).

- Design of innovative systems with concentrators and/or thermoelectric components, aiming at the achievement of high electrical and thermal efficiencies for a wide range of applications (residential, agricultural, industrial, etc.).

- Development of burgeoning systems which form part of the building structure itself (BI solar systems).

On the other hand, high-temperature PVT systems pose challenges such as:

- Utilisation of PV-cell materials and concentrators suitable for high CRs.

- Design of PVT configurations with CRs higher than 1000X and working-fluid temperatures higher than $300{ }^{\circ} \mathrm{C}$, offering a whole host of applications (industrial, largescale power generation and so on).

- Testing (under real and experimental conditions).

In the literature on PVT systems, there are studies which place emphasis on CPVT technologies, highlighting the fact that systems with solar concentration offer a raft of solutions ranging from domestic hot water production to organic-Rankine configurations. In this case, an additional challenge is related to heat-transfer components/medium. Elements such as fins, micro-channels, storage devices, heat exchangers and PCMs were evaluated with a view to examining issues such as heat-transfer performance and thermal/electrical efficiencies. Moreover, the performance of the heat-transfer fluid depends on multiple factors, namely viscosity, density, temperature, thermal mass, time 
and mass flow rate. Furthermore, the systems should be feasible from an economic point of view. To this end, parameters such as feed-in tariff and carbon credit should be considered [216].

Additional CPVT challenges are associated with the evaluation of the systems from different angles (experimental, numerical and so on), investigation of the impact of the concentrators $(\mathrm{CR}$, temperature, etc.) and the role of the COP. The results of the literature on CPVT show that these systems are promising and, in the short run, are expected to be competitive with conventional energy systems [217].

\section{CONCLUSION}

The present article provides a thorough review of PVT systems from a specific viewpoint. In particular, the PVT configurations have been categorised by the temperature of the working fluid. In each case, useful information has been extracted: namely working fluid, PV-cell types, solar concentration ratio, fluid temperature, electrical and thermal efficiencies, type of application and location of the study.

Analyses of the main features of the PVT systems (on the basis of three workingfluid temperature ranges: low, medium and high) have revealed the major trends of the research that has hitherto been conducted. Accordingly, gaps remaining to be filled have been identified (simultaneous improvement of electrical and thermal efficiencies and so on).

By way of illustration, more diverse PV technologies need to be used and developed, especially in the case of systems operating at high temperatures. To this end, thermal systems should be optimised, in line with different levels of solar concentration and resulting temperatures. On the other hand, hybridisation with thermoelectric elements is a hitherto-immature technology and, therefore, further development is needed. The remaining challenges are more numerous for the high-temperature applications, in terms 
of working fluid, heat transfer components and heat storage. Much as modelling and simulations provide solid design tools, tests under real operating conditions are absolutely required. Additional factors such as costs, payback times, materials and environmental impacts (in comparison to conventional energy systems) should also be taken into account.

\section{ACKNOWLEDGMENTS}

The authors would like to thank "Ministerio de Economía y Competitividad" of Spain for the funding (grant reference ENE2016-81040-R). D. Chemisana thanks "Institució Catalana de Recerca i Estudis Avançats (ICREA)" for the ICREA Acadèmia award. Chr. Lamnatou is Lecturer of the Serra Húnter programme. Figures 1-6: reproduced with permission.

\section{REFERENCES}

[1] Tripanagnostopoulos Y. Aspects and improvements of hybrid photovoltaic/thermal solar energy systems. Sol Energy 2007;81:1117-1131.

[2] Dupré O, Vaillon R, Green MA. Thermal Behavior of Photovoltaic Devices, Physics and Engineering, Springer; 2017.

[3] Tripanagnostopoulos Y, Souliotis M, Battisti R, Corrado A. Energy, Cost and LCA Results of PV and Hybrid PV/T Solar Systems. Prog. Photovolt: Res Appl 2005;13:235250

[4] Tripanagnostopoulos Y, Souliotis M, Battisti R, Corrado A. Performance, Cost and Life-cycle Assessment Study of Hybrid PVT/AIR Solar Systems. Prog Photovolt: Res Appl 2006;14:65-76.

[5] Tripanagnostopoulos Y. New designs of building integrated solar energy systems. Energy Proced 2014;57:2186-2194.

[6] Joshi SS, Dhoble AS. Photovoltaic -Thermal systems (PVT): Technology review and future trends. Renew Sust Energy Rev 2018;92:848-882.

[7] Lamnatou Chr, Chemisana D. Photovoltaic/thermal (PVT) systems: A review with emphasis on environmental issues. Renew Energy 2017;105:270-287.

[8] Charalambous PG, Maidment GG, Kalogirou SA, Yiakoumetti K. Photovoltaic thermal (PV/T) collectors: A review. Appl Therm Eng 2007;27:275-286.

[9] Zondag HA. Flat-plate PV-Thermal collectors and systems: A review. Renew Sust Energy Rev 2008;12:891-959. 
[10] Chow TT. A review on photovoltaic/thermal hybrid solar technology. Appl Energy 2010;87:365-379.

[11] Hasan MA, Sumathy K. Photovoltaic thermal module concepts and their performance analysis: A review. Renew Sust Energy Rev 2010;14:1845-1859.

[12] Ibrahim A, Othman MY, Ruslan MH, Mat S, Sopian K. Recent advances in flat plate photovoltaic/thermal (PV/T) solar collectors. Renew Sust Energy Rev 2011;15:352-365.

[13] Avezov RR, Akhatov JS, Avezova NR. A Review on Photovoltaic-Thermal (PV-T) Air and Water Collectors, ISSN 0003-701X. Appl Sol Energy 2011;47(3):169-183.

[14] Zhang L, Jing D, Zhao L, Wei J, Guo L. Concentrating PV/T Hybrid System for Simultaneous Electricity and Usable Heat Generation: A Review. Hindawi Publishing Corporation. Int J Photoenergy 2012a; Article ID 869753, 8 pages, doi:10.1155/2012/869753

[15] Zhang X, Zhao X, Smith S, Xu J, Yu X. Review of R\&D progress and practical application of the solar photovoltaic/thermal (PV/T) technologies. Renew Sust Energy Rev 2012b;16:599-617.

[16] Tyagi VV, Kaushik SC, Tyagi SK. Advancement in solar photovoltaic/thermal (PV/T) hybrid collector technology. Renew Sustain Energy Rev 2012;16:1383-1398.

[17] Vivar M, Clarke M, Pye J, Everett V. A review of standards for hybrid CPV-thermal systems. Renew Sust Energy Rev 2012;16:443-448.

[18] Chow TT, Tiwari GN, Menezo C. Hybrid solar: a review on photovoltaic and thermal power integration. Int J Photoenergy (2012) 307287. doi.10.1155/2012/307287, 17 pages.

[19] Shan F, Tang F, Cao L, Fang G. Performance evaluations and applications of photovoltaic-thermal collectors and systems. Renew Sustain Energy Rev 2014;33:467483.

[20] Sharaf OZ, Orhan MF. Concentrated photovoltaic thermal (CPVT) solar collector systems: Part I - Fundamentals, design considerations and current technologies. Renew Sustain Energy Rev 2015a;50:1500-1565.

[21] Sharaf OZ, Orhan MF. Concentrated photovoltaic thermal (CPVT) solar collector systems: Part II - Implemented systems, performance assessment, and future directions. Renew Sustain Energy Rev 2015b;50:1566-1633.

[22] Makki A, Omer S, Sabir H. Advancements in hybrid photovoltaic systems for enhanced solar cells performance. Renew Sust Energy Rev 2015;41:658-684.

[23] Ju X, Xu C, Liao Z, Du X, Wei G, Wang Z, Yang Y. A review of concentrated photovoltaic-thermal (CPVT) hybrid solar systems with waste heat recovery (WHR). Sci Bulletin 2017a;62:1388-1426. 
[24] Ju X, Xu C, Han X, Du X, Wei G, Yang Y. A review of the concentrated photovoltaic/thermal (CPVT) hybrid solar systems based on the spectral beam splitting technology. Appl Energy 2017b;187:534-563.

[25] Azarian RD, Cuce E, Cuce PM. An Overview of Concentrating Photovoltaic Thermal (CPVT) Collectors. Energy Res J 2017;8(1):11.21, DOI: 10.3844/erjsp.2017.11.21

[26] Sultan SM, Ervina Efzan MN. Review on recent Photovoltaic/Thermal (PV/T) technology advances and applications. Sol Energy 2018;173:939-954.

[27] Fudholi A, Mustapha M, Taslim I, Aliyah F, Gani Koto A, Sopian K. Photovoltaic thermal (PVT) air collector with monofacial and bifacial solar cells: a review. Int J Power Elect Dr Syst (IJPEDS) 2019;10(4):2021-2028, ISSN: 2088-8694, DOI: 10.11591/ijpeds.v10.i4.2021-2028

[28] Vaishak S, Bhale PV. Photovoltaic/thermal-solar assisted heat pump system: Current status and future prospects. Sol Energy 2019;189:268-284.

[29] Candanedo JA, Athienitis AK. A Systematic Approach for Energy Design of Advanced Solar Houses. 2009 IEEE Electrical Power \& Energy Conference, 978-1-42444509-7/09, 2009 IEEE.

[30] Vats K, Tiwari GN. Energy and exergy analysis of a building integrated semitransparent photovoltaic thermal (BISPVT) system. Appl Energy 2012;96:409-416.

[31] Sopian K, Ooshaksaraei P, Fudholi A, Zulkifli R, Zaidi SH, Kazeem HA. Performance characterization of single-path and double-path air-based bifacial photovoltaic thermal solar collector. Recent Advances in Energy, Environment and Geology 2013, ISBN: 978-960-474-338-4.

[32] Rajoria CS, Agrawal S, Tiwari GN. Exergetic and enviroeconomic analysis of novel hybrid PVT array. Sol Energy 2013;88:110-119.

[33] Aelenei L, Pereira R. Innovative Solutions for Net Zero-Energy Building: BIPVPCM System - Modeling, Design and Thermal Performance. 2013 IEEE, 978-1-4673$5556-8 / 13$

[34] Assoa YB, Ménézo C. Dynamic study of a new concept of photovoltaic-thermal hybrid collector. Sol Energy 2014;107:637-652.

[35] Kamthania D, Tiwari GN. Energy metrics analysis of semi-transparent hybrid PVT double pass facade considering various silicon and non-silicon based PV module Hyphen is accepted. Sol Energy 2014;100:124-140.

[36] Aelenei L, Pereira R, Gonçalves H, Athienitis A. Thermal performance of a hybrid BIPV-PCM: modeling, design and experimental investigation. Energy Proced 2014a;48:474-483. 
[37] Aelenei L, Pereira R, Ferreira A, Gonçalves H, Joyce A. Building Integrated Photovoltaic System with integral thermal storage: a case study. Energy Proced 2014b;58:172-178.

[38] Sohel MI, Ma Z, Cooper P, Adams J, Scott R. A dynamic model for air-based photovoltaic thermal systems working under real operating conditions. Appl Energy 2014;132:216-225.

[39] Machniewicz A, Knera D, Heim D. Effect of transition temperature on efficiency of PV/PCM panels. Energy Proced 2015;78:1684-1689.

[40] Xiang Y, Gan G. Optimization of building-integrated photovoltaic thermal air system combined with thermal storage. Int J Low-Carbon Technol 2015;10(2):146-156.

[41] Li S, Joe J, Hu J, Karava P. System identification and model-predictive control of office buildings with integrated photovoltaic-thermal collectors, radiant floor heating and active thermal storage. Sol Energy 2015a;113:139-157.

[42] Slimani MEA, Amirat M, Bahria S, Kurucz I, Aouli M, Sellami R. Study and modeling of energy performance of a hybrid photovoltaic/thermal solar collector: Configuration suitable for an indirect solar dryer. Energy Convers Manage 2016;125:209221.

[43] Delisle V, Kummert M. Cost-benefit analysis of integrating BIPV-T air systems into energy-efficient homes. Sol Energy 2016;136:385-400.

[44] Lin W, Ma Z, Cooper P, Sohel MI, Yang L. Thermal performance investigation and optimization of buildings with integrated phase change materials and solar photovoltaic thermal collectors. Energy Build 2016;116:562-573.

[45] Favoino F, Goia F, Perino M, Serra V. Experimental analysis of the energy performance of an ACTive, RESponsive and Solar (ACTRESS) façade module. Sol Energy 2016;133:226-248.

[46] Haddad S, Touafek K, Tabet I, Amirat Y. Investigation of a Concentrating Photovoltaic Thermal Collector (CPVT) System. 2016 Eleventh International Conference on Ecological Vehicles and Renewable Energies (EVER). 978-1-5090-2464-3/16. 2016 IEEE.

[47] Tiwari S, Tiwari GN, Al-Helal IM. Performance analysis of photovoltaic-thermal (PVT) mixed mode greenhouse solar dryer. Sol Energy 2016a;133:421-428.

[48] Oliveira AC. A novel solar façade concept for energy polygeneration in buildings. Int J Low-Carbon Technol 2016;11:506-510.

[49] Tripathy M, Joshi H, Panda SK. Energy payback time and life-cycle cost analysis of building integrated photovoltaic thermal system influenced by adverse effect of shadow. Appl. Energy 2017;208:376-389. 
[50] Liu ZB, Zhang L, Luo YQ, Wu J, Meng FF. Investigation on a photovoltaic thermoelectric ventilator. Energy Proced 2017;105:511-517.

[51] Dimri N, Tiwari A, Tiwari GN. Thermal modelling of semitransparent photovoltaic thermal (PVT) with thermoelectric cooler (TEC) collector. Energy Convers Manage 2017;146:68-77.

[52] Liu Z, Zhang Y, Zhang L, Luo Y, Wu Z, Wu J, et al. Modeling and simulation of a photovoltaic thermal-compound thermoelectric ventilator system. Appl Energy 2018a;228:1887-1900.

[53] Agathokleous RA, Kalogirou SA, Karellas S. Exergy analysis of a naturally ventilated Building Integrated Photovoltaic/Thermal (BIPV/T) system. Renew Energy 2018; 128:541-552.

[54] Nazri NS, Fudholi A, Bakhtyar B, Yen CH, Ibrahim A, Ruslan MH et al. Energy economic analysis of photovoltaic-thermal-thermoelectric (PVT-TE) air collectors. Renew Sustain Energy Rev 2018a;92:187-197.

[55] Liu ZB, Zhang L, Luo YQ, Zhang YL, Wu ZH. Performance evaluation of a photovoltaic thermal-compound thermoelectric ventilator system. Energy \& Build 2018b;167:23-29.

[56] Nazri NS, Fudholi A, Ruslan MH, Sopian K. Experimental Study of Photovoltaic Thermal-thermoelectric (PVT-TE) Air Collector, Int J Power Electron Drive System (IJPEDS) 2018b;9(3):1390-1396, ISSN: 2088-8694, DOI: 10.11591/ijpeds.v9n3.pp13901396.

[57] Irshad K, Habib K, Algarni S, Saha BB, Jamil B. Sizing and life-cycle assessment of building integrated thermoelectric air cooling and photovoltaic wall system. Appl Thermal Eng 2019;154:302-314.

[58] Pereira R, Aelenei L. Optimization assessment of the energy performance of a BIPV/T-PCM system using Genetic Algorithms. Renew Energy 2019;137:157-166.

[59] Pal Singh H, Jain A, Singh A, Arora S. Influence of absorber plate shape factor and mass flow rate on the performance of the PVT system. Appl Thermal Eng 2019;156:692701.

[60] Kalkan C, Ezan MA, Duquette J, Balaman ŞY, Yilanci A. Numerical study on photovoltaic/thermal systems with extended surfaces. Int J Energy Res 2019;43:52135229.

[61] Ibrahim A, Othman MY, Ruslan MH, Alghoul MA, Yahya M, Zaharim A, et al. Performance of Photovoltaic Thermal Collector (PVT) With Different Absorbers Design. WSEAS Trans on Env Dev 2009;3(5):321-330, ISSN: 1790-5079.

[62] da Silva RM, Fernandes JLM. Hybrid photovoltaic/thermal (PV/T) solar systems simulation with Simulink/Matlab. Sol Energy 2010;84:1985-1996. 
[63] Chemisana D, Ibáñez M, Rosell JI. Characterization of a photovoltaic-thermal module for Fresnel linear concentrator. Energy Convers Manage 2011;52:3234-3240.

[64] Sonneveld PJ, Swinkels GLAM, van Tuijl BAJ, Janssen HJJ, Campen J, Bot GPA. Performance of a concentrated photovoltaic energy system with static linear Fresnel lenses. Sol Energy 2011;85:432-442.

[65] Cristofari C, Canaletti JL, Notton G. Patented Twintex ${ }^{\circledR}$ Hybrid PV/T Collector: Level of Performances and Comparison with Thermal Solar Collector. 978-1-4673-60081/11. 2012 IEEE.

[66] Redpath DAG, Singh H, Tierney C, Dalzell P. An Experimental Comparison of two Solar Photovoltaic- Thermal (PVT) Energy Conversion Systems for Production of Heat and Power. Energy Power 2012;2(4):46-50, DOI: 10.5923/j.ep.20120204.01

[67] Gang P, Huide F, Jie J, Tin-tai C, Tao Z. Annual analysis of heat pipe PV/T systems for domestic hot water and electricity production. Energy Convers Manage 2012;56:821.

[68] Chávez Urbiola EA, Vorobiev Y. Investigation of Solar Hybrid Electric/Thermal System with Radiation Concentrator and Thermoelectric Generator, Hindawi Publishing Corporation. Int J Photoenergy 2013, Article ID 704087, 7 pages, http://dx.doi.org/10.1155/2013/704087

[69] Yin HM, Yang DJ, Kelly G, Garant J. Design and performance of a novel building integrated PV/thermal system for energy efficiency of buildings. Sol Energy 2013;87:184-195.

[70] Amrizal N, Chemisana D, Rosell JI. Hybrid photovoltaic-thermal solar collectors dynamic modeling. Appl Energy 2013;101:797-807.

[71] He W, Zhou J, Hou J, Chen C, Ji J. Theoretical and experimental investigation on a thermoelectric cooling and heating system driven by solar. Appl Energy 2013;107,89-97.

[72] Shan F, Cao L, Fang G. Dynamic performances modeling of a photovoltaic-thermal collector with water heating in buildings. Energy Build 2013;66:485-494.

[73] Vivar M, Everett V, Fuentes M, Blakers A, Tanner A, Le Lievre P, et al. . Initial field performance of a hybrid CPV-T microconcentrator system. Prog Photovolt: Res Appl 2013;21:1659-1671.

[74] El-Seesy IE, Khalil T. An Experimental Study of a Composite Photovoltaic/Thermal Collector with a Tracking Concentrator System. World Appl Sci J 2014;31(6):988-992, ISSN 1818-4952, IDOSI Publications, DOI: 10.5829/idosi.wasj.2014.31.06.14358

[75] Ibrahim A, Fudholi A, Sopian K, Othman MY, Ruslan MH. Efficiencies and improvement potential of building integrated photovoltaic thermal (BIPVT) system. Energy Convers Manage 2014;77:527-534. 
[76] Buker MS, Mempouo B, Riffat SB. Performance evaluation and techno-economic analysis of a novel building integrated PV/T roof collector: An experimental validation. Energy Build 2014;76:164-175.

[77] Buker MS, Mempouo B, Riffat SB. Experimental investigation of a building integrated photovoltaic/thermal roof collector combined with a liquid desiccant enhanced indirect evaporative cooling system. Energy Convers Manage 2015;101:239-254.

[78] Evola G, Marletta L. Exergy and thermoeconomic optimization of a water-cooled glazed hybrid photovoltaic/thermal (PVT) collector. Sol Energy 2014;107,12-25.

[79] Kroiß A, Präbst A, Hamberger S, Spinnler M, Tripanagnostopoulos Y, Sattelmayer T. Development of a seawater-proof hybrid photovoltaic/thermal (PV/T) solar collector. Energy Proced 2014;52:93-103.

[80] He W, Zhou JZ, Chen C, Ji J. Experimental study and performance analysis of a thermoelectric cooling and heating system driven by a photovoltaic/thermal system in summer and winter operation modes. Energy Convers Manage 2014;84:41-49.

[81] Kim JH, Park SH, Kang JG, Kim JT. Experimental performance of heating system with building integrated PVT (BIPVT) collector. Energy Proced 2014;48:1374-1384.

[82] Ziapour BM, Palideh V, Baygan M. Performance comparison of four passive types of photovoltaic-thermal systems. Energy Convers Manage 2014;88:732-738.

[83] Browne MC, Norton B, McCormack SJ. Heat retention of a photovoltaic/thermal collector with PCM. Sol Energy 2016;133:533-548.

[84] Khelifa A, Touafek K, Ben Moussa H, Tabet I. Modeling and detailed study of hybrid photovoltaic thermal (PV/T) solar collector. Sol Energy 2016;135,169-176.

[85] Adeilla S, Sellami N, Mallick T. Experimental Performance of Concentrating Photovoltaic Thermal Module. 7th International Renewable Energy Congress (IREC), 22-24 March 2016, Hammamet, Tunisia, DOI: 10.1109/IREC.2016.7478862, Publisher: IEEE.

[86] He Y, Xiao L, Li L. Theoretical and experimental study on the application of diffusereflection concentrators in PV/T solar system. Int J Energy Res 2016;40:963-970.

[87] Rosa-Clot M, Rosa-Clot P, Tina GM, Ventura C. Experimental photovoltaic-thermal Power Plants based on TESPI panel. Sol Energy 2016;133:305-314.

[88] Finocchiaro P, Beccali M, Cellura M, Guarino F, Longo S. Life cycle assessment of a compact desiccant evaporative cooling system: the case study of the "Freescoo". Sol Energy Mater Sol Cells 2016;156:83-91.

[89] Jouhara H, Milko J, Danielewicz J, Sayegh MA, Szulgowska-Zgrzywa M, Ramos $\mathrm{JB}$, et al. The performance of a novel flat heat pipe based thermal and PV/T (photovoltaic and thermal systems) solar collector that can be used as an energy-active building envelope material. Energy 2016;108:148-154. 
[90] Wang Z, Zhang J, Wang Z, Yang W, Zhao X. Experimental investigation of the performance of the novel HP-BIPV/T system for use in residential buildings. Energy Build 2016a;130:295-308.

[91] Wang Z, Qiu F, Yang W, Zhao X, Mei S. Experimental investigation of the thermal and electrical performance of the heat pipe BIPV/T system with metal wires. Appl Energy 2016b;170:314-323.

[92] Chemisana D, Rosell JI, Riverola A, Lamnatou Chr. Experimental performance of a Fresnel-transmission PVT concentrator for building-façade integration. Renew Energy 2016;85:564-572.

[93] Karimi F, Xu H, Wang Z, Chen J, Yang M. Experimental study of a concentrated PV/T system using linear Fresnel lens. Energy 2017;123:402-412.

[94] Jaaz AH, Hasan HA, Sopian K, Kadhum AAH, Gaaz TS, Al-Amiery AA. Outdoor Performance Analysis of a Photovoltaic Thermal (PVT) Collector with Jet Impingement and Compound Parabolic Concentrator (CPC). Materials 2017, 10, 888; doi:10.3390/ma10080888.

[95] Asaee SR, Nikoofard S, Ugursal VI, Beausoleil-Morrison I. Techno-economic assessment of photovoltaic (PV) and building integrated photovoltaic/thermal (BIPV/T) system retrofits in the Canadian housing stock. Energy Build 2017;152:667-679.

[96] Gautam KR, Andresen GB. Performance comparison of building-integrated combined photovoltaic thermal solar collectors (BiPVT) with other building-integrated solar technologies. Sol Energy 2017;155:93-102.

[97] Buonomano A, Calise F, Palombo A, Vicidomini M. Adsorption chiller operation by recovering low-temperature heat from building integrated photovoltaic thermal collectors: Modelling and simulation. Energy Convers Manage 2017;149:1019-1036.

[98] Li W, Paul MC, Rolley M, Sweet T, Gao M, Baig H, et al. A coupled optical-thermalelectrical model to predict the performance of hybrid PV/T-CCPC roof-top systems. Renew Energy 2017;112:166-186.

[99] Soltani S, Kasaeian A, Sokhansefat T, Shafii MB. Performance investigation of a hybrid photovoltaic/thermoelectric system integrated with parabolic trough collector. Energy Convers Manage 2018;159:371-380.

[100] Yang F, Wang H, Zhang X, Tian W, Hua Y, Dong T. Design and experimental study of a cost-effective low concentrating photovoltaic/thermal system. Sol Energy 2018;160:289-296.

[101] Fayaz H, Rahim NA, Hasanuzzaman M, Nasrin R, Rivai A. Numerical and experimental investigation of the effect of operating conditions on performance of PVT and PVT-PCM. Renew Energy 2019;143:827-841. 
[102] Maadi SR, Khatibi M, Ebrahimnia-Bajestan E, Wood D. Coupled thermal-optical numerical modeling of PV/T module - Combining CFD approach and two-band radiation DO model. Energy Convers Manage 2019;198:111781.

[103] Alves P, Fernandes JFP, Torres JPN, Branco PJC, Fernandes C, Gomes J. From Sweden to Portugal: The effect of very distinct climate zones on energy efficiency of a concentrating photovoltaic/thermal system (CPV/T). Sol Energy 2019;188:96-110.

[104] Wu YY, Wu SY, Xiao L. Performance analysis of photovoltaic-thermoelectric hybrid system with and without glass cover. Energy Convers Manage 2015;93:151-159.

[105] Oruc ME, Desai AV, Kenis PJA, Nuzzo RG. Comprehensive energy analysis of a photovoltaic thermal water electrolyzer. Appl Energy 2016;164:294-302.

[106] Su D, Jia Y, Huang X, Alva G, Tang Y, Fang G. Dynamic performance analysis of photovoltaic-thermal solar collector with dual channels for different fluids. Energy Convers Manage 2016;120:13-24.

[107] Jarimi H, Bakar MNA, Othman M, Din MH. Bi-fluid photovoltaic/thermal (PV/T) solar collector: Experimental validation of a 2-D theoretical model. Renew Energy 2016;85:1052-1067.

[108] Othman MY, Hamid SA, Tabook MAS, Sopian K, Roslan MH, Ibarahim Z. Performance analysis of PV/T Combi with water and air heating system: An experimental study. Renew Energy 2016;86:716-722.

[109] Yazdanifard F, Ebrahimnia-Bajestan E, Ameri M. Performance of a parabolic trough concentrating photovoltaic/thermal system: Effects of flow regime, design parameters, and using nanofluids. Energy Convers Manage 2017;148:1265-1277.

[110] Sardarabadi M, Passandideh-Fard M, Maghrebi MJ, Ghazikhani M. Experimental study of using both $\mathrm{ZnO}$ /water nanofluid and phase change material (PCM) in photovoltaic thermal systems. Sol Energy Mater Sol Cells 2017;161:62-69.

[111] Riverola A, Moreno A, Chemisana D. Performance of a dielectric PVT concentrator for building-façade integration. OPTICS EXPRESS A892, 2018;26(18), https://doi.org/10.1364/OE.26.00A892

[112] Moreno A, Riverola A, Chemisana D. Energetic simulation of a dielectric photovoltaic-thermal concentrator. Sol Energy 2018;169:374-385.

[113] Abdelrazik AS, Al-Sulaiman FA, Saidur R, Ben-Mansour R. Evaluation of the effects of optical filtration and nanoPCM on the performance of a hybrid photovoltaicthermal solar collector. Energy Convers Manage 2019;195:139-156.

[114] Dimri N, Tiwari A, Tiwari GN. Comparative study of photovoltaic thermal (PVT) integrated thermoelectric cooler (TEC) fluid collectors. Renew Energy 2019;134:343356. 
[115] Cristofari C, Notton G, Canaletti JL. Thermal behavior of a copolymer PV/Th solar system in low flow rate conditions. Sol Energy 2009;83:1123-1138.

[116] Rajoria CS, Agrawal S, Tiwari GN. Overall thermal energy and exergy analysis of hybrid photovoltaic thermal array. Sol Energy 2012;86:1531-1538.

[117] Kalogirou SA, Aresti L, Christodoulides P, Florides G. The effect of air flow on a building-integrated PV-panel. Procedia IUTAM 2014;11:89-97.

[118] Herrando M, Markides CN, Hellgardt K. A UK-based assessment of hybrid PV and solar-thermal systems for domestic heating and power: System performance. Appl Energy 2014;122:288-309.

[119] Canelli M, Entchev E, Sasso M, Yang L, Ghorab M. Dynamic simulations of hybrid energy systems in load sharing application. Appl Thermal Eng 2015;78:315-325.

[120] Shyam, Tiwari GN, Fischer O, Mishra RK, Al-Helal IM. Performance evaluation of $N$-photovoltaic thermal (PVT) water collectors partially covered by photovoltaic module connected in series: An experimental study. Sol Energy 2016;134:302-313.

[121] Khanjari Y, Pourfayaz F, Kasaeian AB. Numerical investigation on using of nanofluid in a water-cooled photovoltaic thermal system. Energy Convers Manage 2016;122:263-278.

[122] Sotehi O, Chaker A, Maalouf C. Hybrid PV/T water solar collector for net zero energy building and fresh water production: A theoretical approach. Desalin 2016;385:111 .

[123] Tiwari GN, Saini H, Tiwari A, Deo A, Gupta N, Saini PS. Periodic theory of building integrated photovoltaic thermal (BiPVT) system. Sol Energy 2016b;125:373380 .

[124] Hu J, Chen W, Yang D, Zhao B, Song H, Ge B. Energy performance of ETFE cushion roof integrated photovoltaic/thermal system on hot and cold days. Appl Energy 2016;173:40-51.

[125] Hasan HA, Sopian K, Jaaz AH, Al-Shamani AN. Experimental investigation of jet array nanofluids impingement in photovoltaic/thermal collector. Sol Energy 2017; 144:321-334.

[126] Chialastri A, Isaacson M. Performance and optimization of a BIPV/T solar air collector for building fenestration applications. Energy Build 2017;150:200-210.

[127] Bigaila E, Athienitis AK. Modeling and simulation of a photovoltaic/thermal air collector assisting a façade integrated small scale heat pump with radiant PCM panel. Energy Build 2017;149:298-309.

[128] Gaur A, Ménézo C, Giroux-Julien S. Numerical studies on thermal and electrical performance of a fully wetted absorber PVT collector with PCM as a storage medium. Renew Energy 2017;109:168-187. 
[129] Bellos E, Tzivanidis C. Yearly performance of a hybrid PV operating with nanofluid. Renew Energy 2017;113:867-884.

[130] Herrando M, Ramos A, Freeman J, Zabalza I, Markides CN. Technoeconomic modelling and optimisation of solar combined heat and power systems based on flat-box PVT collectors for domestic applications. Energy Convers Manage 2018;175:67-85.

[131] Zulakmal MY, Fudholi A, Rukman NS, Nazri NS, Yen CH, Asim N, et al. Computational Fluid Dynamics Analysis of Thermoelectric Generators Performance under Solar Photovoltaic-Thermal (PVT) System. J Adv Res Fluid Mech Therm Sci 2019;56(2):223-232.

[132] Xiao L, Shi R, Wu SY, Chen ZL. Performance study on a photovoltaic thermal (PV/T) stepped solar still with a bottom channel. Desalin 2019;471:114129.

[133] Ren X, Li J, Hu M, Pei G, Jiao D, Zhao X, et al. Feasibility of an innovative amorphous silicon photovoltaic/thermal system for medium temperature applications. Appl Energy 2019;252:113427.

[134] Nazri NS, Fudholi A, Mustafa W, Yen CH, Mohammad M, Ruslan MH, et al. Exergy and improvement potential of hybrid photovoltaic thermal/thermoelectric (PVT/TE) air collector. Renew Sustain Energy Rev 2019;111:132-144.

[135] Boumaaraf B, Touafek K, Ait-cheikh MS, Slimani MEA. Comparison of electrical and thermal performance evaluation of a classical PV generator and a water glazed hybrid photovoltaic-thermal collector. Math Comp Simul 2020;167:176-193.

[136] Haiping C, Xinxin G, Heng Z, Yang L, Haowen L, Yuegang B. Experimental study on a flash tank integrated with low concentrating PV/T (FT-LCPVT) hybrid system for desalination. Appl Therm Eng 2019;159:113874.

[137] Sun J, Shi MH. Numerical study on optical and electric-thermal performance for solar concentrating PV/T air system. Sci China Ser E-Tech Sci 2009;52(12):3514-3520, doi: 10.1007/s11431-009-0242-X

[138] Cui W, Zhao L, Wu W, Wang K, Jen TC. Energy efficiency of a quasi CPC concentrating solar PV/T system. Proceedings of the ASME 2010 International Mechanical Engineering Congress \& Exposition, IMECE2010, November 12-18, 2010, Vancouver, British Columbia, Canada, IMECE2010-38341.

[139] Bernardo LR, Perers B, Håkansson H, Karlsson B. Performance evaluation of low concentrating photovoltaic/thermal systems: A case study from Sweden. Sol Energy 2011;85:1499-1510.

[140] Kerzmann T, Schaefer L. System simulation of a linear concentrating photovoltaic system with an active cooling system. Renew Energy 2012;41:254-261. 
[141] Ong CL, Escher W, Paredes S, Khalil ASG, Michel B. A novel concept of energy reuse from high concentration photovoltaic thermal (HCPVT) system for desalination. Desalin 2012;295:70-81.

[142] Jiang L, Lan C, Kim YS, Ma Y, Winston R. An Evacuated PV/Thermal Hybrid Collector with the Tube/XCPC design. In World Renewable Energy Forum, WREF 2012, Including World Renewable Energy Congress XII and Colorado Renewable Energy Society (CRES) Annual Conferen.

[143] Calise F, Dentice d'Accadia M, Vanoli L. Design and dynamic simulation of a novel solar trigeneration system based on hybrid photovoltaic/thermal collectors (PVT). Energy Convers Manage 2012;60:214-225.

[144] Petrucci L, Fabbri G, Boccaletti C, Cardoso AJM. Powering and Cooling of a Server Room Using a Hybrid Trigeneration System. Int J Comput Theory Eng 2013;5(2).

[145] Xu Z, Kleinstreuer C. Concentration photovoltaic-thermal energy co-generation system using nanofluids for cooling and heating. Energy Convers Manage 2014;87:504512.

[146] Jaffré D, Gualdi F, Sicre M, El Ouamari R, Dollet A, Baud G et al. Design and characterization of a curved linear Fresnel lens concentrating photovoltaic and thermal system. AIP Conference Proceedings 1616, 173-176 (2014); https://doi.org/10.1063/1.4897054.

[147] Tan L, Ji X, Li M, Leng C, Luo X, Li H. The experimental study of a two-stage photovoltaic thermal system based on solar trough concentration. Energy Convers Manage 2014;86:410-417.

[148] Garcia-Heller V, Paredes S, Ong CL, Ruch P, Michel B. Exergoeconomic analysis of high concentration photovoltaic thermal co-generation system for space cooling. Renew Sustain Energy Rev 2014;34:8-19.

[149] Hughes AJ, O'Donovan TS, Mallick TK. Experimental evaluation of a membrane distillation system for integration with concentrated photovoltaic/thermal (CPV/T) energy. Energy Proced 2014;54:725-733.

[150] Kiflemariam R, Almas M, Lin C. Modeling Integrated Thermoelectric GeneratorPhotovoltaic Thermal (TEG-PVT) System. Excerpt from the Proceedings of the 2014 COMSOL Conference in Boston.

[151] Renno C, De Giacomo M. Dynamic Simulation of a CPV/T System Using the Finite Element Method. Energies 2014;7:7395-7414; doi:10.3390/en7117395

[152] Del Col D, Bortolato M, Padovan A, Quaggia M. Experimental and numerical study of a parabolic trough linear CPVT system. Energy Proced 2014;57:255-264.

[153] Atheaya D, Tiwari A, Tiwari GN, Al-Helal IM. Analytical characteristic equation for partially covered photovoltaic thermal (PVT) compound parabolic concentrator (CPC). Sol Energy 2015;111:176-185. 
[154] Imtiaz Hussain M, Lee GH. Experimental and numerical studies of a U-shaped solar energy collector to track the maximum CPV/T system output by varying the flow rate. Renew Energy 2015;76:735-742.

[155] Gholami H, Sarwat AI, Hosseinian H, Khalilnejad A. Evaluation of optimal dual axis concentrated photovoltaic thermal system with active ventilation using Frog Leap algorithm. Energy Convers Manage 2015;105:782-790.

[156] Li G, Pei G, Ji J, Su Y. Outdoor overall performance of a novel air-gap-lens-walled compound parabolic concentrator (ALCPC) incorporated with photovoltaic/thermal system. Appl Energy 2015b;144:214-223.

[157] Wiesenfarth M, Went J, Bösch A, Dilger A, Kec T, Kroll A, et al. CPV-T Mirror Dish System Combined with Water Desalination Systems. AIP Conference Proceedings 1766, 020008 (2016); https://doi.org/10.1063/1.4962076

[158] Imtiaz Hussain M, Ali A, Lee GH. Multi-module concentrated photovoltaic thermal system feasibility for greenhouse heating: Model validation and techno-economic analysis. Sol Energy 2016;135:719-730.

[159] Ziapour BM, Palideh V, Mokhtari F. A Performance improvement of the finned passive PVT system using reflectors like removable insulation covers. Appl Therm Eng 2016;94:341-349.

[160] Al Imam MFI, Beg RA, Rahman MS, Khan MZH. Performance of PVT solar collector with compound parabolic concentrator and phase change materials. Energy Build 2016;113:139-144.

[161] Mohsenzadeh M, Shafii MB, mosleh HJ. A novel concentrating photovoltaic/thermal solar system combined with thermoelectric module in an integrated design. Renew Energy 2017;113:822-834.

[162] Calise F, Figaj RD, Massarotti N, Mauro A, Vanoli L. Polygeneration system based on PEMFC, CPVT and electrolyzer: Dynamic simulation and energetic and economic analysis. Appl Energy 2017;192:530-542.

[163] Elsafi AM. Integration of humidification-dehumidification desalination and concentrated photovoltaic-thermal collectors: Energy and exergy-costing analysis. Desalin 2017;424:17-26.

[164] Akrami E, Nemati A, Nami H, Ranjbar F. Exergy and exergoeconomic assessment of hydrogen and cooling production from concentrated PVT equipped with PEM electrolyzer and $\mathrm{LiBr}-\mathrm{H}_{2} \mathrm{O}$ absorption chiller. Int J Hydrogen Energy 2018;43:622-633.

[165] Guo XX, Zhang H, Chen HP. Experimental investigation on a vacuum still integrated with concentrating PVT hybrid system, IOP Conf. Series: Earth and Environmental Science 188 (2018) 012066, NEFES 2018, doi:10.1088/17551315/188/1/012066, IOP Publishing. 
[166] Shadmehri M, Narei H, Ghasempour R, Shafii MB. Numerical simulation of a concentrating photovoltaic-thermal solar system combined with thermoelectric modules by coupling Finite Volume and Monte Carlo Ray-Tracing methods. Energy Convers Manage 2018;172:343-356.

[167] Kandil KM, Alzanki TH, Kadad IM. Assessment of High Concentrated Photovoltaic/Thermal Collector in Hot Climate. Smart Grid Renew Energy 2019;10: 119140, ISSN Online: 2151-4844, ISSN Print: 2151-481X, Scientific Research Publishing.

[168] Gomaa MR, Mustafa RJ, Rezk H. An experimental implementation and testing of a concentrated hybrid photovoltaic/thermal system with monocrystalline solar cells using linear Fresnel reflected mirrors. Int J Energy Res 2019;1-14.

[169] Crisostomo F, Taylor RA, Zhang T, Perez-Wurfl I, Rosengarten G, Everett V, et al. Experimental testing of $\mathrm{SiN}_{\mathrm{x}} / \mathrm{SiO}_{2}$ thin film filters for a concentrating solar hybrid $\mathrm{PV} / \mathrm{T}$ collector. Renew Energy 2014;72:79-87.

[170] Widyolar B, Jiang L, Ferry J, Winston R, Kirk A, Osowski M, et al. Theoretical and experimental performance of a two-stage (50X) hybrid spectrum splitting solar collector tested to $600^{\circ} \mathrm{C}$. Appl Energy 2019;239:514-525.

[171] Mittelman G, Kribus A, Mouchtar O, Dayan A. Water desalination with concentrating photovoltaic/thermal (CPVT) systems. Sol Energy 2009;83:1322-1334.

[172] Otanicar T, Chowdhury I, Phelan PE, Prasher R. Parametric analysis of a coupled photovoltaic/thermal concentrating solar collector for electricity generation. J Appl Phys 2010;108:114907, American Institute of Physics.

[173] Zhao J, Luo Z, Zhang Y, Shou C, Ni M. Optimal design and performance analysis of a low concentrating photovoltaic/thermal system using the direct absorption collection concept. 978-1-4244-4813-5/10, 2010 IEEE.

[174] Jiang S, Hu P, Mo S, Chen Z. Optical modeling for a two-stage parabolic trough concentrating photovoltaic/thermal system using spectral beam splitting technology. Sol Energy Mater Sol Cells 2010;94:1686-1696.

[175] Al-Alili A, Hwang Y, Radermacher R, Kubo I. A high efficiency solar air conditioner using concentrating photovoltaic/thermal collectors. Appl Energy 2012;93:138-147.

[176] Chávez-Urbiola EA, Vorobiev YV, Bulat LP. Solar hybrid systems with thermoelectric generators. Sol Energy 2012;86:369-378.

[177] Buonomano A, Calise F, Dentice d'Accadia M, Vanoli L. A novel solar trigeneration system based on concentrating photovoltaic/thermal collectors. Part 1: Design and simulation model. Energy 2013a;61:59-71.

[178] Buonomano A, Calise F, Palombo A. Solar heating and cooling systems by CPVT and ET solar collectors: A novel transient simulation model. Appl Energy 2013b;103:588-606. 
[179] Wu Y, Everett V, Thomsen E, Blakers A. Investigation of the temperature dependence of the optical properties of thermal transfer fluids for hybrid CPV-T systems, AIP Conference Proceedings 1556, 84-87, 2013; https://doi.org/10.1063/1.4822205

[180] Calise F, Dentice d'Accadia M, Palombo A, Vanoli L. Dynamic simulation of a novel high-temperature solar trigeneration system based on concentrating photovoltaic/thermal collectors. Energy 2013;61:72-86.

[181] Polonsky G, Shelef G, Flitsanov Y, Wiesenfarth M, Steiner M, Helmers H, et al. Efficiency of dense-array CPVT module with front-side interconnected cells, AIP Conference Proceedings 1556, 180 (2013); https://doi.org/10.1063/1.4822226

[182] Helmers H, Bett AW, Parisi J, Agert C. Modeling of concentrating photovoltaic and thermal systems. Prog Photovolt: Res Appl 2014;22:427-439, DOI: 10.1002/pip.2287

[183] Calise F, Cipollina A, Dentice d'Accadia M, Piacentino A. A novel renewable polygeneration system for a small Mediterranean volcanic island for the combined production of energy and water: Dynamic simulation and economic assessment. Appl Energy 2014a; 135:675-693.

[184] Gomes J, Diwan L, Bernardo R, Karlsson B. Minimizing the Impact of Shading at Oblique Solar Angles in a Fully Enclosed Asymmetric Concentrating PVT Collector. Energy Proced 2014;57:2176-2185.

[185] DeJarnette D, Otanicar T, Brekke N, Hari P, Roberts K, Saunders AE, et al. Plasmonic nanoparticle based spectral fluid filters for concentrating PV/T collectors. Proc. SPIE, volume 9175, High and Low Concentrator Systems for Solar Energy Applications IX, edited by Adam P. Plesniak, Candace Pfefferkorn, 2014, doi: $10.1117 / 12.2064680$

[186] Liu Y, Hu P, Zhang Q, Chen Z. Thermodynamic and optical analysis for a CPV/T hybrid system with beam splitter and fully tracked linear Fresnel reflector concentrator utilizing sloped panels. Sol Energy 2014;103:191-199.

[187] Mojiri A, Stanley C, Rosengarten G. Spectrally splitting hybrid photovoltaic/thermal receiver design for a linear concentrator. Energy Proced 2014;48:618-627.

[188] Calise F, Dentice d'Accadia M, Piacentino A. A novel solar trigeneration system integrating PVT (photovoltaic/thermal collectors) and SW (seawater) desalination: Dynamic simulation and economic assessment. Energy 2014b;67:129-148.

[189] Looser R, Vivar M, Everett V. Spectral characterisation and long-term performance analysis of various commercial Heat Transfer Fluids (HTF) as Direct-Absorption Filters for CPV-T beam-splitting applications. Appl Energy 2014;113:1496-1511.

[190] Calise F, Dentice d'Accadia M, Piacentino A. Exergetic and exergoeconomic analysis of a renewable polygeneration system and viability study for small isolated communities. Energy 2015;92:290-307. 
[191] Mojiri A, Stanley C, Taylor RA, Kalantar-zadeh K, Rosengarten G. A spectrally splitting photovoltaic-thermal hybrid receiver utilising direct absorption and wave interference light filtering. Sol Energy Mater Sol Cells 2015;139:71-80.

[192] Otanicar TP, Theisen S, Norman T, Tyagi H, Taylor RA. Envisioning advanced solar electricity generation: Parametric studies of CPV/T systems with spectral filtering and high temperature PV. Appl Energy 2015;140:224-233.

[193] Renno C, Petito F. Choice model for a modular configuration of a point-focus CPV/T system. Energy Build 2015;92:55-66.

[194] Crisostomo F, Taylor RA, Surjadi D, Mojiri A, Rosengarten G, Hawkes ER. Spectral splitting strategy and optical model for the development of a concentrating hybrid PV/T collector. Appl Energy 2015;141:238-246.

[195] Abdelkader HI, Hatata AY, Elansari A, Abo-Elsoud MA. Modeling and Simulation of Hybrid Concentrated Photovoltaic/Thermal System. Int J Sci \& Eng Res 2015;6(5), ISSN 2229-5518, IJSER.

[196] Atheaya D, Tiwari A, Tiwari GN, Al-Helal IM. Performance evaluation of inverted absorber photovoltaic thermal compound parabolic concentrator (PVT-CPC): Constant flow rate mode. Appl Energy 2016;167:70-79.

[197] Sharaf OZ, Orhan MF. Thermodynamic analysis and optimization of denselypacked receiver assembly components in high-concentration CPVT solar collectors. Energy Convers Manage 2016;121:113-144.

[198] Stanley C, Mojiri A, Rahat M, Blakers A, Rosengarten G. Performance testing of a spectral beam splitting hybrid PVT solar receiver for linear concentrators. Appl Energy 2016;168:303-313.

[199] Tripathi R, Tiwari GN. Energetic and exergetic analysis of N partially covered photovoltaic thermal-compound parabolic concentrator (PVT-CPC) collectors connected in series. Sol Energy 2016;137:441-451.

[200] Tripathi R, Tiwari GN, Al-Helal IM. Thermal modelling of $N$ partially covered photovoltaic thermal (PVT) - Compound parabolic concentrator (CPC) collectors connected in series. Sol Energy 2016;123:174-184.

[201] Hassani S, Saidur R, Mekhilef S, Taylor RA. Environmental and exergy benefit of nanofluid-based hybrid PV/T systems. Energy Convers Manage 2016;123:431-444.

[202] Abdelhamid M, Widyolar BK, Jiang L, Winston R, Yablonovitch E, Scranton G, et al. Novel double-stage high-concentrated solar hybrid photovoltaic/thermal (PV/T) collector with nonimaging optics and GaAs solar cells reflector. Appl Energy 2016;182:68-79.

[203] Radwan A, Ookawara S, Ahmed M. Analysis and simulation of concentrating photovoltaic systems with a microchannel heat sink. Sol Energy 2016;136:35-48. 
[204] Singh DB, Tiwari GN. Enhancement in energy metrics of double slope solar still by incorporating N identical PVT collectors. Sol Energy 2017;143:142-161.

[205] Riggs BC, Biedenharn R, Dougher C, Ji YV, Xu Q, Romanin V, et al. Technoeconomic analysis of hybrid PV/T systems for process heat using electricity to subsidize the cost of heat. Appl Energy 2017;208:1370-1378.

[206] Widyolar BK, Abdelhamid M, Jiang L, Winston R, Yablonovitch E, Scranton G, et al. Design, simulation and experimental characterization of a novel parabolic trough hybrid solar photovoltaic/thermal (PV/T) collector. Renew Energy 2017;101:1379-1389.

[207] Lamnatou Chr, Lecoeuvre B, Chemisana D, Cristofari C, Canaletti JL. Concentrating photovoltaic/thermal system with thermal and electricity storage: $\mathrm{CO}_{2 \text {.eq }}$ emissions and multiple environmental indicators. J Clean Prod 2018;192:376-389.

[208] Lecoeuvre B, Canaletti JL, Cristofari C. An innovative concentrated hybrid solar system integrated in the technology platform "PAGLIAORBA" - reflective adjustable blades solar system. ISSN(p): 2347-6982, ISSN(e): 2349-204X, Inter J Indus Electron Electr Eng 6 (2), Feb.-2018, http://ijieee.org.in.

[209] Gomaa MR, Mustafa RJ, Rezk H, Al-Dhaifallah M, Al-Salaymeh A. Sizing Methodology of a Multi-Mirror Solar Concentrated Hybrid PV/Thermal System. Energies 2018;11:3276; doi:10.3390/en11123276

[210] Moaleman A, Kasaeian A, Aramesh M, Mahian O, Sahota L, Tiwari GN. Simulation of the performance of a solar concentrating photovoltaic-thermal collector, applied in a combined cooling heating and power generation system. Energy Convers Manage 2018;160:191-208.

[211] Ben Youssef W, Maatallah T, Menezo C, Ben Nasrallah S. Assessment viability of a concentrating photovoltaic/thermal-energy cogeneration system (CPV/T) with storage for a textile industry application. Sol Energy 2018;159:841-851.

[212] Vossier A, Zeitouny J, Katz EA, Dollet A, Flamant G, Gordon JM. Performance bounds and perspective for hybrid solar photovoltaic/thermal electricity-generation strategies. Sustain Energy Fuels 2018;2:2060-2067.

[213] Alayi R, Kasaeian A, Atabi F. Thermal Analysis of Parabolic Trough Concentration Photovoltaic/Thermal System for Using in Buildings. Environ Progress \& Sustain Energy, DOI 10.1002/ep, 2019 American Institute of Chemical Engineers.

[214] Al Nimr MA, Al Ammari WA. A novel PVT/PTC/ORC solar power system with PV totally immersed in transparent organic fluid. Int J Energy Res. 2019;1-17, https://doi.org/10.1002/er.4615

[215] Valizadeh M, Sarhaddi F, Adeli MM. Exergy performance assessment of a linear parabolic trough photovoltaic thermal collector. Renew Energy 2019;138:1028-1041. 
[216] George M, Pandey AK, Rahim NA, Tyagi VV, Shahabuddin S, Saidur R. Concentrated photovoltaic thermal systems: A component-by-component view on the developments in the design, heat transfer medium and applications. Energy Convers Manage 2019;186:15-41.

[217] Daneshazarian R, Cuce E, Cuce PM, Sher F. Concentrating photovoltaic thermal (CPVT) collectors and systems: Theory, performance assessment and applications. Renew Sustain Energy Rev 2018;81:473-492. 